University of Rhode Island

DigitalCommons@URI

Open Access Dissertations

$9-2013$

\title{
THE ROLE OF FLOW SENSING BY THE LATERAL LINE SYSTEM IN PREY DETECTION IN TWO AFRICAN CICHLID FISHES
}

Margot Anita Bergstrom Schwalbe

University of Rhode Island, mbergstrom@my.uri.edu

Follow this and additional works at: https://digitalcommons.uri.edu/oa_diss

\section{Recommended Citation}

Schwalbe, Margot Anita Bergstrom, "THE ROLE OF FLOW SENSING BY THE LATERAL LINE SYSTEM IN PREY DETECTION IN TWO AFRICAN CICHLID FISHES" (2013). Open Access Dissertations. Paper 111. https://digitalcommons.uri.edu/oa_diss/111

This Dissertation is brought to you for free and open access by DigitalCommons@URI. It has been accepted for inclusion in Open Access Dissertations by an authorized administrator of DigitalCommons@URI. For more information, please contact digitalcommons-group@uri.edu. 
THE ROLE OF FLOW SENSING BY THE LATERAL LINE SYSTEM IN PREY DETECTION IN TWO AFRICAN CICHLID FISHES

BY

MARGOT ANITA BERGSTROM SCHWALBE

A DISSERTATION SUBMITTED IN PARTIAL FULFILLMENT OF THE REQUIREMENTS FOR THE DEGREE OF

DOCTOR OF PHILOSOPHY

IN

BIOLOGICAL SCIENCES

UNIVERSITY OF RHODE ISLAND

2013 


\section{DOCTOR OF PHILOSOPHY DISSERTATION}

OF

MARGOT ANITA BERGSTROM SCHWALBE

\section{APPROVED:}

Dissertation Committee:
Major Professor Dr. Jacqueline Webb
Dr. Cheryl Wilga
Dr. Graham Forrester
Dr. Nasser H. Zawia
DEAN OF THE GRADUATE SCHOOL 


\begin{abstract}
The mechanosensory lateral line system is found in all fishes and mediates critical behaviors, including prey detection. Widened canals, one of the four patterns of cranial lateral line canals found among teleosts, tend to be found in benthic fishes and/or fishes that live in hydrodynamically quiet or light-limited environments, such as the deep sea. Little is known about the functional significance of widened canals because most fishes with this morphology are inaccessible for laboratory study. A representative of one genus of Lake Malawi cichlid fishes, Aulonocara, has widened canals and provides an opportunity to investigate the role of widened lateral line canals in prey detection. In addition, its behavior can be compared to that of Tramitichromis sp., another Lake Malawi cichlid that has narrow canals, since both feed on benthic invertebrates in sandy substrates. A behavioral assay was developed in which several pairs of "benthic" live and dead prey (tethered brine shrimp) were placed on the bottom of a large tank to determine if Aulonocara stuartgranti (Chapter 1) and Tramitichromis (Chapter 2) used the visual and hydrodynamic stimuli generated live, mobile prey (tethered brine shrimp) compared to immobile, dead prey, under both light and dark conditions. In addition, some fish were treated with cobalt chloride to temporarily inactive the lateral line system. Behavior was recorded using high definition video and statistically analyzed using generalized linear mixed models. The hydrodynamic stimuli generated by the brine shrimp were visualized and characterized using digital particle imaging velocimetery (DPIV). These two studies demonstrated that $A$. stuartgranti (widened canals) uses both vision and the lateral line
\end{abstract}


system to feed under light conditions, but uses its lateral line system to feed in the dark, contributing to our appreciation of multimodal interactions and strongly suggesting that widened lateral line canals are an adaptation for prey detection. The later study showed that, in contrast, Tramitichromis (narrow canals) is a visual predator that does not use their narrow lateral line canals to find prey as illustrated by the fact that their behavior was unaffected by ablation of the lateral line system.

A similar set of experiments using the same behavioral assay was carried out to determine how a range of light intensities that mimicked intensities during sunrise/sunset and at depth affected the ability of Aulonocara and Tramitichromis to detect live and dead prey (Chapter 3). The results of this study showed that Tramitichromis does not feed in the dark, but can feed at surprisingly low light levels (1 lx), and demonstrated that Aulonocara feed at all light levels, including darkness, and thus at light intensities available at the range of depths that members of the genus occupy in Lake Malawi. These results all suggest that sensory biology of closely related species that exploit a common food resource may have important ecological implications, especially how sensory capabilities may contribute to trophic niche segregation.

Finally, a novel artificial stimulus delivery system (the "apparatus") was designed to deliver two different water flow stimuli (Type I, Type II, visualized using DPIV) at different flow rates (in the range known to be generated by invertebrates) through tubes below the sandy substrate that mimicked benthic invertebrate prey, and were thus biologically relevant (Chapter 4). This apparatus was used to determine the role of the lateral line system in the absence of visual and olfactory cues presented by 
live and dead prey. Aulonocara were trained to respond to water flows generated by the apparatus using a food reward system. Fish responded to all flow rates and to both flow types but with a range of behaviors. The temporary inactivation of the lateral line system with cobalt chloride significantly reduced the ability of Aulonocara to detect flows, but flow sensing behavior returned to pretreatment levels within seven days. This work has established Lake Malawi cichlids as model system for the study of the sensory basis for prey detection behavior using both natural and artificial stimuli under different environmental conditions and has demonstrated the reversible effects of cobalt chloride on the lateral line system. 


\section{ACKNOWLEDGEMENTS}

In memory of my father, Randy Bergstrom, and my grandmother, Anita Bergstrom, who were foremost among my biggest cheerleaders and always supported me in all of my endeavors.

This research would not have been possible without my major professor, Dr. Jacqueline Webb. Through her guidance, support and mentorship, I became a better researcher, writer and teacher. Jackie's advice, experience and wisdom kept me focused, three attributes that created some lively discussions for which I am forever grateful. Her endless patience while I wrote manuscripts and prepared presentations is equally appreciated.

I would like to thank my committee members, Drs. Cheryl Wilga, Graham Forrester, Evan Preisser and Jennifer Specker. Their valuable comments greatly improved my proposal, which helped me develop and complete my research. Additional thanks go to Cheryl Wilga for her expertise and guidance with specific components of my experiments, and continuous advice throughout my graduate career at URI.

I am extremely grateful to our Aquaria Facilities Manager, Edward Baker, for overseeing animal husbandry, building new racks for aquaria, and solving many technical issues associated with my experiments. I also thank the undergraduate students who helped with fish husbandry: Joshua Hower, Brandon Fuller, Callie Veelenturf, Rebecca Scott, Benjamin Sevey, and Christopher Holland. Thanks also go 
to those who assisted me with the artificial stimulus delivery system: Kevin Borsay and Adam Arraghi. Also, I enjoyed working with Benjamin Sevey and Christopher Holland on undergraduate research projects, and greatly appreciated their hard work, enthusiasm and insight.

I am very lucky to have met so many wonderful friends at URI. My lab mates - Emily Becker, Nathan Bird, and Lauren Carter - made spending so much lab time enjoyable. Special thanks to Anabela Maia for all of our great discussions, help with the DPIV, and sanity checks. Also, thanks to Rachel Holbert, Leanne Elder, Lacie Westbrook, Eleni Gesch-Karamanlidis, Jason Ramsay, Chris Newton, Michele Guidone, Nicole Rohr, Abigail Bockus, and Al Nyack for all those entertaining conversations and lunch dates.

Special thanks to Critter Hut in Narragansett for having a reliable supply of brine shrimp. Without this service, my research would have been much more challenging.

Finally, I am eternally grateful to the endless support, patience, and laughter from my husband, John, and my family, Mimi, Brett, Ted, Kelli, and Kristin. My husband is a saint for moving across the country so I could complete this degree, and for keeping me happy and well fed throughout this whole process. I looked forward to all of our family visits, no matter where they were, to recharge my batteries and keep moving forward.

Funding for this project was provided by NSF Grant \# IOS 0843307 to JFW, NSF EPSCoR Cooperative Agreement EPS-1004057, and the University of Rhode Island Graduate Fellowship. 


\section{PREFACE}

This dissertation is presented in manuscript format in accordance with the guidelines set forth by the Graduate School of the University of Rhode Island. Each chapter is written to stand alone as a separate research question while contributing to the greater body of knowledge regarding lateral-line-mediated feeding behaviors in teleost fishes. Chapter 1 is published in the Journal of Experimental Biology. Chapter 2 is accepted by Zoology. Chapter 3 is in preparation for Journal of Comparative Physiology A. Chapter 4 is in preparation for Journal of Experimental Biology. 


\section{TABLE OF CONTENTS}

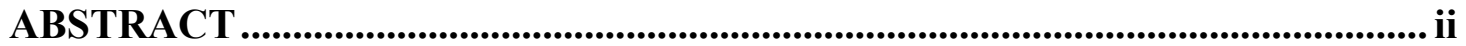

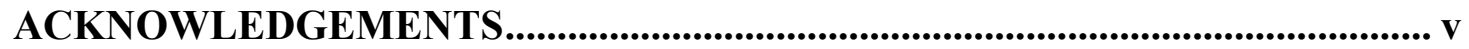

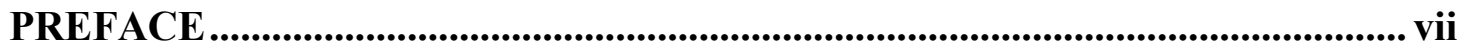

TABLE OF CONTENTS................................................................................ viii

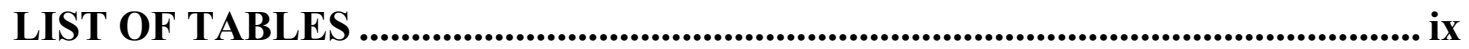

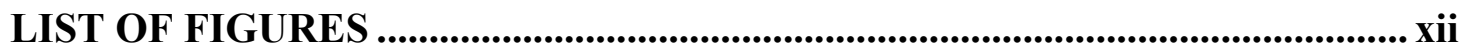

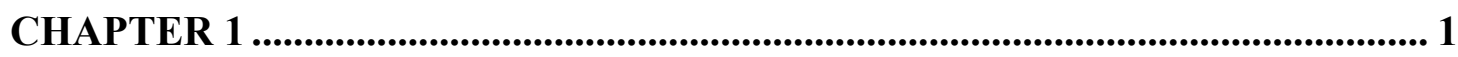

FEEDING IN THE DARK: LATERAL-LINE-MEDIATED PREY DETECTION

IN THE PEACOCK CICHLID AULONOCARA STUARTGRANTI ......................... 1

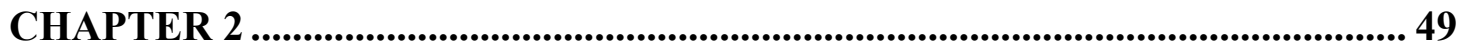

SENSORY BASIS FOR DETECTION OF BENTHIC PREY IN TWO LAKE

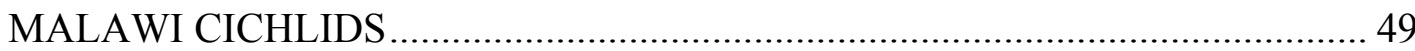

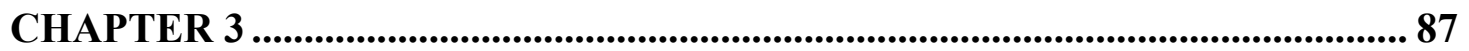

LIGHT ENVIRONMENT INFLUENCES PREY DETECTION BEHAVIOR IN

TWO SAND-DWELLING LAKE MALAWI CICHLIDS ................................. 87

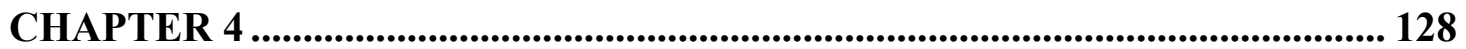

DETECTION OF ARTIFICIAL WATER FLOWS BY THE LATERAL LINE

SYSTEM AS A CONDITIONED BEHAVIORAL RESPONSE IN THE

PEACOCK CICHLID, AULONOCARA STUARTGRANTI ................................ 128 


\section{LIST OF TABLES}

\section{CHAPTER 1}

Table 1. Number and frequency of prey detections leading to strikes in Experiments I and II that occur during the glide or the pause phase of swimming in Aulonocara stuartgranti.................................................... 34

Table 2. Mean prey preference scores for live or dead prey in light and dark trials in Experiments I and II following Taplin (Taplin, 2007)....................... 35

Table 3. Detection distance for live and dead brine shrimp prey in Experiments I and II .36

Table 4. Mean time to first detection (min) of prey in light and dark trials in Experiments I and II

\section{CHAPTER 2}

Table 1. Generalized linear mixed model results for Tramitichromis feeding on live and dead prey during light and dark trials (Experiment I).....

Table 2. Mean prey preference scores for Tramitichromis (Experiments I and II) and A. stuartgranti (Experiment I only) feeding on live and dead prey in light and dark (Experiment I only) trials following Taplin (2007) .................75

Table 3. Generalized linear mixed model results for Tramitichromis feeding on live and dead prey during light trials after cobalt chloride treatment (Experiment II) 
Table 4. Generalized linear mixed model results for Tramitichromis and A. stuartgranti feeding on live and dead prey during light and dark trials

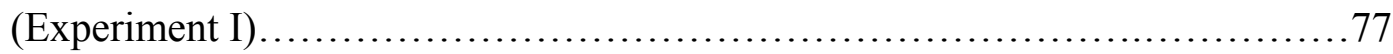

\section{CHAPTER 3}

Table 1. The relationships of measured light intensity and predicted depth at which these intensities occur in Lake Malawi.

Table 2. Prey detection behavior for A. stuartgranti and Tramitichromis feeding on six live and six dead prey at five light intensities

Table 3. Comparison of prey detection behavior by A. stuartgranti and Tramitichromis feeding on six live and six dead prey at five light intensities....115

Table 4. Summary of behavioral parameters in trials for A. stuartgranti and Tramitichromis at five light intensities with reference to the critical light intensity

\section{CHAPTER 4}

Table 1. Flow rates generated by the peristaltic pump, velocities calculated and also visualized with DPIV, and mean peak velocity coming from six different active holes in the apparatus

Table 2. Positive reinforcement training protocol used to condition five $A$. stuartgranti to flows coming from the apparatus....

Table 3. Definitions of behavioral responses and non-responses displayed by A. stuartgranti to open holes from highest to lowest rank. 
Table 4. Comparison of number of behavioral responses and types of responses by A. stuartgranti to four hole types at each flow rate, for both Types I and II flow

Table 5. Comparison of number of behavioral responses and type of responses by A. stuartgranti to four hole types among flow rates, for Types I and II flow.....

Table 6. Comparison of number of behavioral responses and types of responses by A. stuartgranti to four hole types among flow rates and flow types...

Table 7. Comparison of types of responses by A. stuartgranti to active holes in rounds with flow among flow rates and flow types........................ 165

Table 8. Comparison of number of behavioral responses by A. stuartgranti to four hole types at each day before and after treatment with $\mathrm{CoCl} 2 \ldots \ldots \ldots \ldots \ldots \ldots . \ldots 166$

Table 9. Comparison of number of behavioral responses and type of responses by A. stuartgranti to active holes with flow among days before and after treatment with $\mathrm{CoCl}_{2}$

Table 10. Comparisons of number of responses by A. stuartgranti to active holes with flow by day. 


\section{LIST OF FIGURES}

\section{CHAPTER 1}

Figure 1. The mechanosensory lateral line system of Aulonocara spp...............38

Figure 2. Quantification of feeding behavior of Aulonocara stuartgranti..............39

Figure 3. Velocity vector field and the color map of flow magnitudes during one

beat cycle above a single tethered adult brine shrimp...........................40

Figure 4. Number of strikes on live and dead brine shrimp in (A) Experiment I

and (B) Experiment II..................................................... 41

Figure 5. Orientation to prey at time of detection in the light and dark trials of

(A) Experiment I and (B) Experiment II.................................42

\section{CHAPTER 2}

Figure 1. Ventral view of the mandible of Tramitichromis sp. and Aulonocara spp. illustrating the canal and superficial neuromasts and mandibular lateral

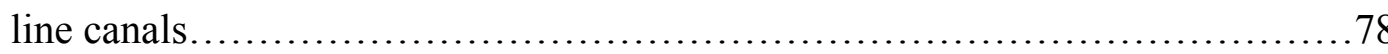

Figure 2. Number of prey strikes live and dead prey for (A) Tramitichromis

(Experiment I) and A. stuartgranti light and dark trials, and (B) Tramitichromis

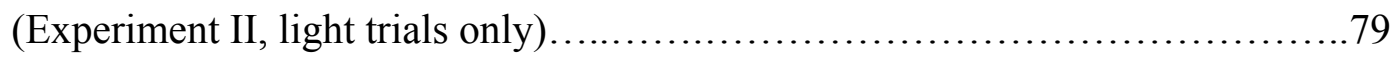

Figure 3. Detection distance for live and dead prey for (A) Tramitichromis

(Experiment I) and A. stuartgranti in light and dark trials, and (B)

Tramitichromis (Experiment II, light trials only)............................. 80

Figure. 4. Orientation to prey (live and dead combined) at time of detection for

(A) Tramitichromis (Experiment I) and A. stuartgranti light and dark trials 
and (B) Tramitichromis (Experiment II, light trials only) $\ldots \ldots \ldots \ldots \ldots \ldots \ldots . \ldots 1$

Figure 5. Frequency of prey detections that occurred during the glide or pause phase of swimming leading to prey strikes in (A) Tramitichromis (Experiment I) and A. stuartgranti light and dark trials, and (B) Tramitichromis (Experiment

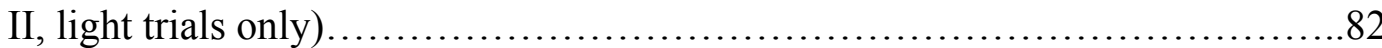

\section{CHAPTER 3}

Figure 1. Experimental tank used to record feeding behavior of A. stuartgranti and Tramitichromis

Figure 2. Total number of prey detections by prey type for (A) A. stuartgranti and (B) Tramitichromis at five light intensities

Figure 3. Three parameters defining prey detection behavior in Aulonocara stuartgranti and Tramitichromis on six live and six dead prey at five light intensities....

Figure 4. Frequency of prey strikes (live and dead prey combined) that occurred during glide and pause phases of swimming at five light intensities in (A) $A$. stuartgranti and (B) Tramitichromis.

Figure 5. Detection angles for live and dead prey combined at different light intensities for (A) A. stuartgranti and (B) Tramitichromis

Figure 6. Mean prey preference scores for (A) A. stuartgranti and (B)

Tramitichromis feeding on six live and six dead tethered adult brine shrimp in each trial, for trials at five light intensities 


\section{CHAPTER 4}

Figure 1. Artificial stimulus delivery system designed for this study....

169

Figure 2. Visualization of flow from apparatus using digital particle image velocimetry.

Figure 3. Number of responses by $A$. stuartgranti to active and inactive holes in rounds with flow and with diverted flow for (A) Type I flow and (B) Type II flow

Figure 4. Number of responses by behavioral type by A. stuartgranti to active and inactive holes in rounds with flow and with diverted flow for (A) Type I flow and (B) Type II flow...

Figure 5. Number of responses by A. stuartgranti to active and inactive holes in rounds with flow and with diverted flow through time

Figure 6. Proportion of different response types by A. stuartgranti to active holes only in rounds with flow, before and after treatment with $\mathrm{CoCl}_{2}$. . . 174

Figure 7. Canal neuromasts of $A$. stuartgranti stained with fluorescent dye 


\section{CHAPTER 1}

\section{FEEDING IN THE DARK: LATERAL-LINE-MEDIATED PREY DETECTION IN THE PEACOCK CICHLID AULONOCARA STUARTGRANTI}

Margot A. B. Schwalbe ${ }^{*}$, , Daniel K. Bassett ${ }^{1,2}$, and Jacqueline F. Webb ${ }^{1}$

${ }^{1}$ Department of Biological Sciences, University of Rhode Island, 120 Flagg Road, Kingston, RI 02881, USA

${ }^{2}$ Ocean Sciences Centre, Memorial University of Newfoundland, St John's, NL, Canada, A1C 5S7

(*author for correspondence: email: mbergstrom@my.uri.edu) Manuscript published in Journal of Experimental Biology (2012) 215: 2060-2071 


\section{SUMMARY}

The cranial lateral line canal system of teleost fishes is morphologically diverse and is characterized by four patterns. One of these, widened lateral line canals, has evolved convergently in a wide range of teleosts, including the Lake Malawi peacock cichlids (Aulonocara), and has been attributed to its role in prey detection. The ability to study Aulonocara in the laboratory provides an opportunity to test the hypothesis that their reported ability to feed on invertebrate prey living in sandy substrates in their natural habitat is the result of lateral-line-mediated prey detection. The goal of this study was to determine whether Aulonocara stuartgranti could detect hydrodynamic stimuli generated by tethered brine shrimp (visualized using digital particle image velocimetry) under light and dark conditions, with and without treatment with cobalt chloride, which is known to temporarily inactivate the lateral line system. Fish were presented with six pairs of tethered live and dead adult brine shrimp and feeding behavior was recorded with HD digital video. Results demonstrate that $A$. stuartgranti: (1) uses the same swimming/feeding strategy as they do in the field; (2) detects and consumes invertebrate prey in the dark using its lateral line system; (3) alters prey detection behavior when feeding on the same prey under light and dark conditions, suggesting the involvement of multiple sensory modalities; and (4) after treatment with cobalt chloride, exhibits a reduction in their ability to detect hydrodynamic stimuli produced by prey, especially in the dark, thus demonstrating the role of the lateral line system in prey detection. 


\section{KEYWORDS}

cichlid, lateral line, neuromast, prey detection

\section{INTRODUCTION}

Vision mediates prey detection in most fishes (Blaxter, 1988; Guthrie and Muntz, 1993; Evans, 2004), but the non-visual modalities, including the lateral line system, also play a crucial role. This is especially important in fishes feeding in light-limited environments (Holland, 1978; Hara, 1993; MacIver et al., 2001; Bergstrom and Mensinger, 2009; reviewed by Webb et al., 2008). However, fishes rarely rely on input from only one sensory system and can modulate their responses to cues using several sensory modalities depending on behavioral demands and the sensory environment in which they are foraging (von der Emde and Bleckmann, 1998; New, 2002; Gardiner and Atema, 2007; Bassett and Montgomery, 2011). Nevertheless, the presence of morphological and physiological specializations of individual sensory systems (e.g. Livingston, 1987; Schwarz et al., 2011) is traditionally used as an indication of the enhancement of behavioral capabilities. This correlation provides evidence for adaptive evolution, but the link between sensory morphology and prey detection behavior is not always clear.

The mechanosensory lateral line system of fishes is composed of a spatial array of neuromast receptor organs that is used to detect unidirectional and oscillatory water flows in a diversity of behavioral contexts, including prey detection (Coombs and Montgomery, 1999; Coombs and Van Netten, 2006; reviewed in Webb et al., 
2008). In addition to having superficial neuromasts on the skin of the head, trunk and tail, bony fishes have a series of pored cranial lateral line canals associated with dermal bones on the head. They also tend to have one trunk canal contained in the lateral line scales that travels down the body to the caudal fin (Webb, 1989). Among teleost fishes, there are four cranial lateral line canal patterns: narrow, branched, widened and reduced (Webb, 1989). Most teleosts have narrow canals (which are well ossified with small pores and canal neuromasts), but widened canals (characterized by weak ossification of the canal roof, large pores and large canal neuromasts) are found only in a small number of fish families (Webb, 1989).

The convergent evolution of widened lateral line canals in diverse teleost taxa that tend to be benthic and/or feed on active prey in hydrodynamically quiet or lightlimited environments (Coombs et al., 1988; Janssen, 1997) has been used to suggest that widened canals are an adaptation for prey detection. Several fishes are thought to use their widened canals to sense prey in the water column [e.g. melamphaeids and other mesopelagic species (Marshall, 1996)] and either on or in a sandy or muddy substrate [e.g. witch flounder, Glyptocephalus zachirus (Webb, 1995), silverjaw minnow, Notropis buccatus (Reno, 1966; Reno, 1971; Wallace, 1976), Eurasian ruffe, Gymnocephalus cernuus (Janssen, 1997)]. The ruffe, a freshwater percid with widened lateral line canals (Denton and Gray, 1989; Gray and Best, 1989; Janssen, 1997; Ćurčić -Blake and van Netten, 2006), is an invasive species in North American waters (Ogle et al., 1995) that has been used to explore the role of the lateral line canal system in prey detection. In the laboratory, the ruffe has been shown to detect freeswimming prey (Daphnia) and tethered tube-dwelling prey (mayfly larvae) in the 
dark, during the glide phase of a thrust and glide swimming strategy at distances of $<1$ body length (Janssen, 1997). Behavioral and ecological comparisons of the exotic ruffe (widened canals) and native yellow perch (narrow canals) in the field have shown that these two species feed on similar crustacean prey throughout their lives (Bergman, 1991). However, ruffe tend to feed at night [reducing competitive interference from perch (Schleuter and Eckmann, 2006)], and are able to increase in abundance in reduced light conditions (Bergman, 1991). Theoretical and experimental work has shown that widened canals are most sensitive to lower frequencies $(<60 \mathrm{~Hz})$, like those produced by crustacean prey, and tend to be more sensitive, but respond more slowly (due to canal resonance), than narrow canals (Denton and Grey, 1988; Denton and Grey, 1989; van Netten and van Maarseveen, 1994; reviewed by Coombs et al., 1992). Thus, it is reasonable to hypothesize that the evolution of widened canals among diverse teleost taxa is considered to be an adaptation for prey detection, especially in low noise environments in which fish may successfully compete or exploit novel or underappreciated trophic niches.

Cichlid fishes (Perciformes, Cichlidae) possess an impressive range of feeding morphologies and feeding strategies, a hallmark of the process of explosive adaptive radiation for which they are so well known (Fryer and Iles, 1972; Albertson et al., 2005). Their visual system is well studied (Carleton et al., 2006; O'Quin et al., 2011) and is considered to be critical for communication and sexual selection (Fernald and Liebman, 1980; Seehausen and van Alphen, 1998; Couldridge and Alexander, 2002; Seehausen et al., 2008). The sensory basis for prey search and detection behavior has not been well established in cichlids, but given the importance of vision in other 
aspects of their behavior, it is not surprising that cichlids are generally considered to be visual feeders (Fryer and Iles, 1972). Like most teleost fishes, the vast majority of cichlids have narrow lateral line canals [as illustrated in the classic studies of Greenwood (Greenwood, 1981) and Trewavas (Trewavas, 1983)], but a few genera endemic to Lake Tanganyika (e.g. Trematocara and Aulonocranus) and Lake Malawi (Aulonocara, Alticorpus and Trematocranus) have widened canal systems (Konings, 2007). The 16-21 species of peacock cichlids of the genus Aulonocara [one of 56 endemic cichlid genera in Lake Malawi (Meyer et al., 1987; Konings, 1990; Konings, 2007)] have been described as 'sonar feeders' (Konings, 2007), that have 'deep pits' (Fryer, 1959), 'an acoustic system on the enlarged suborbital bones which consists of swollen pit organs' (Meyer et al., 1987), 'enlarged cephalic pores' (Konings, 1990), or an 'enlarged lateral line system...visible externally as pits and grooves especially on the lower part of the head' (Konings, 2007) (Fig. 1). Aulonocara is also reported to employ an unusual feeding strategy in the field in which they swim just a few millimeters above the sandy sediment and strike at invertebrate prey buried in the substrate. Observations of this behavior have been the basis for the assertion that the obvious widened lateral line canals on the lower jaw are used for prey detection by these fishes (Fryer, 1959; Konings, 1990; Konings, 2007). However, experimental evaluation of this assertion has been lacking.

The goal of this study was to test the hypothesis that A. stuartgranti uses the lateral line system to detect hydrodynamic stimuli generated by live, benthic invertebrate prey. Behavioral trials were carried out in which fish were presented with live (mobile) and dead (immobile) prey under light and dark conditions (Experiment 
I). The role of the lateral line system in prey detection was then determined by treating fish with cobalt chloride, which is known to temporarily inactivate the lateral line system (Experiment II). Knowledge of how the widened lateral line canal system is used in prey detection and its role in crepuscular or nocturnal feeding (not currently known in these fishes) would add a new dimension to our understanding of the ecology and evolution of this genus and of cichlid fishes more generally.

\section{MATERIALS AND METHODS}

Adult Aulonocara stuartgranti Meyer and Riehl 1985 were acquired from commercial suppliers (Bluegrass Aquatics, Louisville, KY, USA) and housed in 1901 aquaria at $26 \pm 1{ }^{\circ} \mathrm{C}$ and $1.0 \pm 0.2$ p.p.t. salinity (using Cichlid Lake Salt, Seachem Laboratories, Inc., Madison, GA, USA) with appropriate mechanical and biological filtration. Fish were fed cichlid pellets (New Life Spectrum Cichlid Formula, New Life International, Inc., Homestead, FL, USA) one to two times daily and supplemented with live adult brine shrimp. Fish were provided with standard white fluorescent light on a $12 \mathrm{h:12} \mathrm{h}$ diurnal cycle (lights on 07:00-19:00 h). Individual fish were not used in feeding experiments if breeding behavior was observed. Animal care and all experimental procedures followed an approved University of Rhode Island IACUC protocol.

\section{Behavioral experiments}

Behavioral trials (in Experiments I and II) were conducted in an experimental tank $(120 \times 90 \times 60 \mathrm{~cm} ; 375$ l) lined with light colored sand (Aragamax Sand, CaribSea, Fort 
Pierce, FL, USA) over quartz gravel, intended to mimic the sandy substrate of the fishes' natural habitat in which they feed in Lake Malawi (Fig. 2A). Two methods were used to present live and dead (freshly frozen) adult brine shrimp (Artemia) to individual fish. Brine shrimp were attached with aquarium-grade silicone to the back of $8.5 \mathrm{~cm}$ diameter glass Petri dishes. Alternatively, brine shrimp were attached to square platforms $(10 \times 10 \mathrm{~cm})$ made of plastic egg crate louver covered with a fine plastic mesh with elastic thread ( $1 \mathrm{~mm}$ diameter) woven through the mesh. The first three fish in Experiment I were presented with prey tethered with silicone to glass Petri dishes, whereas all other fish in Experiments I and II were presented with prey tethered to mesh platforms. Brine shrimp were secured to the platform by positioning them ventral side up and placing the elastic thread over their abdomen, allowing the brine shrimp to freely move their appendages, which generated a hydrodynamic stimulus that was visualized using digital particle image velocimetry (DPIV; see below). To measure the frequency of hydrodynamic stimuli generated by brine shrimp tethered to platforms, movements of brine shrimp appendages were recorded using an HD digital video camera (Sony HDR-CX550V; 30 frames s $^{-1}$ ) under light ( $\left.N=3\right)$ and dark $(N=3)$ conditions. Beat rate (beats s$\left.{ }^{-1}\right)$ was calculated at $0,10,20$ and 30 min for each individual, and parametric statistics (data were normally distributed) were used to compare beat frequency under light vs dark conditions (Student's $t$-test) at the beginning and end of a $30 \mathrm{~min}$ period (paired $t$-test), and at $0,10,20$ and $30 \mathrm{~min}$ (ANOVA).

One or two fish were allowed to acclimate to the experimental tank for at least $24 \mathrm{~h}$ and food was withheld for $24 \mathrm{~h}$ before a behavioral trial. When two fish were in 
the experimental tank, they were separated from one another at all times. Fish were placed behind opaque dividers during the setup of a trial and the process of tethering the brine shrimp was carried out in a separate water-filled container. One live and one dead brine shrimp were positioned on opposite sides of each dish or platform, approximately $7 \mathrm{~cm}$ apart. Six dishes or platforms were then gently lowered into the experimental tank and arranged in a $2 \times 3$ grid flush with the surface of the sandy substrate (Fig. 2B). The relative placement of the live and dead prey on all six dishes or platforms was the same in a trial. To avoid spatial learning, all dishes or platforms were rotated 90 deg in sequential trials in Experiment I, but this was not done in Experiment II, after it became apparent that spatial learning was not an issue.

Observations confirmed that brine shrimp remained tethered (and alive) for more than 30 min when fish were not present.

Immediately following the placement of the six dishes or platforms, one fish was released into the experimental arena from behind an opaque divider. Feeding behavior was recorded for 30 min using either a standard (Sony Handycam DCRHC65-NTSC, 30 frames s $^{-1}$ ) or an HD (Sony HDR-CX550V, 30 frames s ${ }^{-1}$ ) digital video camera mounted directly above the tank with a vertical view of the entire experimental arena. Light trials were carried out under standard white fluorescent illumination and dark trials were carried out in complete darkness with infrared illumination ( $840 \mathrm{~nm}$; Speco Provideo, IR-200/24, Amityville, NY, USA), which is out of the visible range of these fishes (Carleton, 2009). Day trials were carried out between 10:00 and 18:00 $\mathrm{h}$ and dark trials began shortly after lights went off at 19:00 
h. All water pumps and filtration systems in the experimental tank were turned off prior to the start of a trial to eliminate acoustic and hydrodynamic noise.

Two experiments, involving a total of 39 light and 39 dark trials, were carried out over a period of 20 months using 13 different fish [total length (TL) $=6.2-12.5 \mathrm{~cm}$; only one fish was used in Experiment I and then in Experiment II]. In Experiment I, normal feeding behavior was recorded for each of six fish $(\mathrm{TL}=6.2-10.1 \mathrm{~cm}$; two females and four males) in three light and three dark trials (six trials per fish). All trials were carried out in the same sequence (three light trials then three dark trials), all on separate days; the mean time between the first light trial and last dark trial was 47 days. At the end of each trial, all prey remaining on the tethering dishes or platforms were counted and live prey were confirmed to be alive. Strike success was confirmed in video recordings. One additional light and one additional dark trial were carried out using each of two fish and recorded in lateral view to examine the vertical position of the fish in the water column relative to the substrate during the course of a $30 \mathrm{~min}$ trial.

Video sequences leading to individual prey strikes were cut from each $30 \mathrm{~min}$ video using Adobe Premier Pro (v.2.0 or CS5, Adobe Systems, San Jose, CA, USA). All sequences were viewed to identify when detections occurred relative to the start of the trial and during which phase of swimming behavior (thrust, glide or pause) prey was detected. These phases were defined as: thrusts (quick accelerations generated by the beating of the caudal fin), glides (characterized by a decrease in swimming velocity, varied in duration, and may have included a left or right maneuver), and 
pauses (a lack of forward movement when a fish was stationary, with pectoral fins extended). No strikes occurred during a thrust, so data are recorded as a percentage of total strikes occurring during either a glide or a pause. Detection distance and detection angle were measured in still images exported from behavioral sequences using ImageJ (v.1.41o, National Institutes of Health, Bethesda, MD, USA). Detection distance was defined as the distance from the tip of a fish's mouth to the prey, in the frame immediately before the fish oriented towards it (e.g. before a turn or swimming reversal; Fig. 2C). Detection angle was defined as the angle between the prey and the midpoint between the fish's eyes, with reference to the long axis of the fish's body, in the same captured frame in which detection distance was determined.

In Experiment II, the role of the lateral line system in prey detection was demonstrated by treating the fish with cobalt (II) chloride heptahydrate (cobalt chloride; Sigma-Aldrich, St Louis, MO, USA) to temporarily inactivate the lateral line system (Karlsen and Sand, 1987). At the time of the planning of these experiments, it was still thought that aminoglycoside antibiotics deactivated only canal neuromasts but not superficial neuromasts (e.g. Song et al., 1995); however, recent studies have now demonstrated that these antibiotics ablate all neuromasts (Van Trump et al., 2010; Brown et al., 2011). Cobalt chloride was chosen for the present study because it was known to deactivate both superficial and canal neuromasts, and shorter exposures and lower doses of cobalt chloride have been shown to have little or no side effects (Karlsen and Sand, 1987). Each of seven fish $(\mathrm{TL}=8.2-12.5 \mathrm{~cm}$; five females and two males) was run through one light and one dark 'pre-cobalt' trial (the same protocol as Experiment I) on the same day. Then, within 2-7 days, each fish was treated with 
cobalt chloride $\left(0.1 \mathrm{mmol}^{-1}\right.$ in conditioned tap water) for $3 \mathrm{~h}$, after which it was returned to the experimental tank. A light trial with cobalt treatment ('cobalt trial') commenced only after a fish appeared to be behaving normally, which was indicated by normal respiration rate and swimming (this occurred $2-3 \mathrm{~h}$ after cobalt treatment). A dark trial was then carried out 3-4 h later, shortly after the overhead lights went off. All fish resumed feeding on commercial pellets and/or brine shrimp immediately following cobalt dark trials. After 21-28 days, each fish was then run through one light and one dark 'post-cobalt' trial to assess recovery. All light trials were carried out during the day (11:30-17:30 h) and all dark trials were started within $1 \mathrm{~h}$ after the overhead lights went off (19:00-20:00 h). The effect of cobalt chloride has been shown to begin wearing off within hours of a fish being placed in water containing calcium (Karlsen and Sand, 1987), so light and dark trials were completed within a few hours of each other. All fish were observed to eat more than 24 brine shrimp in one day during routine feeding, so fish in Experiment II could not have been satiated by the end of each light trial, in which only 12 brine shrimp were presented. In addition, fish were starved for $24 \mathrm{~h}$ before each set of trials. To determine whether feeding behavior was altered by handling during cobalt treatment, each of two fish were run through a light and dark trial (normal trial) followed by $3 \mathrm{~h}$ immersion in conditioned tap water in the same type of container used for cobalt treatment. Then, a light and a dark trial (cobalt sham trial) were carried out as in Experiment II. All video analysis was carried out as described for Experiment I. 


\section{Statistical analysis}

The number of prey strikes, detection distance, detection angle, time to first detection and order of prey capture (live vs dead) were tested with various statistical tests to find significant differences among prey (live or dead) and trial type (light and dark; precobalt, cobalt and post-cobalt) using SPSS (v.19, IBM, Armonk, NY, USA) or Oriana (v.3, Kovach Computing Services, Anglesey, UK; detection angles only). All data were tested for normality using the Kolmogorov-Smirnov test. A generalized linear mixed model (GLMM) was used to analyze the number of prey strikes and detection distance in Experiments I and II. This approach allowed the selection of random (individual) and fixed effects (light vs dark, live vs dead prey, treatment type) while addressing repeated measures for the same individual. However, a repeated-measures model (GLM repeated measures) was not appropriate because the data were not balanced (e.g. if prey were not consumed, detection distance could not be recorded). For analysis of detection distance in Experiment I, data were $\log _{10}$-transformed to achieve normality, which is appropriate for a GLMM analysis. Time to first detection was analyzed using univariate ANOVA in both Experiments I and II. Prey preference was calculated following a method described in Taplin (Taplin, 2007). Briefly, Taplin's analysis involves determining prey preference by ranking the prey by the order in which they were consumed, and then calculating a preference score by taking the mean of the order values for each prey type. Assumptions for this analysis include that multiple types of prey must be offered simultaneously (e.g. live and dead tethered brine shrimp) and prey consumed last cannot be distinguished from uneaten prey. Scores closer to one indicate a strong preference, whereas scores closer to 12 (total 
number of prey offered) indicate no preference or rejection. Preference scores for live or dead prey in each trial type (light and dark; pre-cobalt, cobalt and post-cobalt) were compared using paired $t$-tests. In Experiment I, means of prey preference scores from the three replicate trials carried out for each fish were calculated prior to carrying out the paired $t$-test, so that the replicate variable was the fish (individual) and not the trial. All tests were considered significant at $P<0.05$. Values are given as means \pm s.e.m. unless otherwise specified.

\section{Digital particle image velocimetry}

The hydrodynamic stimulus generated by adult brine shrimp $(N=4$, tethered to a mesh platform as described above) was visualized and quantified using DPIV. A tethered brine shrimp was placed in a 191 tank seeded with silver coated, near neutrally buoyant, reflective particles at a density of $0.1 \mathrm{~g}^{-1}$ (12-14 mm diameter; Potters Industries, Inc., Parsipanny, NJ, USA). A light beam from a continuous $5 \mathrm{~W}$ argon-ion laser was focused into a 2-mm-thick and 10-cm-wide vertical sheet that illuminated the brine shrimp along its midline. A high-speed, high-resolution (1024×512 pixels) Photron APX camera (Photron USA, San Diego, CA, USA) was positioned perpendicular to the laser sheet to record brine shrimp and particle movement at 60 frames s ${ }^{-1}$. Images were processed using DaVis 7.0 software (LaVision, Goettingen, Germany) using sequential cross-correlation without pre-processing. A mask was added to exclude movements of the brine shrimp itself in order to analyze only those water movements generated by the brine shrimp. An initial correlation window of $12 \times 12$ pixels was selected using multi-pass with decreasing smaller size to a final 
interrogation window of $8 \times 8$ pixels with $50 \%$ overlap. All vectors above the threshold of $2 \mathrm{~mm} \mathrm{~s}^{-1}$ were considered to represent significant flows generated by the movements of the brine shrimp.

\section{RESULTS}

Tethered brine shrimp generated a flow that was produced by the upstroke and downstroke of their feeding and swimming appendages (Fig. 3). A weaker flow was generated by the upstroke when the appendages moved in a caudal to rostral direction (range $=2-4 \mathrm{~mm} \mathrm{~s}^{-1}$; Fig. 3B), compared with the stronger flow generated by the downstroke when the appendages moved in a rostral to caudal direction (range $=3-7$ $\mathrm{mm} \mathrm{s}^{-1}$; Fig. 3D). Little flow was observed during the pre-upstroke phase (Fig. 3A), the transition between the upstroke and downstroke (Fig. 3C) or in the postdownstroke phase (Fig. 3E) of appendage movement. Vortices were visualized $\sim 1 \mathrm{~cm}$ above the abdomen (upstroke) or head (downstroke), and moved along the body axis, and were no longer visible $1 \mathrm{~cm}$ beyond the body. It appeared that vortices were short lived, or were shed obliquely, and were thus out of the plane of the laser sheet. Vortices were only seen in the immediate vicinity of the brine shrimp, and it is unlikely that vortices generated by more than one live brine shrimp would overlap given the spacing of the tethering platforms in feeding trials. Flow velocities appeared to vary somewhat among individual brine shrimp, which was likely a reflection of brine shrimp size $(\mathrm{TL}=7-12 \mathrm{~mm})$, where larger brine shrimp generated higher flow rates. 
The frequency at which tethered brine shrimp move $\left(\sim 2-4\right.$ beats $\left.\mathrm{s}^{-1}\right)$ did not differ under light and dark conditions (Student's $t$-test, $P>0.05$ ), although it appears that in the dark the beat frequencies tended to be somewhat lower than those in the light. Overall, the frequency did not vary significantly over time under either light or dark conditions (ANOVA, $P>0.05$ ). However, there was no difference in beat frequency at the beginning and end of a $30 \mathrm{~min}$ period in the light (paired $t$-test, $P>0.05$ ), whereas under dark conditions the beat frequency was significantly higher at $30 \mathrm{~min}\left(2.4 \pm 0.5\right.$ beats s $\left.^{-1}\right)$ than at $0 \mathrm{~min}\left(2.1 \pm 0.5\right.$ beats s $^{-1}$; paired $t$-test, $\left.P<0.05\right)$.

\section{Behavioral experiments}

Aulonocara stuartgranti successfully fed on tethered brine shrimp in both light and dark trials. They demonstrated differences in number of prey strikes, detection distance, detection angle, prey preference and time to first detection depending on light conditions. Treatment with cobalt chloride resulted in a change in prey detection behavior, especially in the dark.

\section{Experiment I: normal light and dark trials}

In light trials, the fish swam throughout the water column, appearing to explore the tank. Upon first prey detection, the fish would swim a few millimeters above the substrate until it detected other prey, and then it would return to a more general exploration of the tank. This sequence was repeated until the end of the trial. In dark

trials, the fish appeared to spend more time in the bottom half of the tank prior to first prey detection, but then similar behavior near the bottom of the tank was observed. 
When swimming immediately above the substrate, all fish searched for prey with a series of quick thrusts (mediated by several beats of the caudal fin) followed by glides [with decreasing swimming velocity (D.K.B. and J.F.W., unpublished data)], at the end of which they appeared to pause. Prey detection was indicated by the initiation of either a turn towards the prey or a forward glide over the prey followed by a reversal in swimming direction, which was facilitated by pectoral fin movements (observed in dark trials only). In light trials, $A$. stuartgranti tended to detect prey during a pause (70.4\% of the time; Table 1), whereas in dark trials more prey were detected during a glide ( $92.6 \%$ of the time).

Prey detection was defined by an approach ending in a strike. In the event of a miss (as visualized in video), only the first strike on that prey was included in data analysis. No differences were detected in number of prey strikes, detection distance or detection angle among the three replicate light or dark trials for an individual (GLMM, $P>0.05)$. Furthermore, the two tethering methods used did not influence number of prey strikes (GLMM, $P>0.05$ ) or detection distance (GLMM, $P>0.05$ ), but mean detection angle differed in light trials only (Watson's $U^{2}$-test, $U^{2=} 0.24, P=0.02$ ), suggesting a difference in visual cues associated with tethering method. Interestingly, fish detected more prey tethered to Petri dishes with an approach to their right side (mean angle $=20.0 \pm 6.3 \mathrm{deg}$ ) and detected more prey tethered to mesh platforms with an approach to their left side (mean angle $=351.6 \pm 3.7$ deg, i.e. a mean of 9.4 deg to the left).

All individuals successfully struck at and consumed prey in both light and dark trials. There were more prey strikes in light trials than in dark trials (GLMM, 
$F=129.98, P<0.001$; Fig. 4 A), but in the dark trials there were more strikes on live prey than dead prey (GLMM, $F=7.36, P<0.01$ ). Furthermore, strikes on live prey preceded strikes on dead prey in both light and dark trials (paired $t$-test; light, $t=5.55$, $P<0.01$; dark, $t=5.23, P<0.01$; Table 2). Mean detection distance for strikes on both types of prey in light trials was twice as long as that in dark trials (GLMM, $F=71.10$, $P<0.001$; Table 3). Mean prey detection angle was significantly different in light and dark trials (Watson's $U^{2}$-test, $U^{2}=0.33, P<0.005$ ) and at detection, prey were not distributed uniformly around the fish (Rayleigh test; light, $Z=119.96, P<0.001$; dark, $Z=11.75, P<0.001 ;$ Fig. $5 \mathrm{~A})$. No differences were found in prey detection angle for live vs dead prey in light or dark trials (Watson's $\mathrm{U}^{2}$-test, $P>0.05$ ). In light trials, most prey (e.g. live and dead) were detected in front of the fish (anterior 180 deg) rather than being detected around and directly behind the head in dark trials. Although the average time to first detection in dark trials was twice that in light trials, there was no statistically significant difference (univariate ANOVA, $P>0.05$; Table 4 ) because of variability among trials.

\section{Experiment II: lateral line ablation trials}

Significant differences were found among the variables measured (number of prey strikes, detection distance and detection angle) during the different treatments. Specific comparisons are described below.

Results for light and dark trials prior to cobalt treatment (pre-cobalt trials) were similar to those in Experiment I. The fish detected more prey during a pause $(66.3 \%$ of the time) in light trials than during a glide ( $84.2 \%$ of the time) in dark trials (Table 1$)$. 
The number of strikes on live vs dead prey did not differ in either light or dark trials (GLMM, $P>0.05$; Fig. 4B). Although fish tended to strike first at live prey in light trials (paired $t$-test, $t=3.77, P<0.01$ ), preference for prey type was not evident in dark trials (paired $t$-test, $t=1.62, P=0.16$; Table 2). Mean detection distance was greater for both live and dead prey in light trials than in dark trials (GLMM, $F=20.07, P<0.001$; Table 3). In light trials, live prey were detected at a greater distance than dead prey (GLMM, $F=10.37, P=0.002$ ), but this was not the case in dark trials (GLMM, $P>0.05$, Table 3). In light trials, detection angles were not uniformly distributed around the fish (Rayleigh test, $Z=32.17, P<0.001$ ) and most prey were detected in front of the fish (anterior $180 \mathrm{deg}$ ), whereas in dark trials detection angles were statistically uniform (Rayleigh test, $P>0.05$; Fig. 5B) and prey were detected in all directions around the fish.

In light trials with cobalt treatment, only four of the seven fish demonstrated feeding behavior, even though all of them actively swam around the experimental tank. The four fish that did feed generally struck at all 12 live and dead prey (Fig. 4B), which occurred during a pause $75.7 \%$ of the time (Table 1). Both detection distance (GLMM, $P>0.05$ ) and detection angle (Watson's $U^{2}$-test, $P>0.05$ ) were similar to those in other light trials in Experiment II (Table 3, Fig. 5B). However, fish did not show a preference for live prey (paired $t$-test, $P>0.05$; Table 2), suggesting that lateral line inactivation influenced prey detection behavior. In dark trials, no strike behavior was observed among the seven fish despite the fact that they swam frequently over the tethered brine shrimp. 
In post-cobalt recovery trials, carried out $21-28$ days after cobalt treatment, more strikes occurred in the light trials than in the dark trials (GLMM, $F=56.80$, $P<0.001$; Fig. 4B) and there was no difference in the number of strikes on live and dead prey in these trials (GLMM, $P>0.05$ ). As in pre-cobalt trials, prey tended to be detected during a pause in light trials (62.3\% of the time) compared with a glide in dark trials $(91.7 \%$ of the time; Table 1). Fish demonstrated longer detection distances in light vs dark trials (GLMM, $F=18.58, P<0.001)$ and detection distance in light trials was similar to that in pre-cobalt and cobalt trials (GLMM, $P>0.05$; Table 3 ). The range of detection angles in light and dark post-cobalt trials was consistent with that in the pre-cobalt trials: most prey were detected in front of the fish (anterior $180 \mathrm{deg}$; Rayleigh test, $Z=21.84, P<0.001$ ), whereas in dark trials prey were detected in all directions around the fish (Rayleigh test, $P>0.05$; Fig. 5B). The same total strikes occurred in post-cobalt trials as in pre-cobalt trials (GLMM, $P>0.05$ ).

Thus, prey detection behavior appeared to be restored in post-cobalt trials, but certain aspects of behavior did not return to pre-cobalt levels. For instance, unlike precobalt trials, fish struck at live and dead prey equally in post-cobalt light trials (paired $t$-test, $P>0.05$ ), but live prey were struck at first in dark trials (paired $t$-test, $t=2.81$, $P=0.031)$. Interestingly, the same individuals used in pre-cobalt trials showed a preference for live prey in the light, but a statistically insignificant tendency to prefer live prey in dark trials (paired $t$-test, $t=1.62, P=0.16$; Table 2). These two results suggest that the lateral line system may not have completely recovered from cobalt chloride treatment. 
Time to first prey detection was similar in all light trials in Experiment II (precobalt, cobalt and post-cobalt; univariate ANOVA, $P>0.05$ ) and although not significant, the first prey strike appeared to occur sooner in pre- and post-cobalt light trials (within the first 1-5 min) than in dark trials (within the first 5-10 min; Table 4). In light trials with cobalt treatment, of the four fish that did strike at prey, they did so either within the first $10 \mathrm{~min}$ or near the end of the $30 \mathrm{~min}$ trial.

When two fish were immersed in conditioned tap water in the same type of container used for cobalt treatment (=cobalt sham) and run through a light and dark trial, their feeding behavior (e.g. detection distance, number of prey captured) was comparable to that in the light and dark pre-cobalt trials in Experiment II. Most importantly, both fish consumed prey during these dark cobalt sham trials. These results show that handling had no effect on feeding behavior.

\section{DISCUSSION}

This study has demonstrated that $A$. stuartgranti: (1) uses the same feeding strategy (swimming and hovering over the sandy substrate) as observed by others in the field; (2) detects and consumes live invertebrate prey in the dark; (3) alters aspects of prey detection behavior when feeding on the same prey under light and dark conditions, suggesting the importance of multimodal input in prey detection; and (4) appears to use its lateral line system to detect hydrodynamic stimuli produced by prey, especially in the dark, as demonstrated by treatment with cobalt chloride. The ability of fishes to feed under low light conditions and nocturnally has indeed been established in many 
taxa [e.g. yellow perch (Richmond et al., 2004) and bluegill (Vinyard and O'Brien, 1976) (reviewed in Webb et al., 2008)]. With the results of this study, Aulonocara joins a relatively short list of teleost fishes in which the ability to detect prey [live or simulated (vibrating sphere)] using the lateral line system has been experimentally demonstrated [e.g. mottled sculpin (Coombs and Janssen, 1990; Coombs and Patton, 2009); yellow perch and Eurasian ruffe (Janssen, 1997); goldfish (Coombs, 1994; Engelmann et al., 2002); rainbow trout (Engelmann et al., 2002); common bully (Bassett et al., 2006); scorpionfish (Bassett et al., 2007); oscar (Mogdans and Nauroth, 2011); and bastard cod (Bassett and Montgomery, 2011; Yoshizawa et al., 2010; reviewed in Webb et al., 2008)].

The results of this study provide the first experimental evidence to support prior assertions based on field observations (Fryer, 1959; Konings, 1990; Konings, 2007) that Aulonocara uses its lateral line system to detect benthic prey. Aulonocara use a thrust, glide and pause swimming strategy, and detect prey during either a glide or subsequent pause at short detection distances ( $<1$ body length). This is additional evidence of the need to detect hydrodynamic stimuli generated by prey against selfgenerated flows, especially in species with increased sensitivity provided by widened lateral line canals (Denton and Gray, 1988; Denton and Gray, 1989). The results of these experiments have illustrated the importance of the lateral line system for detection of live prey in the dark, but suggest that multimodal input appears to be necessary for robust responses to prey under light conditions. Our results shed light on the role of the non-visual senses in feeding behavior in cichlids more generally (see 
also Mogdans and Nauroth, 2011), and argue for the adaptive significance of the convergent evolution of widened lateral line canals among teleost fishes.

\section{Swimming and prey detection behavior}

All fish exhibited a saltatory search strategy [defined in O'Brien et al. and Bassett et al. (O’Brien et al., 1989; Bassett et al., 2007)] in light and dark trials in both Experiments I and II. Swimming behavior was defined as consisting of three phases (thrust, glide and pause), which is similar to that described for the ruffe (Janssen, 1997). The phase during which A. stuartgranti detected prey (pause vs glide) differed depending on light condition; prey tended to be detected during a pause in light trials, whereas prey tended to be detected during a glide in dark trials. The detection of prey during a pause is consistent with the use of vision because movement of the background across the visual field can make it increasingly difficult to discern prey from the background, especially when prey are cryptic. Prey detection capabilities of the lateral line system may be compromised because of self-generated hydrodynamic noise (Bassett, 2008), especially when detection sensitivity is enhanced [e.g. with widened canals (Denton and Gray, 1988; Denton and Gray, 1989)]. Thus, background noise (e.g. environmental water flow or flow generated by swimming movements) becomes even more of a challenge for prey detection. Nevertheless, prey detection in dark trials, which depends on the lateral line system, occurred more often during glides [as in ruffe (Janssen, 1997)]. During a glide in the light, a fish may move to within a distance appropriate for detection by the lateral line system (e.g. one to two body lengths) and at a decreasing velocity, such that self-generated noise does not 
overwhelm lateral line input. In the dark, detection during a pause would not be effective unless the fish had already detected the prey and moved within strike range. Interestingly, Aulonocara swimming velocity at prey detection in the dark was approximately half that of the swimming velocity in light trials (D.K.B. and J.F.W., unpublished data).

Some benthic fishes are known to re-orient to prey after initial detection using their lateral line system [sculpins (Coombs and Conley, 1997) and gobies (Bassett et al., 2006; Bergstrom and Mensinger, 2009)]. In contrast, Aulonocara maintains the same trajectory towards a prey once it is detected under both light and dark conditions. However, it is interesting to note that in the dark, Aulonocara frequently glides over prey and then performs a 180 deg swimming reversal, which serves to position the prey under the lower jaw before striking (present study; D.K.B. and J.F.W., unpublished data). Aulonocara most likely uses its ventrally directed mandibular, lower preopercular and perhaps infraorbital canals (see Fig. 1B,C) to detect its benthic prey during slow glides just millimeters above the substrate.

Generally, fishes use their lateral line system to detect water flows within one to two body lengths (Kalmijn, 1988; Coombs, 1999), but benthic predators have been shown to detect and successfully capture free-swimming prey within half a body length [oyster toadfish Opsanus tau (Price and Mensinger, 1999; Palmer et al., 2005); mottled sculpin Cottus bairdi (Hoekstra and Janssen, 1986); and freshwater sculpins Cottus spp. and the round goby Apollonia melanostoma (Bergstrom and Mensinger, 2009)]. These benthic species all have narrow canals [except for the round goby, which has reduced canals (Webb, 1989)] and are either ambush predators [oyster 
toadfish (Phillips and Swears, 1979)] or use a saltatory search strategy [sculpins (Hoekstra and Janssen, 1985) and gobies (Bassett et al., 2007) (M.A.B.S. and A. Mensinger, unpublished observations)]. These benthic fishes detect prey in the water column while generating little if any hydrodynamic noise, which is associated with swimming. The results of the present study demonstrate that, like the ruffe (Janssen, 1997), A. stuartgranti can also detect prey within half a body length using its lateral line system, and thus its lateral-line-mediated detection capabilities are comparable to those of the benthic predators mentioned above.

\section{Evidence for multimodal sensory interaction in prey detection}

The results of this study are consistent with the use of lateral-line-mediated prey detection. Differences in parameters that define prey detection behavior, including prey preference (tendency to strike first at live vs dead prey) in light and dark trials, suggests that $A$. stuartgranti uses different combinations of sensory input depending on light conditions.

It could be argued that live brine shrimp present a stronger stimulus than dead brine shrimp because of the generation of a combination of visual, hydrodynamic, olfactory and perhaps tactile cues generated by the movement of their appendages. Thus, significant differences in the order of prey strikes (preference for live vs dead prey) under conditions in which different subsets of sensory modalities are available can be used to reveal the nature of sensory input that is necessary and sufficient for the initiation of prey detection behavior. For instance, results for Experiment I show a preference for live prey in both light and dark trials (Table 2). Multiple sensory 
modalities likely contribute to prey detection behavior during light trials, but lateral line (and olfactory and tactile) cues are sufficient to generate a preference for live prey in dark trials. In this study, it was assumed that similar olfactory cues were presented by offering live and freshly dead brine shrimp, but the movements of live brine shrimp may generate a stronger olfactory cue (in addition to a more obvious visual cue) that reinforces the preference for live prey. Tactile stimulation may have also contributed to some prey strikes (especially in the dark), as the fish swim just millimeters above the substrate and their bodies and/or pelvic fins could come in contact with the brine shrimp, resulting in the initiation of strike behavior. In pre-cobalt trials in Experiment II (same methodology as Experiment I), in which all sensory systems were available, fish showed a preference for live prey only in light trials. The statistically insignificant prey preference in the dark $(P=0.16)$ suggests that fish may not be able to discern the difference between live and dead prey using a tactile sense.

The results of Experiment I suggest that visual cues are used for prey detection in light trials. This is based on the fact that detections occurred while the fish were stationary (e.g. in a pause), at longer detection distances and with a smaller range of detection angles. Fish showed an equally high number of strikes on both live and dead prey, a shorter time to first prey strike and a predominance of prey detections (live and dead prey) during a pause, regardless of whether the fish had been treated with cobalt chloride. In light trials with cobalt treatment, only some of the fish struck at prey even when visual cues were available. In dark trials (Experiment I, and in pre- and postcobalt trials in Experiment II), more prey were detected during a glide, at shorter detection distances and with a broader range of detection angles (including $180 \mathrm{deg}$ 
swimming reversals). The fish also struck at more live (vs dead) prey and generally during glides in the absence of cobalt treatment, indicating the role of the lateral line system when vision was not available. In dark trials with cobalt treatment, none of the fish struck at prey in the dark, even when the same fish struck at prey in light trials just a few hours earlier. Thus, it is concluded that lateral line input is required for prey detection behavior under dark as well as light conditions.

In cobalt trials, fish did not show a preference for live prey in the light, and did not strike at any prey in the dark. Although vision and olfaction are not thought to be affected by cobalt chloride (Liao, 2006; Yoshii and Kurihara, 1983), the absence of both preference for live prey in light trials and any prey strikes in dark trials (Experiment II) shows that, under these conditions, olfactory and tactile cues were not sufficient for the localization of prey and initiation of prey strikes in the dark. During post-cobalt recovery trials, fish did not show a preference for live prey in either light or dark trials as they did in Experiment I, which suggests that the lateral line system may not have fully recovered from cobalt chloride treatment.

\section{Cobalt chloride ablation of the lateral line system}

There has been much discussion about methods used for the chemical or pharmacological ablation of the lateral line system using aminoglycoside antibiotics (e.g. Song et al., 1995; Janssen, 2000; Santos et al., 2006; Van Trump et al., 2010; Brown et al., 2011), so a consideration of ablation methods using cobalt chloride deserves a short discussion here. Karlsen and Sand (Karlsen and Sand, 1987) reported that after treatment with cobalt chloride in calcium-free water, a fish's sensitivity to 
water flows returned within hours to weeks when placed in calcium-enriched water. Cobalt chloride blocks the calcium channels in the membranes of the sensory hair cells that compose the neuromasts, which is reversible when the cobalt ions are replaced with calcium ions (that normally occur in freshwater and seawater). Subsequent studies used a wide range of concentrations and exposure times [e.g. 0.003-1.0 mmol $\mathrm{l}^{-1}$ for $1 \mathrm{~h}$ to $1-2$ weeks (Karlsen and Sand, 1987); $2 \mathrm{mmol}^{-1}$ for $3 \mathrm{~h}$ (Montgomery et al., 1997); $0.15 \mathrm{mmol}^{-1}$ for 3-4 h (Liao, 2006); and $0.05 \mathrm{mmol} \mathrm{l}^{-1}$ for $24 \mathrm{~h}$ (Patton et al., 2010)]. In the present study, the concentration and duration of cobalt chloride treatment $\left(0.1 \mathrm{mmol}^{-1}\right.$ for $\left.3 \mathrm{~h}\right)$ appeared to inactivate the lateral line system of $A$. stuartgranti as demonstrated by the behavioral results.

Interestingly, behavioral changes were observed despite the fact that calcium was present in water during cobalt chloride treatment $\left(60 \mathrm{mg} \mathrm{l}^{-1}\right.$; Hach hardness test kit, Loveland, CO, USA) and in the experimental tank (140-160 $\left.\mathrm{mg} \mathrm{l}^{-1}\right)$. It was also demonstrated that handling (cobalt sham trials) did not affect feeding behavior. Results of this study show that treatment with cobalt chloride significantly affected prey detection behavior, especially in the dark. This is interpreted as being the result of successful lateral line inactivation by cobalt chloride. Interestingly, prey detection behavior in post-cobalt (recovery) trials was not as robust as that prior to cobalt treatment (e.g. pre-cobalt trials), providing evidence that $3-4$ weeks was not long enough for the fish to fully recover. Although most of the behavioral parameters measured (e.g. detection distance, detection angles, median number of strikes and time to first detection) were not significantly different in post-cobalt trials than in precobalt trials, the number of strikes on live prey was lower and the preference for live 
prey seen in pre-cobalt trials was not evident in light post-cobalt trials. This result suggests that $A$. stuartgranti can regain sensitivity to hydrodynamic stimuli within several hours after exposure to cobalt chloride, but that this sensitivity may not be strong enough to elicit a robust response, including preference for live prey in the dark, when visual cues are not available. Furthermore, lateral line morphology must be taken into account when interpreting the present results concerning recovery time. Prior studies were carried out in a species with narrow canals that contain small canal neuromasts [the roach Rutilus rutilus (Karlsen and Sand, 1987)]. Larger neuromasts (a characteristic of widened canals, including those of Aulonocara) have more hair cells, so collectively, these neuromasts likely have more calcium channels and may require a longer period to recover. Thus, the effective recovery period may indeed be longer than previously reported, especially for species with larger neuromasts and widened canals. Here recovery occurs at least 3 to 4 weeks post treatment compared with 2 to 3 weeks reported by Karlsen and Sand (Karlsen and Sand, 1987). It is recommended that in future studies, the morphology of the lateral line system should be carefully considered and the course of post-cobalt recovery should be monitored by assaying several parameters of prey detection behavior (e.g. prey preferences) to determine when complete recovery has indeed been achieved.

Finally, to provide some morphological verification of the effects of cobalt chloride, juvenile fishes were treated and then stained with a fluorescent mitochondrial stain, DASPEI, to visualize the neuromasts. When juvenile A. stuartgranti [standard length $(\mathrm{SL})=40-44 \mathrm{~mm}]$ were stained $(0.01 \%$ DASPEI for $30 \mathrm{~min})$ immediately after cobalt treatment $\left(0.1 \mathrm{mmol} \mathrm{l}^{-1}\right.$, for $3 \mathrm{~h}$ in tank water, as in Experiment II), many 
neuromasts showed an unstained central region that is interpreted as negative staining of hair cells (M.A.B.S. and E. A. Becker, unpublished data), suggesting a physiological effect of cobalt chloride treatment. When juvenile A. stuartgranti $(\mathrm{SL}=23-36 \mathrm{~mm})$ were treated at a lower concentration $\left(0.05 \mathrm{mmol}^{-1}\right.$ for $3 \mathrm{~h}$ in tank water; paired with control fish not treated with cobalt chloride) and then different individuals were stained with DASPEI (as above) at different time points over the course of 3 weeks, a decrease in staining intensity was observed for several days. More than 1 week after cobalt treatment, the intensity of DASPEI fluorescence had increased so that it was comparable to that in control fish (E. A. Becker and M.A.B.S., unpublished data). Thus, it is concluded that cobalt chloride does indeed have an effect on neuromasts, which is apparent over the course of 1 week, but that it may have more subtle effects that could not be visualized with DASPEI over the 3-4 week recovery period. Although providing verification that differences in feeding behavior were likely not due to non-specific effects of treatment with cobalt chloride, the impact of cobalt chloride (a calcium channel blocker) on neuromast staining with DASPEI (a mitochondrial stain) deserves more study.

\section{Sensory biology and trophic niches of cichlids}

The demonstration that $A$. stuartgranti can detect, successfully strike at and consume live benthic prey in the dark reveals the importance of non-visual senses in the feeding biology of cichlids, which have traditionally been considered to be diurnal visual feeders. This finding, coupled with what is known about the ecology of Aulonocara (Grant et al., 1987), can now provide hints concerning the role of non-visual senses in 
this genus. Some Aulonocara species are reported to occupy relatively low-light environments (e.g. $>40 \mathrm{~m}$ depth, up to $70 \mathrm{~m}$ ) and live and/or maintain territories in caves adjacent to the sandy substrates in which they feed (Meyer et al., 1987; Konings, 1990). Furthermore, evidence of nocturnal courtship behavior (D.K.B., unpublished observations) suggests that non-visual sensory modalities may be important for other aspects of their behavior. Although the present study has shown that A. stuartgranti can feed in the dark in the laboratory, these fishes are not known to be active at night in Lake Malawi (A. Konings, personal communication). However, it remains possible that these fishes are indeed nocturnally active, perhaps at depths greater than those at which they have been observed, and/or in the caves that some Aulonocara species occupy.

The ability to feed in low-light environments, or to feed nocturnally on inconspicuous and especially infaunal invertebrate prey, may reduce competition with visual feeders (Schleuter and Eckmann, 2006) by allowing access to novel spatial and temporal niches and providing refuge from a fish's own diurnally active predators (Helfman, 1993; Bassett, 2008). Modulation of prey detection behavior depending on light conditions, as we have demonstrated in A. stuartgranti, may be beneficial for fishes that are normally active in a range of light conditions, in habitats where food resources are diverse (e.g. cryptic, non-cryptic) and/or in habitats where prey are unpredictably distributed. Non-visual detection of prey may confer an advantage for species in habitats with increased turbidity levels (Bergman, 1991; Schleuter and Eckmann, 2006) in which the ability to visually detect prey is compromised. 
Some ambush predators are able to detect prey in the water column using neuromasts in narrow canals [e.g. mottled sculpin (Coombs et al., 2001; Kanter and Coombs, 2003) and trout and goldfish (Sand and Bleckmann, 2008)] or superficial neuromasts [common bully Gobiomorphus cotidianus (Bassett et al., 2006)]. However, neuromasts in canals, and in widened canals in particular, present some important advantages for detection of benthic (as opposed to free-swimming) prey. First, canal neuromasts are protected from abrasion and fouling by sediment and thus appear to be advantageous for close-range detection of hydrodynamic flows generated by prey living on or in gravel, sand or mud. Second, canal neuromasts are able to better detect prey in background flows - those generated by currents moving past a fish or generated by the swimming motion of a fish (Kanter and Coombs, 2003; Engelmann et al., 2000; Engelmann et al., 2002; Bassett et al., 2006). Third, neuromasts in widened canals (which are generally larger with more variable morphology) are more sensitive than neuromasts in narrow, well-ossified canals (Denton and Gray, 1988; Denton and Gray, 1989; Janssen, 1997). The evolution of widened canals in Aulonocara coupled with their particular prey search and prey detection behaviors makes a strong case for the evolution of widened canals in this genus as an adaptation for the detection of hydrodynamic stimuli generated by benthic invertebrate prey. 


\section{ACKNOWLEDGEMENTS}

We thank Drs Cheryl Wilga and Anabela Maia for their expertise with DPIV;

Douglas Moore (Orthopedics Research Lab, Rhode Island Hospital) and Timothy Alberg, who generated and analyzed microCT data; and Emily Becker, Adam Arraghi and Benjamin Sevey, who assisted with experiments and data analysis. We thank Edward Baker (Facilities Manager, RI NSF EPSCoR Marine Life Science Facility), Juleen Dickson, Joshua Hower and Brandon Fuller for assistance with fish husbandry.

\section{FUNDING}

This research was funded by the University of Rhode Island College of the Environment and Life Sciences and the National Science Foundation (NSF) [grant IOS 0843307 to J.F.W.], and was supported in part by NSF EPSCoR Cooperative Agreement EPS-1004057. 
Table 1. Number and frequency (\%) of prey detections leading to strikes in Experiments I ( $N=6$ fish) and II ( $N=7$ fish) that occur during the glide or the pause phase of swimming in Aulonocara stuartgranti. Percentages were calculated for live prey $(N=6)$, dead prey $(N=6)$ or all prey (live + dead, $N=12)$ for each type of trial (light, $N=3$; dark, $N=3$ ).

\begin{tabular}{|c|c|c|c|c|c|c|c|c|}
\hline & & & \multicolumn{2}{|c|}{ Live Prey } & \multicolumn{2}{|c|}{ Dead Prey } & \multicolumn{2}{|c|}{ All Prey } \\
\hline & & & Pause & Glide & Pause & Glide & Pause & Glide \\
\hline \multirow{2}{*}{ Experiment I } & & Light & $\begin{array}{c}67 \\
(73.6 \%)\end{array}$ & $\begin{array}{c}24 \\
(26.4 \%)\end{array}$ & $\begin{array}{c}52 \\
(66.7 \%)\end{array}$ & $\begin{array}{c}26 \\
(33.3 \%)\end{array}$ & $\begin{array}{c}119 \\
(70.4 \%)\end{array}$ & $\begin{array}{c}50 \\
(29.6 \%)\end{array}$ \\
\hline & & Dark & $\begin{array}{c}3 \\
(7.7 \%) \\
\end{array}$ & $\begin{array}{c}36 \\
(92.3 \%) \\
\end{array}$ & $\begin{array}{c}1 \\
(6.7 \%) \\
\end{array}$ & $\begin{array}{c}14 \\
(93.3 \%) \\
\end{array}$ & $\begin{array}{c}3 \\
(7.4 \%) \\
\end{array}$ & $\begin{array}{c}50 \\
(92.6 \%) \\
\end{array}$ \\
\hline \multirow{6}{*}{ Experiment II } & Pre- & Light & $\begin{array}{c}32 \\
(76.2 \%)\end{array}$ & $\begin{array}{c}10 \\
(23.8 \%)\end{array}$ & $\begin{array}{c}21 \\
(55.3 \%)\end{array}$ & $\begin{array}{c}17 \\
(44.7 \%)\end{array}$ & $\begin{array}{c}53 \\
(66.3 \%)\end{array}$ & $\begin{array}{c}27 \\
(33.7 \%)\end{array}$ \\
\hline & Cobalt & Dark & $\begin{array}{c}2 \\
(12.5 \%)\end{array}$ & $\begin{array}{c}14 \\
(87.5 \%)\end{array}$ & $\begin{array}{c}1 \\
(33.3 \%)\end{array}$ & $\begin{array}{c}2 \\
(66.7 \%)\end{array}$ & $\begin{array}{c}3 \\
(15.8 \%)\end{array}$ & $\begin{array}{c}16 \\
(84.2 \%)\end{array}$ \\
\hline & \multirow[t]{2}{*}{ Cobalt } & Light & $\begin{array}{c}15 \\
(78.9 \%)\end{array}$ & $\begin{array}{c}4 \\
(21.1 \%)\end{array}$ & $\begin{array}{c}13 \\
(72.2 \%)\end{array}$ & $\begin{array}{c}5 \\
(27.8 \%)\end{array}$ & $\begin{array}{c}28 \\
(75.7 \%)\end{array}$ & $\begin{array}{c}9 \\
(24.3 \%)\end{array}$ \\
\hline & & Dark & 0 & 0 & 0 & 0 & 0 & 0 \\
\hline & \multirow{2}{*}{$\begin{array}{l}\text { Post- } \\
\text { Cobalt }\end{array}$} & Light & $\begin{array}{c}25 \\
(73.5 \%)\end{array}$ & $\begin{array}{c}9 \\
(26.5 \%)\end{array}$ & $\begin{array}{c}18 \\
(51.4 \%)\end{array}$ & $\begin{array}{c}17 \\
(48.6 \%)\end{array}$ & $\begin{array}{c}43 \\
(62.3 \%)\end{array}$ & $\begin{array}{c}26 \\
(37.1 \%)\end{array}$ \\
\hline & & Dark & $\begin{array}{c}1 \\
(12.5 \%)\end{array}$ & $\begin{array}{c}7 \\
(87.5 \%)\end{array}$ & $\begin{array}{c}0 \\
(0 \%)\end{array}$ & $\begin{array}{c}4 \\
(100 \%)\end{array}$ & $\begin{array}{c}1 \\
(8.3 \%)\end{array}$ & $\begin{array}{c}11 \\
(91.7 \%)\end{array}$ \\
\hline
\end{tabular}


Table 2. Mean prey preference scores for live $(N=6)$ or dead $(N=6)$ prey in light $(N=3)$ and dark $(N=3)$ trials in Experiments I ( $N=6$ fish) and II ( $N=7$ fish) following Taplin (Taplin, 2007).

\begin{tabular}{cccc}
\hline & & Light Trials & Dark Trials \\
\hline \multirow{2}{*}{ Experiment I } & & Live: $5.49^{*}$ & $\begin{array}{l}\text { Live: } 5.74^{*} \\
\text { Dead: } 7.26\end{array}$ \\
& & Dead: 7.51 & Live: 5.93 \\
& \multirow{2}{*}{ Pre-Cobalt } & Live: $5.12^{*}$ & Dead: 7.07 \\
\cline { 2 - 4 } Experiment II & \multirow{2}{*}{ Cobalt } & Lead: 7.88 & No Strikes 6.45 \\
\cline { 2 - 4 } & \multirow{2}{*}{ Post-Cobalt } & Dead: 6.55 & Live: 6.29 \\
& & Dead: 6.71 & Live: $6.19^{*}$ \\
& \multirow{2}{*}{ Dead: 6.82} \\
\hline
\end{tabular}


Table 3. Detection distance (mean \pm s.e.m.; $\mathrm{cm})$ for live $(N=6)$ and dead $(N=6)$ brine shrimp prey in Experiments I ( $N=6$ fish) and II ( $N=7$ fish $)$.

\begin{tabular}{cccc}
\hline & & Light Trials & Dark Trials \\
\hline \multirow{2}{*}{ Experiment I } & & Live: $8.47 \pm 0.65$ & Live: $4.42 \pm 0.64$ \\
& & Dead: $7.17 \pm 0.66$ & Dead: $3.93 \pm 0.83$ \\
\hline \multirow{2}{*}{ Experiment II } & \multirow{2}{*}{ Cobalt } & Live: $9.72 \pm 0.57$ & Live: $3.27 \pm 0.47$ \\
\cline { 2 - 4 } & \multirow{2}{*}{ Cobalt } & Live: $9.95 \pm 1.50$ & No Strikes \\
\cline { 2 - 4 } & \multirow{2}{*}{ Post-Cobalt } & Lead: $8.46 \pm 0.90$ & Live: $8.41 \pm 0.74$ \\
& Dead: $7.63 \pm 0.38$ & Live: $2.91 \pm 0.60$ \\
& & & Dead: $2.05 \pm 0.52$ \\
\hline
\end{tabular}


Table 4. Mean (min.-max.) time to first detection ( $\min$ ) of prey (live, $N=6$; dead, $N=6)$ in light $(N=3)$ and dark $(N=3)$ trials in Experiments I $(N=6$ fish $)$ and II $(N=7$ fish).

\begin{tabular}{lccc}
\hline & & Light Trials & Dark Trials \\
\hline Experiment I & Pre-Cobalt & $5.6(1.0 / 15.9)$ & $10.5(0.6 / 29.6)$ \\
\hline \multirow{2}{*}{ Experiment II } & Cobalt & $9.2(0.3 / 28.1)$ & No Strikes \\
& Post-Cobalt & $6.6(0.1 / 19.7)$ & $7.8(0.6 / 20.2)$ \\
\hline
\end{tabular}



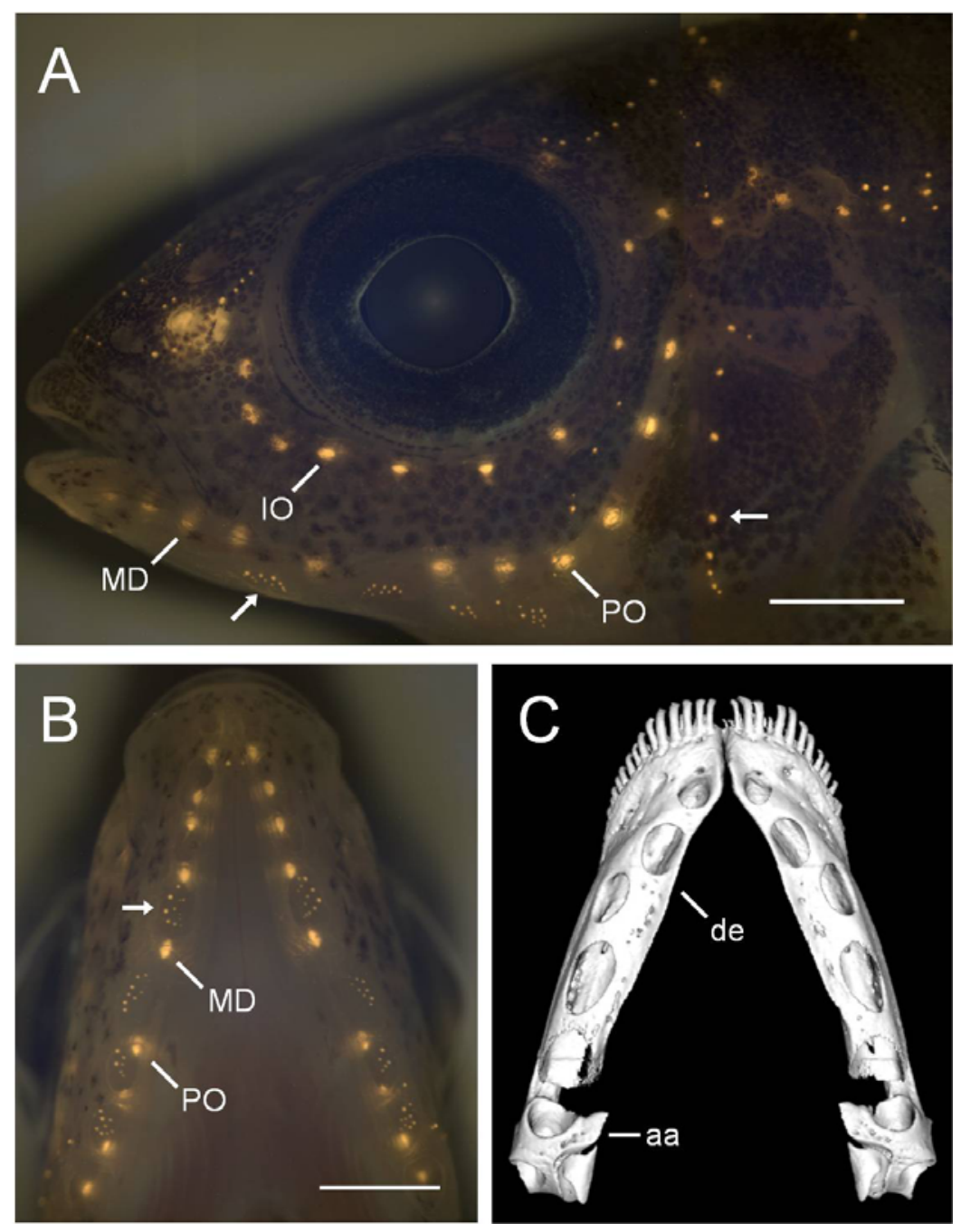

Figure 1. The mechanosensory lateral line system of Aulonocara spp. (A) Juvenile $A$. stuartgranti [standard length $(\mathrm{SL})=28 \mathrm{~mm}$ ] stained with DASPEI $(0.01 \%$, for $30 \mathrm{~min})$ to reveal lines and clusters (arrows) of small superficial neuromasts and lines of larger canal neuromasts, which are enclosed in canals: the infraorbital canal (below the eye; IO), the mandibular canal (in the lower jaw; MD), which continues as the curved preopercular canal (PO), which extends dorsally to its junction with the infraorbital and otic canals, which then continue caudally. The supraorbital canal (above the eye) is not visible in this image. The olfactory organ (rostral to the eye) is stained intensely by DASPEI and is seen through the skin and single naris. (B) Ventral view of the fish shown in A showing large canal neuromasts in the mandibular canal (five neuromasts) and in the ventral portion of the preopercular canal (four neuromasts), and clusters (arrow) of small superficial neuromasts in the skin (pierced by small pores, not visible) overlying the large bony pores of the canal. (C) MicroCT image of the isolated mandible [dentary (de) and anguloarticular (aa) bones] showing the large bony pores in the mandibular canal of an adult fish (A. baenschi, SL=87 mm). Scale bars, $2.0 \mathrm{~mm}$. 
A

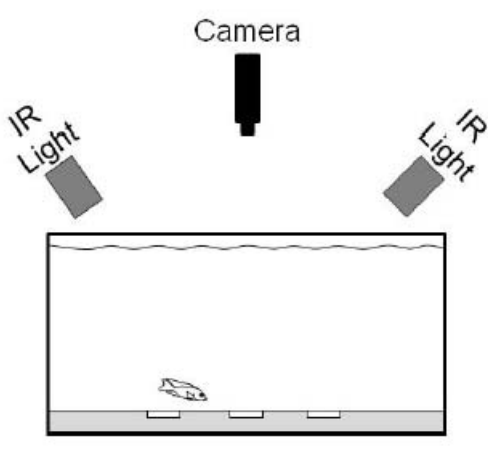

C

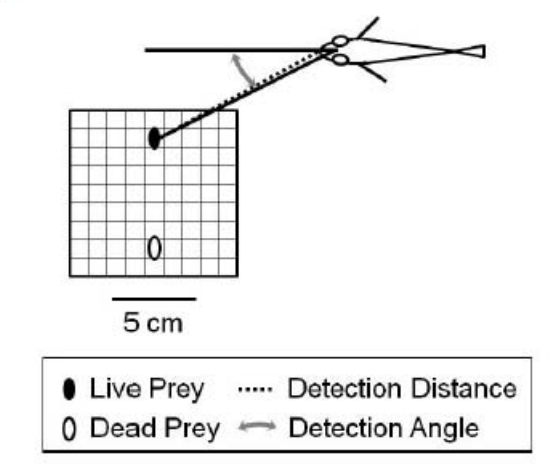

- Live Prey ..... Detection Distance 0 Dead Prey $\longrightarrow$ Detection Angle

C

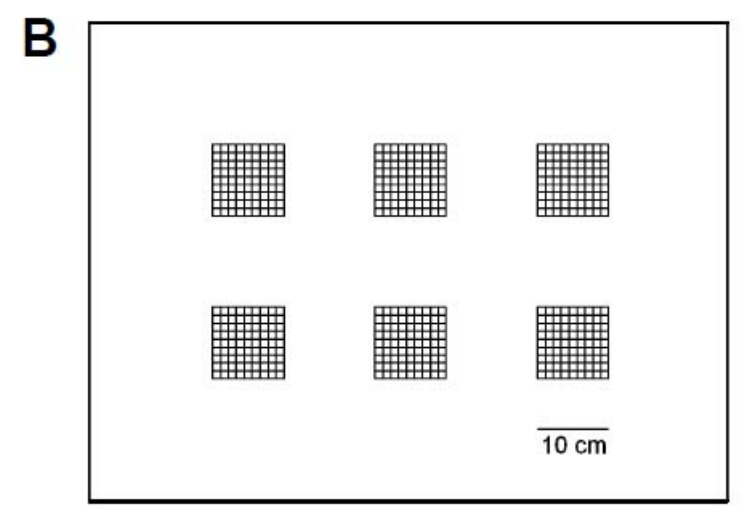

Figure 2. Quantification of feeding behavior of Aulonocara stuartgranti. (A) Diagram showing the experimental setup used to record feeding behavior on tethered brine shrimp. (B) Camera view of experimental arena. (C) Illustration of tethering dish indicating positions of live (black oval) and dead (white oval) prey. The lines connecting the fish to the live prey represent detection distance (dashed) and angle (solid). 

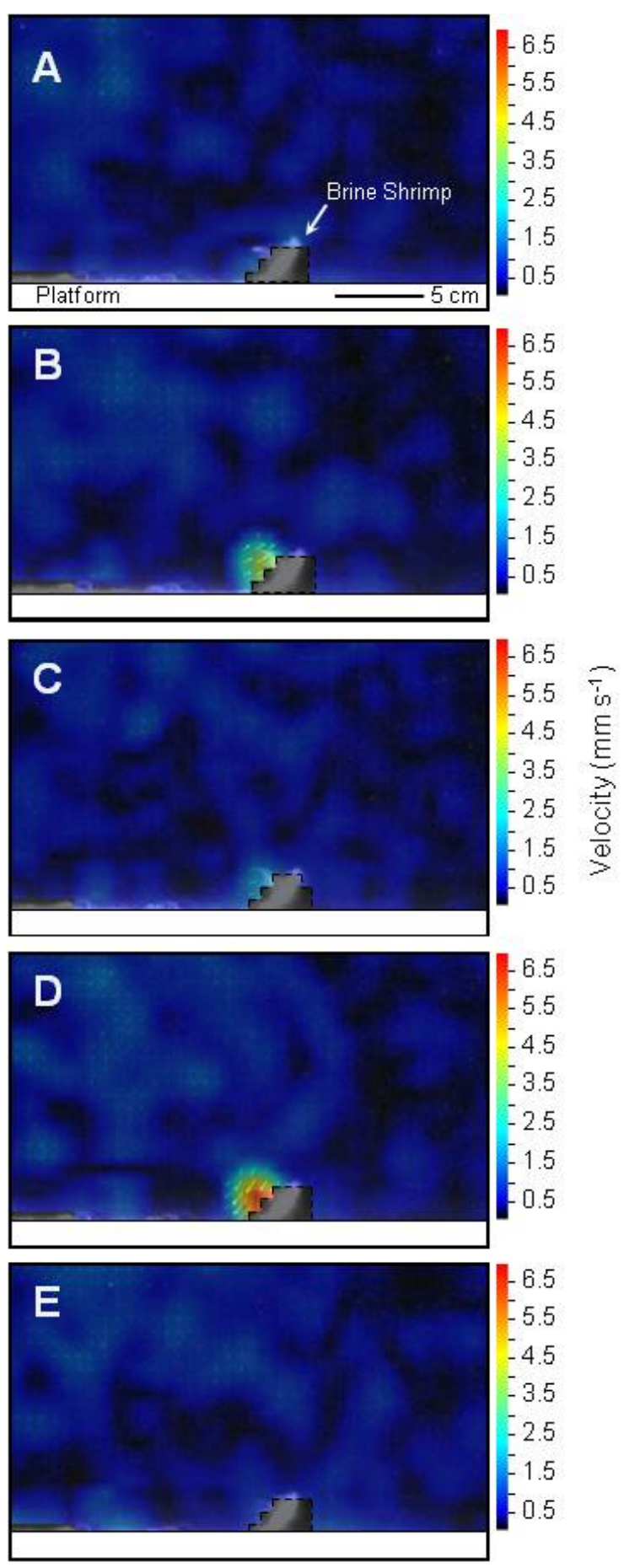

Figure 3. Velocity vector field (arrows) and the color map of flow magnitudes (red = maximum, $\sim 7 \mathrm{~mm} \mathrm{~s}^{-1}$; dark blue $=$ minimum) during one beat cycle (time elapsed $=$ $167 \mathrm{~ms}$ ) above a single adult brine shrimp tethered ventral-side-up to a platform. Each box represents a phase of movement identified during a beat cycle: (A) pre-upstroke, (B) upstroke, (C) transition between upstroke and downstroke, (D) downstroke and (E) post-downstroke. The dashed box represents the masked area around the brine shrimp. 

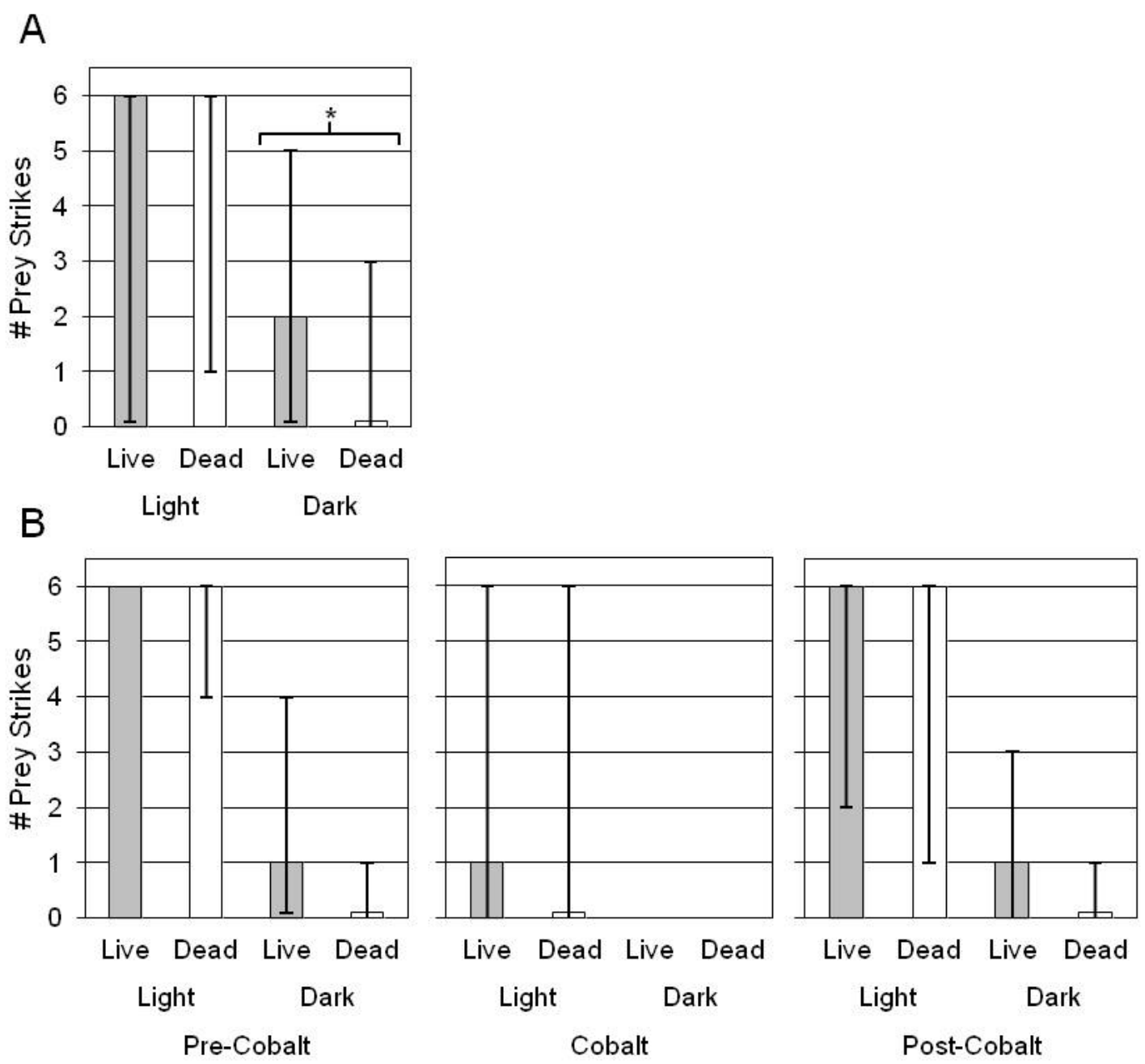

Figure 4. Number of strikes (median \pm min./max.) on live $(N=6)$ and dead $(N=6)$ brine shrimp in (A) Experiment I and (B) Experiment II. The asterisk indicates a significant difference between number of strikes on live and dead prey $(P<0.05)$. 
A

Light

Dark
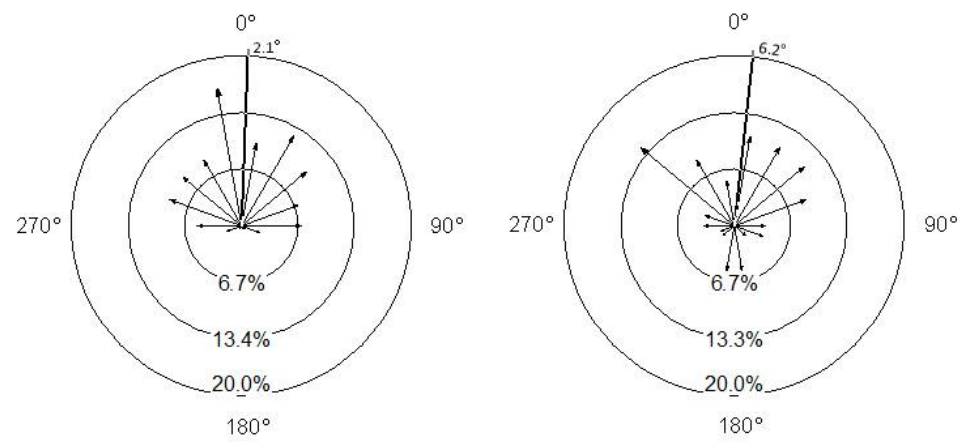

B
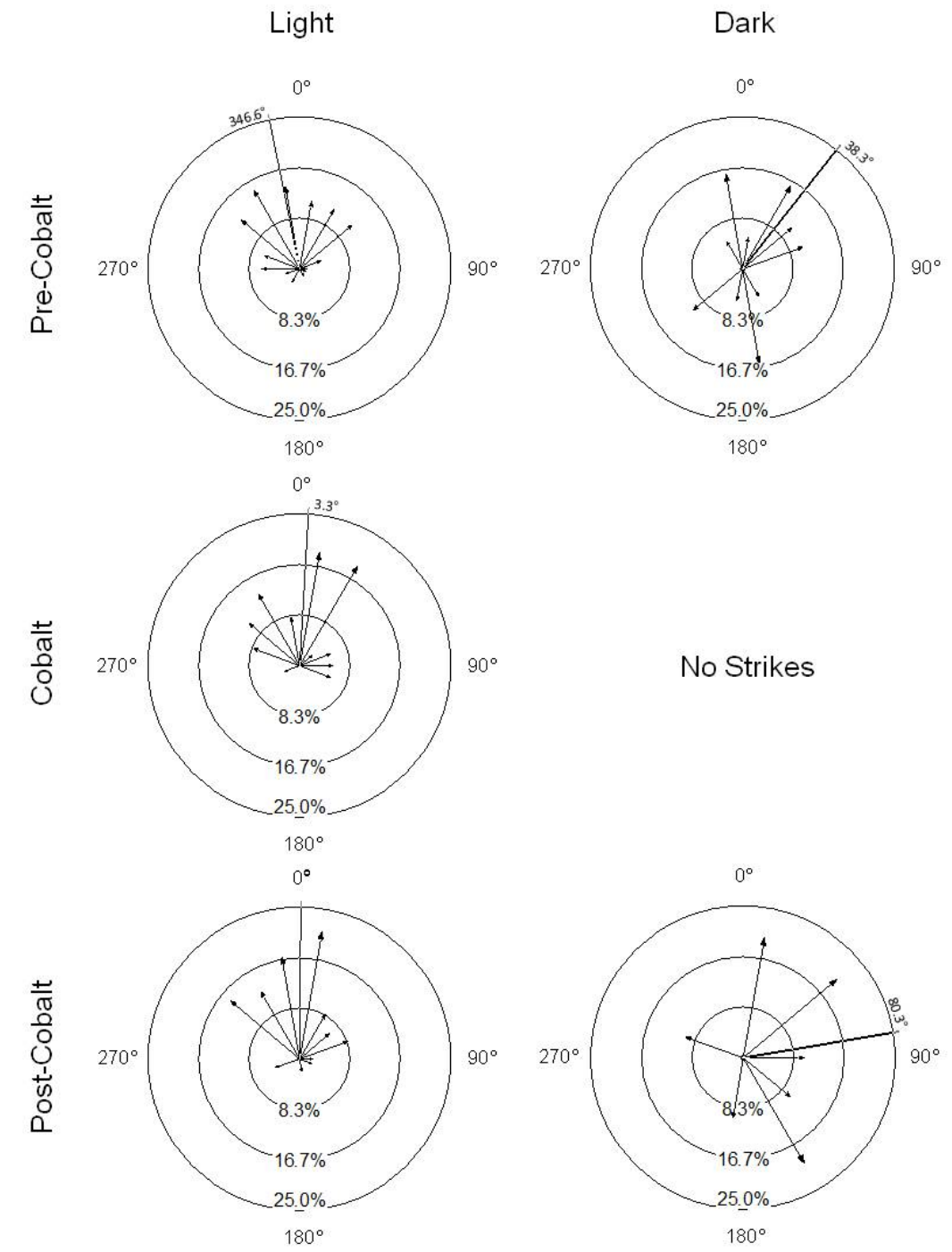

Figure 5. Orientation to prey at time of detection in the light and dark trials of (A) Experiment I ( $N=6$ fish) and (B) Experiment II ( $N=7$ fish). Arrows represent the proportion of the total number of combined live and dead detection events grouped into 20 deg intervals; the line represents the mean angle. The midpoint between the eyes is the center of the polar plot, facing $0 \mathrm{deg}$. 


\section{REFERENCES}

Albertson, R. C., Streelman, J. T., Kocher, T. D. and Yelick, P. C. (2005). Integration and evolution of the cichlid mandible: molecular basis of alternate feeding strategies. Proc. Natl. Acad. Sci. USA 102, 16287-16292.

Bassett, D. K. (2008). Predatory behaviour of nocturnal reef fish. PhD dissertation, University of Auckland.

Bassett, D. K. and Montgomery, J. C. (2011). The feeding response of Pseudophycas barbata to multisensory prey cues in a low light environment. $J$. Fish Biol. 79, 526-532.

Bassett, D. K., Carton, A. G. and Montogmery, J. C. (2006). Flowing water decreases hydrodynamic signal detection in a fish with an epidermal lateralline system. Mar. Freshw. Res. 57, 611-617.

Bassett, D. K., Carton, A. G. and Montgomery, J. C. (2007). Saltatory search in a lateral line predator. J. Fish Biol. 70, 1148-1160.

Bergman, E. (1991). Changes in abundance of two percids, Perca fluviatilis and Gymnocephalus cernuus, along a productivity gradient: relations to feeding strategies and competitive abilities. Can. J. Fish. Aquat. Sci. 48, 536-545.

Bergstrom, M. A. and Mensinger, A. F. (2009). Interspecific resource competition between the invasive round goby and three native species: logperch, slimy sculpin, and spoonhead sculpin. Trans. Am. Fish. Soc. 138, 1009-1017.

Blaxter, J. H. S. (1988). Sensory performance, behavior and ecology of fish. In Sensory Biology of Aquatic Animals (ed. J. Atema, R. R. Fay, A. N. Popper and W. N. Tavolga), pp. 203-232. New York: Springer-Verlag.

Brown, A. D., Mussen, T. D., Sisneros, J. A. and Coffin, A. B. (2011). Reevaluating the use of aminoglycoside antibiotics in behavioral studies of the lateral line. Hearing Res. 272, 1-4.

Carleton, K. L. (2009). Cichlid fish visual systems: mechanisms of spectral tuning. Integr. Zool. 4, 75-86.

Carleton, K. L., Spady, T. C. and Kocher, T. D. (2006). Visual communication in East African cichlid fishes. In Communication in Fishes (ed. F. Ladich, S. P. Collin, P. Moller and B. G. Kapoor), pp. 485-515. Enfield, NH: Science Publisher Inc.

Coombs, S. (1994). Nearfield detection of dipole sources by the goldfish (Carassius auratus) and the mottled sculpin (Cottus bairdi). J. Exp. Biol. 190, 109-129.

Coombs, S. (1999). Signal detection theory, lateral-line excitation patterns and prey capture behaviour of mottled sculpin. Anim. Behav. 58, 421-430.

Coombs, S. and Conley, R. A. (1997). Dipole source localization by mottled sculpin, I. Approach strategies. J. Comp. Physiol. A 180, 387-399.

Coombs, S. and Janssen, J. (1990). Behavioral and neurophysiological assessment of lateral line sensitivity in the mottled sculpin, Cottus bairdi. J. Comp. Physiol. A 167, 557-567.

Coombs, S. and Montgomery, J. C. (1999). The enigmatic lateral line system. In Comparative Hearing: Fish and Amphibians (ed. R. R. Fay and A. N. Popper), pp. 319-362. New York: Springer-Verlag. 
Coombs, S. and Patton, P. (2009). Lateral line stimulation patterns and prey orienting behavior in the Lake Michigan mottled sculpin (Cottus bairdi). J. Comp. Physiol. A 195, 279-297.

Coombs, S. and van Netten, S. (2006). The hydrodynamics and structural mechanics of the lateral line system. In Fish Biomechanics (ed. R. E. Shadwick and G. V. Lauder), pp. 103-139. San Diego, CA: Elsevier Academic Press.

Coombs, S., Janssen, J. and Webb, J. F. (1988). Diversity of lateral line systems: evolutionary and functional considerations. In Sensory Biology of Aquatic Animals (ed. J. Atema, R. R. Fay, A. N. Popper and W. N. Tavolga), pp. 553593. New York: Springer-Verlag.

Coombs, S., Janssen, J. and Montgomery, J. (1992). Functional and evolutionary implications of peripheral diversity in lateral line systems. In The Evolutionary Biology of Hearing (ed. D. B. Webster, R. R. Fay and A. N. Popper), pp. 267294. New York: Springer-Verlag.

Coombs, S., Braun, C. and Donovan, B. (2001). The orienting response of Lake Michigan mottled sculpin is mediated by canal neuromasts. J. Exp. Biol. 204, 337- 348.

Couldridge, V. C. K. and Alexander, G. J. (2002). Colour patterns and species recognition in four closely related species of Lake Malawi cichlids. Behav. Ecol. 13, 59-64.

Ćurčić-Blake, B. and van Netten, S. M. (2006). Source location encoding in the fish lateral line canal. J. Exp. Biol. 209, 1548-1559.

Denton, E. J. and Gray, J. A. B. (1988). Mechanical factors in the excitation of the lateral lines of fish. In Sensory Biology of Aquatic Animals (ed. J. Atema, R. R. Fay, A. N. Popper and W. N. Tavolga), pp. 595-617. New York: SpringerVerlag.

Denton, E. J. and Gray, J. A. B. (1989). Some observations on the forces acting on neuromasts in fish lateral line canals. In The Mechanosensory Lateral Line: Neurobiology and Evolution (ed. S. Coombs, P. Gorner and H. Münz), pp. 229-246. New York: Springer-Verlag.

Engelmann, J., Hanke, W., Mogdans, J. and Bleckmann, H. (2000). Hydrodynamic stimuli and the fish lateral line. Nature 408, 51-52.

Engelmann, J., Hanke, W. and Bleckmann, H. (2002). Lateral line reception in still and running water. J. Comp. Physiol. A 188, 513-526.

Evans, B. I. (2004). A fish's eye view of habitat change. In The Senses of Fish Adaptations for the Reception of Natural Stimuli (ed. G. von der Emde, J. Mogdans and B. G. Kapoor), pp. 1-30. Boston, MA: Kluwer Academic Publisher.

Fernald, R. D. and Liebman, P. A. (1980). Visual receptor pigments in the African cichlid fish, Haplochromis burtoni. Vision Res. 20, 857-864.

Fryer, G. (1959). The trophic interrelationships and ecology of some littoral communities of Lake Nyasa with especial reference to the fishes, and a discussion of the evolution of a group of rock-frequenting Cichlidae. Proc. Zool. Soc. Lond. 132, 153-281.

Fryer, G. and Iles, T. D. (1972). The Cichlid Fishes of the Great Lakes of Africa: Their Biology and Evolution. Edinburgh: Oliver and Boyd. 
Gardiner, J. M. and Atema, J. (2007). Sharks need the lateral line to locate odor sources: rheotaxis and eddy chemotaxis. J. Exp. Biol. 210, 1925-1934.

Grant, S. M., Dieckhoff, H. W., Mayland, H. J. and Meyer, M. K. (1987). Ecology of Aulonocara Regan, 1922 in Lake Malawi. Cour. Forsch.-Inst. Senckenberg 94, 131-139.

Gray, J. A. B. and Best, A. C. G. (1989). Patterns of excitation of the lateral line of the ruffe. J. Mar. Biol. Assoc. UK 69, 289-306.

Greenwood, P. H. (1981). The Haplochromine Fishes of the East African Lakes. Ithaca, NY: Cornell University Press.

Guthrie, D. M. and Muntz, W. R. A. (1993). Role of vision in fish behaviour. In Behaviour of Teleost Fishes, 2nd edn (ed. T. Pitcher), pp. 89-128. London: Chapman and Hall.

Hara. T. (1993). Role of olfaction in fish behavior. In Behaviour of Teleost Fishes, 2nd edn (ed. T. J. Pitcher), pp. 171-200. London: Chapman and Hall.

Helfman, G. S. (1993). Fish behaviour by day, night and twilight. In Behaviour of Teleost Fishes, 2nd edn (ed T. J. Pitcher), pp. 479-512. London: Chapman and Hall.

Hoekstra, D. and Janssen, J. (1985). Non-visual feeding behavior of the mottled sculpin, Cottus bairdi, in Lake Michigan. Environ. Biol. Fish. 12, 111-117.

Hoekstra, D. and Janssen, J. (1986). Lateral line receptivity in the mottled sculpin (Cottus bairdi). Copeia 1986, 91-96.

Holland, K. (1978). Chemosensory orientation to food by a Hawaiian goatfish (Parupeneus porphyreus, Mullidae). J. Chem. Ecol. 4, 173-186.

Janssen, J. (1997). Comparison of response distance to prey via the lateral line in theruffe and yellow perch. J. Fish Biol. 51, 921-930.

Janssen, J. (2000). Toxicity of $\mathrm{Co}^{2+}$ : implications for lateral line studies. J. Comp. Physiol. A 186, 957-960.

Kalmijn, A. J. (1988). Hydrodynamic and acoustic field detection. In Sensory Biology of Aquatic Animals (ed. J. Atema, R. R. Fay, A. N. Popper and W. N. Tavolga), pp. 83-130. New York: Springer-Verlag.

Kanter, M. and Coombs, S. (2003). Rheotaxis and prey detection in uniform currents by Lake Michigan mottled sculpin (Cottus bairdi). J. Exp. Biol. 206, 59-70.

Karlsen, H. E. and Sand, O. (1987). Selective and reversible blocking of the lateral line in freshwater fish. J. Exp. Biol. 133, 249-262.

Konings, A. (1990). Koning's Book of Cichlids and Other Fishes of Lake Malawi. Neptune City, NJ: TFH Publications Inc.

Konings, A. (2007). Malawi Cichlids in Their Natural Habitat, 4th edn. El Paso, TX: Cichlid Press.

Liao, J. (2006). The role of the lateral line and vision on body kinematics and hydrodynamic preference of rainbow trout in turbulent flow. J. Exp. Biol. 209, 4077-4090.

Livingston, M. E. (1987). Morphological and sensory specializations of five New Zealand flatfish species, in relation to feeding behaviour. J. Fish Biol. 31, 775795. 
MacIver, M. A., Sharabash, N. M. and Nelson, M. E. (2001). Prey-capture behavior in gymnotid electric fish: motion analysis and effects of water conductivity. $J$. Exp. Biol. 204, 543-557.

Marshall, N. J. (1996). The lateral line system of three deep-sea fish. J. Fish Biol. 49 Suppl. A, 239-258.

Meyer, M. K., Riehl, R. and Zetzsche, H. (1987). A revision of the cichlid fishes of the genus Aulonocara Regan, 1922 from Lake Malawi, with descriptions of six new species (Pisces, Perciformes, Cichlidae). Cour. Forsch.-Inst. Senckenberg 94, 7-53.

Mogdans, J. and Nauroth, I. E. (2011). The oscar, Astronotus ocellatus, detects and discriminates dipole stimuli with the lateral line system. J. Comp. Physiol. A 197, 959-968.

Montgomery, J. C., Baker, C. F. and Carton, A. G. (1997). The lateral line can mediate rheotaxis in fish. Nature 389, 960-963.

New, J. (2002). Multimodal integration in the feeding behaviors of predatory teleost fishes. Brain Behav. Evol. 59, 177-189.

O'Brien, W. J., Evans, B. I. and Browman, H. I. (1989). Flexible search tactics and efficient foraging in saltatory searching animals. Oecologia 80, 100-110.

O’Quin, K. E., Smith, A. R., Sharma, A. and Carleton, K. L. (2011). New evidence for the role of heterochrony in the repeated evolution of cichlid opsin expression. Evol. Dev. 13, 193-203.

Ogle, D. H., Selgeby, J. H., Newman, R. M. and Henry, M. G. (1995). Diet and feeding periodicity of the ruffe in the St. Louis River estuary, Lake Superior. Trans. Am. Fish. Soc. 124, 356-369.

Palmer, L. M., Deffenbaugh, M. and Mensinger, A. F. (2005). Sensitivity of the anterior lateral line to natural stimuli in the oyster toadfish, Opsanus tau (Linnaeus). J. Exp. Biol. 208, 3441-3450.

Patton, P., Windsor, S. and Coombs, S. (2010). Active wall following by Mexican blind cave fish. J. Comp. Physiol. A 196, 853-867.

Phillips, R. R. and Swears, S. B. (1979). Social hierarchy, shelter use, and avoidance of predatory toadfish (Opsanus tau) by the striped blenny (Chasmodes bosquianus). Anim. Behav. 27, 1113-1121.

Price, N. N. and Mensinger, A. F. (1999). Predator-prey interactions of juvenile toadfish, Opsanus tau. Biol. Bull. 197, 246-247.

Reno, H. W. (1966). The infraorbital canal, its lateral-line ossicles and neuromasts, in the minnows Notropis volucellus and N. buchanani. Copeia 1966, 403-413.

Reno, H. W. (1971). The lateral-line system of the silverjaw minnow, Ericymba buccata Cope. Southwest Nat. 15, 347-358.

Richmond, H. E., Hrabik, T. R. and Mensinger, A. F. (2004). Light intensity, prey detection and foraging mechanisms of age 0 year yellow perch. J. Fish Biol. 65, 195-205.

Sand, O. and Bleckmann, H. (2008). Orientation to auditory and lateral line stimuli. In Fish Bioacoustics (ed. J. F. Webb, R. R. Fay and A. N. Popper), pp. 183232. New York: Springer-Verlag. 
Santos, F., MacDonald, G., Rubel, E. W. and Raible, D. W. (2006). Lateral line hair cell maturation is a determinant of aminoglycoside susceptibility in zebrafish (Danio rerio). Hearing Res. 213, 25-33.

Schleuter, D. and Eckmann, R. (2006). Competition between perch (Perca fluviatilis) and ruffe (Gymnocephalus cernuus): the advantage of turning night into day. Freshwater Biol. 51, 287-297.

Schwarz, J. S., Reichenbach, T. and Hudspeth, A. J. (2011). A hydrodynamic sensory antenna used by killifish for nocturnal hunting. J. Exp. Biol. 214, 1857-1866.

Seehausen, O. and van Alphen, J. J. M. (1998). The effect of male coloration on female mate choice in closely related Lake Victoria cichlids (Haplochromis hyererei complex). Behav. Ecol. Sociobiol. 42, 1-8.

Seehausen, O., Terai, Y., Magalhae, I. S., Carleton, K. L., Mrosso, H. D. J., Miyagi, R., van der Sluijs, I., Schneider, M. V., Maan, M. E., Tachida, H., Imai, H. and Okada, N. (2008). Speciation through sensory drive in cichlid fish. Nature 455, 620-627.

Song, J., Hong, Y. Y. and Popper, A. N. (1995). Damage and recovery of hair cells in fish canal (but not superficial) neuromasts after gentamicin exposure. Hearing Res. 91, 63-71.

Taplin, R. H. (2007). Experimental design and analysis to investigate predator preferences for prey. J. Mar. Biol. Ecol. 344, 116-122.

Trewavas, E. (1983). Tilapiine Fishes of the Genera Sarotherodon, Oreochromis, and Danakilia. London: British Museum (Natural History).

van Netten, S. M. and van Maarseveen, J. T. P. (1994). Mechanophysiological properties of the supraorbital lateral line canal in ruffe (Acerina cernua). Proc. R. Soc. Lond. B 256, 239-246.

Van Trump, W. J., Coombs, S., Duncon, K. and McHenry, M. J. (2010). Gentamicin is ototoxic to all hair cells in the fish lateral line system. Hearing Res. 261, 42-50.

Vinyard, G. L. and O'Brien, W. J. (1976). Effects of light and turbidity on the reactive distance of bluegill (Lepomis macrochirus). J. Fish. Res. Board Can. 33, 2845-2849.

Von der Emde, G. and Bleckmann, H. (1998). Finding food: senses involved in foraging for insect larvae in the electric fish Gnathonemus petersii. J. Exp. Biol. 201, 969-980.

Wallace, D. C. (1976). Feeding behavior and developmental, seasonal and diel changes in the food of the silverjaw minnow, Ericymba buccata Cope. Am. Midl. Nat. 95, 361-376.

Webb, J. F. (1989). Gross morphology and evolution of the mechanosensory lateral line system in teleost fishes. Brain Behav. Evol. 33, 34-53.

Webb, J. F. (1995). How do asymmetric cranial bones develop in the flatfish, Glyptocephalus zachirus? Am. Zool. 35, 106A.

Webb, J. F., Montgomery, J. C. and Mogdans, J. (2008). Bioacoustics and the lateral line system of fishes. In Fish Bioacoustics (ed. J. F. Webb, A. N. Popper and R. R. Fay), pp. 145-182. New York: Springer-Verlag. 
Yoshii, K. and Kurihara, K. (1983). Role of cations in olfactory reception. Brain Res. 274, 239-248.

Yoshizawa, M., Gorički, S., Soares, D. and Jeffery, W. R. (2010). Evolution of a behavioral shift mediated by superficial neuromasts helps cavefish find food in darkness. Curr. Biol. 20, 1631-1636. 
CHAPTER 2

\title{
SENSORY BASIS FOR DETECTION OF BENTHIC PREY IN TWO LAKE MALAWI CICHLIDS
}

\author{
Margot A. B. Schwalbe* and Jacqueline F. Webb \\ Department of Biological Sciences, University of Rhode Island, \\ 120 Flagg Road, Kingston, RI 02881, USA \\ (*author for correspondence: email: mbergstrom@my.uri.edu) \\ Manuscript submitted to Zoology and accepted on September 1, 2013
}




\section{Abstract}

The adaptive radiations of African cichlids resulted in a diversity of feeding morphologies and strategies, but the role of sensory biology in prey detection and feeding ecology remains largely unexplored. Two endemic Lake Malawi cichlid genera, Tramitichromis and Aulonocara, feed on benthic invertebrates, but differ in lateral line morphology (narrow and widened lateral line canals, respectively) and foraging strategy. The hypothesis that they use their lateral line systems differently was tested by looking at the relative contribution of the lateral line system and vision in prey detection by Tramitichromis sp. and comparing results to those from a complementary study using A. stuartgranti (Schwalbe et al., 2012). First, behavioral trials were used to assess the ability of Tramitichromis sp. to detect live (mobile) and dead (immobile) benthic prey under light and dark conditions. Second, trials were run before, immediately after, and several weeks after chemical ablation of the lateral line system to determine its role in feeding behavior. Results show that Tramitichromis is a visual predator that neither locates prey in the dark, nor depends on lateral line input for prey detection and is thus distinct from A. stuartgranti, which uses its lateral line or a combination of vision and lateral line to detect prey depending on light condition. Investigating how functionally distinctive differences in sensory morphology are correlated with feeding behavior in the laboratory and determining the role of sensory systems in feeding ecology will provide insights into how sensory capabilities may contribute to trophic niche segregation. 
Key words: Aulonocara, Tramitichromis, lateral line, detection distance, sensory environment

\section{Introduction}

The mechanosensory lateral line system of fishes plays critical roles in prey detection, predator avoidance, communication, rheotaxis, and navigation around obstacles (reviewed in Webb et al., 2008; Bleckmann and Zelick, 2009). The system demonstrates a considerable degree of morphological variation among bony fishes (Webb, 1989b), but understanding the relationship between structure and function in the lateral line system and lateral-line mediated behavior continues to be a particularly challenging task because of the multiple levels at which both structure and function may vary.

The physiological response of the lateral line system (and ultimately behavior) depends on the properties of the different morphological components that define the system. Variation in morphology of the neuromasts (hair cell morphology, density, and orientation, neuromast shape, shape and length of the cupula into which the apical ciliary bundles of the hair cells are embedded, and patterns of neuromast innervation and central projections), and that of the lateral line canals in which canal neuromasts are found (canal diameter, pore size, presence of canal constrictions), and the hydrodynamic context (biotic, abiotic, and self-generated flows) in which the system functions all contribute to physiological, and thus behavioral, responses. Ecological correlates of lateral line morphology have been proposed (Dijkgraaf, 1963; reviewed 
by Webb, 1989b), but there are notable exceptions. For instance, fishes in hydrodynamically active environments tend to have narrow canals and fewer superficial neuromasts, but this relationship does not always hold in light of different sets of selection pressures (Carton and Montgomery, 2004). In addition, some types of morphological variation (differences in canal diameter in the vicinity of canal neuromasts) do not result in differences in physiological responses by neuromasts (Antarctic notothenioids, Coombs and Montgomery, 1992; Montgomery et al., 1994).

Testing hypotheses concerning the functional evolution of the lateral line system requires that experiments be carried out in a well-defined comparative context using closely-related species pairs with divergent morphology and the presentation of ecologically relevant stimuli. Narrow and widened cranial lateral line canals, two of the four types of lateral line canals defined among teleosts (Webb, 1989a), are of particular interest because of their distinctive morphologies and contrasting functional properties (theoretical and experimental work of Denton and Gray, 1988, 1989). Narrow canals are well-ossified with small canal pores and widened canals are typically weakly ossified with partial ossification of the canal roof over the canal neuromasts leaving large canal pores between neuromast positions that are covered by a tympanum-like epithelium typically pierced by very small pores. Narrow canals are widespread among teleosts, while widened canals have evolved convergently in just a dozen or so teleost families suggesting that the evolution of widened canals is adaptive, and further, that it represents an adaptation for prey detection.

The ability to determine the functional distinctions between narrow and widened canals has been hampered by the inability to identify appropriate species 
pairs that are accessible for experimental study. The percid fishes are a useful model system for illustrating the relationship between the functional morphology of the lateral line system and feeding ecology of fishes. European perch (Perca fluviatilis) and yellow perch ( $P$. flavescens) have narrow canals and Eurasian ruffe (Gymnocephalus cernuus) has widened canals. The sensitivity of the large neuromasts in the widened canals of ruffe (van Netten, 2006) generally supports behavioral and ecological findings. European perch and ruffe have some seasonal and life stagedependent diet overlap in their native habitat where they co-occur (Rezsu and Specziar, 2006; Schleuter and Eckmann, 2008), but ruffe occupy a greater depth range than perch and spend more time close to the substrate (Bergman, 1987, 1991). In addition, ruffe are able to feed more successfully in visually compromised habitats when compared to Perca spp. (Disler and Smirnov, 1977; Bergman, 1988; Janssen, 1997; Schleuter and Eckmann, 2006) and increase in abundance and replace perch in turbid water and/or low light conditions (Bergman, 1991). Interestingly, the accidental introduction of ruffe in the North American Great Lakes has generated concern over potential for competition with native yellow perch (P. flavescens, Ogle et al., 1995).

The speciose cichlids of the African Rift Lakes also provide opportunities for comparative studies of sensory biology, feeding behavior, and ecology. There has been intense study of the functional morphology of the cichlid feeding apparatus and the diverse trophic niches that they occupy (Fryer and Iles, 1972; Liem, 1973, 1980; Albertson et al., 2005; Hulsey et al., 2010), but only a few studies have addressed the sensory basis for prey detection (Hofman et al., 2009; O'Quin et al., 2010; Mogdans and Nauroth, 2011; Schwalbe et al., 2012). The vast majority of cichlid species have 
narrow cranial lateral line canals (e.g., Branson, 1961; Peters, 1973; Webb, 1989b). However, a few genera in Lake Tanganyika (Aulonocranus and Trematocara) and in Lake Malawi (Aulonocara, Alticorpus, and Trematocranus) and have widened canals (Konings, 2007).

One of these genera, Aulonocara (16-20 spp.), and a genus with narrow canals, Tramitichromis ( $\sim 6 \mathrm{spp}$.), are found at either the rock-sand interface or over sand and feed on invertebrates buried in the sand (Fryer and Iles, 1972; Konings, 2007), but differ in prey search strategy. Tramitichromis plunges into the substrate filling their mouths with sand, and sift out invertebrate prey using their gill rakers ("sand sifting," Fryer, 1959). How they choose to direct their plunges, and thus the sensory basis for the detection of their benthic prey, is still unknown. In contrast, A. stuartgranti swims just above the substrate, detect water flows generated by prey with their lateral line system (as confirmed with cobalt chloride ablations), and strike at individual prey in the sand (Konings, 2007; Schwalbe et al., 2012). With respect to lateral line morphology, the narrow canals of Tramitichromis spp. are well-ossified with small pores while the widened canals of Aulonocara spp. have large canal pores covered by an epithelium pierced by small perforations. A recent analysis of neuromast morphology in juvenile Tramitichromis sp. and A. stuartgranti (Becker, 2013; Becker et al., in prep.) has shown that these fishes have the same number of canal neuromasts and canal pores, despite distinct differences in canal and pore morphology (Fig. 1). They also have the same number of linear series or clusters of very small superficial neuromasts on the head, but late stage juvenile (and presumably adult) A. stuartgranti tend to have more superficial neuromasts within some of these series. The canal 
neuromasts are diamond-shaped in both species, but those in A. stuartgranti are a bit larger (Fig. 1B) and tend to sit in slight constrictions in the canal, which is a characteristic of many species with widened canals.

Thus, Tramitichromis sp. and A. stuartgranti present an excellent model system in which to ask questions about the relationship of lateral line morphology to its role in prey detection. These fish differ with respect to only some aspects of the morphology of the lateral line system (narrow versus widened canals, known to be functionally distinct in other taxa, and minor differences in canal neuromast size [but not general shape], and the number of superficial neuromasts). Experimental work has already determined that the lateral line system is critical for prey detection in $A$. stuartgranti (Schwalbe et al., 2012) and it is hypothesized that the role of the lateral line system in prey detection in Tramitichromis sp. would be different than in A. stuartgranti. In order to test this, behavioral trials (as in Schwalbe et al., 2012) were conducted in the laboratory in which Tramitichromis sp. was presented with live (mobile) and dead (immobile) prey (tethered adult brine shrimp) under light and dark conditions (Experiment I). Then, the role of the lateral line system in prey detection was directly addressed by temporarily inactivating the lateral line system with cobalt chloride (Experiment II). Data on number of prey strikes, prey detection distance and angle and preference for live or dead prey was then compared with that of $A$.

stuartgranti (from Schwalbe et al., 2012) to contrast the roles of the lateral line system and vision in prey detection behavior. 


\section{Materials and methods}

\subsection{Study Species}

Adult Tramitichromis sp. (= Tramitichromis for remainder of manuscript, unless otherwise noted) were acquired from a commercial supplier (Old World Exotic Fish, Inc., Homestead, FL, USA) and housed in small groups in 190 L aquaria with mechanical and biological filtration. For housing and experimental procedures, fish were maintained at 1 ppt salt (Cichlid Lake Salt, Seachem Laboratories, Inc., Madison, GA, USA) at $26 \pm 1{ }^{\circ} \mathrm{C}$ with a $12: 12 \mathrm{hr}$ light:dark cycle. Fish were fed daily with cichlid pellets (New Life Spectrum Cichlid Formula; New Life International, Inc., Homestead, FL, USA) and supplemented with live adult brine shrimp. Animal care and all experimental procedures followed an approved University of Rhode Island IACUC protocol.

\subsection{Behavioral Trials}

Two experiments were conducted to determine the ability of Tramitichromis to detect live and dead prey in light and dark trials (Experiment I) and to determine the contribution of the lateral line system to prey detection in light trials (Experiment II). 


\subsubsection{Experiment I - Light and Dark Trials}

Light and dark trials were conducted using Tramitichromis following Schwalbe et al. (2012). Briefly, trials were performed in a large experimental tank (375 L) lined with sand. Adult brine shrimp (Artemia sp.) were tethered with elastic thread in pairs (1 live, 1 dead [freshly frozen]) onto each of six mesh platforms (a total of 6 live prey +6 dead prey $=12$ total prey) to serve as a proxy for naturally occurring benthic prey. Platforms were placed on the bottom of the tank in a $2 \times 3$ grid so that their top surfaces were flush with that of the sand. All filters in the experimental tank were turned off to eliminate hydrodynamic noise during all behavioral trials.

At the start of a trial, a fish was released from behind an opaque barrier into the experimental arena and recorded for 30 minutes using a HD digital video camera (Sony, HDR-CX550V, 30 frames per second) mounted directly above the tank. Light trials were carried out under standard white fluorescent illumination and dark trials were conducted under infrared (IR) illumination (peak $=840 \mathrm{~nm}$; Speco Provideo, IR200/24, Amityville, NY, USA). Each of six naïve male fish (total length [TL] = 99 $110 \mathrm{~mm}$ ) was run sequentially through three light and then three dark trials for a total of 18 light trials and 18 dark trials. Each trial was performed on a different day, and trials were carried out over the course of five months with a mean time between the first light trial and last dark trial of 19 days for an individual fish. Several additional light and dark trials were recorded in lateral view to observe the fishes' position relative to the substrate. 


\subsubsection{Experiment II - Chemical Ablation of the Lateral Line System}

In order to determine the role of the lateral line system in prey detection by Tramitichromis, fish were treated with cobalt (II) chloride heptahydrate (cobalt chloride; Sigma-Aldrich, St Louis, MO, USA) to deactivate the lateral line system as in Schwalbe et al. (2012). The results of Experiment I (above) demonstrated that while all fish were active during dark trials, the majority of fish did not feed in the dark so Experiment II consisted only of light trials. Each of three fish (all males, not used in Experiment I; TL $=92-98 \mathrm{~mm}$ ) was run through a sequence of three different trials. First, a 30 minute "pre-cobalt" trial (identical to the light trials in Experiment I) was carried out to establish a behavioral baseline. Two to three days later, the fish was treated in a large container filled with $0.1 \mathrm{mM}$ cobalt chloride in conditioned tap water for three hours (calcium $=60 \mathrm{mg} / \mathrm{L}$; Hach hardness test kit, Loveland, CO, USA) and returned to the experimental tank (calcium $=260 \mathrm{mg} / \mathrm{L}$ ). When the fish appeared to be behaving normally (e.g., normal respiration and swimming, about two hours after cobalt treatment), a "cobalt trial" was conducted. All fish resumed feeding on commercial pellets and/or live brine shrimp immediately following cobalt trials. After 21 days (in the experimental tank), the fish was run through a "post-cobalt" trial to assess recovery from cobalt treatment and allow a comparison with the "pre-cobalt" and "cobalt" trials. In a previous study (Schwalbe et al., 2012), the effect of handling was assess by running fish through one light and dark trial a few days before and immediately after a sham cobalt chloride treatment ( $=4$ trials/fish). For the sham treatment, fish $(n=2)$ were placed in a large container of conditioned tap water for 
three hours instead of the cobalt chloride solution. Fish consumed prey during both light and dark trials before and after sham treatment, so it appeared that handling had no effect on feeding behavior.

\subsection{Data analysis}

At the end of each trial, remaining prey were counted to determine the number and type of prey (live and dead) that had been consumed and strike success was also confirmed in video recordings. Video was analyzed using Premier Pro (Adobe, CS5) and images from video sequences of prey detections (e.g. when the fish oriented towards the prey) to prey strikes were exported for further analysis. These images were used to identify when detections occurred relative to the start of the trial, during which phase of saltatory search strategy each prey was detected (defined by O'Brien et al., 1989; a cycle of three swimming phases - caudal fin thrust, glide and pause), and the order of prey strikes (live vs. dead) as an approximation of "prey preference." In addition, detection distance and detection angle for each strike was measured from the images using ImageJ (NIH, v. 1.41o).

All data were tested for normality (Kolmogorov-Smirnov test) and only detection distance data needed to be $\log _{10}$ transformed to achieve normality. Separate tests using a generalized linear mixed model (GLMM, SPSS, v.19) with pairwise posthoc comparisons (least significant differences, LSD) were used to detect differences in four variables (number of prey strikes, detection distance, swimming phase in which strikes occurred, and order of prey capture) with reference to prey type (live vs. dead) 
and light condition (light vs. dark). This approach allowed the selection of random (individual) and fixed effects (species, light condition, prey type) while addressing repeated measures for the same individual. Prey preference was calculated using a method described in Taplin (2007) in which prey preference was assessed by ranking the prey according to the order in which they were consumed, and then calculating a preference score by taking the mean of the order values for each prey type. Necessary assumptions for this analysis were satisfied: multiple types of prey were offered simultaneously (e.g. live and dead tethered brine shrimp) and prey consumed last could not be distinguished from uneaten prey. Scores closer to one indicate a strong preference, whereas scores closer to twelve (= total number of prey offered) indicate no preference or rejection. Preference scores for live or dead prey in each light condition (light, dark) were compared using paired $t$-tests. Means of prey preference scores from the three replicate trials carried out for each fish were calculated prior to performing the paired $t$-test, so that the replicate variable was the fish (individual) and not the trial. Finally, Watson's $U^{2}$-tests (Oriana, Kovach Computing Services, Anglesey, UK, v.3) were used to analyze differences in detection angles with reference to prey type and light condition. Differences were considered to be significant at the $P<0.05$ level for all statistical tests. Values are given as mean $\pm \mathrm{SE}$ unless otherwise specified.

\section{Results}

Experiments I and II show that Tramitichromis is a visual predator that does 
not seek out prey in the dark and does not depend on its lateral line system for detection of benthic invertebrate prey in light trials. Tramitichromis is thus quite distinct from Aulonocara stuartgranti, which relies on the interaction of vision and lateral line for prey detection and uses the lateral line system for detection of prey in the dark (Schwalbe et al. 2012).

\subsection{Experiment I - Light and Dark Trials}

Tramitichromis explored the tank by moving throughout the vertical extent of the water column. After the first prey detection, fish generally swam within $\sim 10 \mathrm{~cm}$ of the sand and struck at and removed prey from the platforms. Fish alternated between moving around the entire tank (vertically and horizontally) and swimming close to the sand, even after all 12 tethered brine shrimp were captured. Sand sifting was frequently observed during trials and after all prey were consumed.

In light trials, all Tramitichromis successfully struck at and consumed prey (94.4\% of total prey presented) but fish attacked more live prey than dead prey (LSD, $P=0.005$; Table 1, Fig. 2A). Strikes on live prey preceded those on dead prey (paired $t$-test, $t_{5}=8.851, P<0.001 ;$ Table 2 ) and live prey were detected at a greater distance than dead prey $($ live $=11.3 \pm 0.5 \mathrm{~cm}$, dead $=9.0 \pm 0.5 \mathrm{~cm}$; LSD,$P=0.002$; Table 1 ,

Fig. 3A). Prey was detected non-uniformly around the fishes' bodies (Rayleigh test, Z $=107.98, P<0.001 ;$ Fig. 4 A) and all fish detected prey in the same relatively narrow range in front of the snout $\left( \pm 40^{\circ}\right.$ from body axis; Watson's $U^{2}$-test, $\left.P>0.05\right)$. Tramitichromis swam close to the substrate (but higher above the substrate than $A$. 
stuartgranti) and demonstrated a saltatory search strategy (cyclic sequence of caudal fin thrust, glide, and pause). Prey was never detected during a caudal fin thrust, and more prey (live and dead prey combined) was detected during a pause (77.3\%) than during a glide (22.7\%, Fig. 5A).

The results of dark trials were quite different. The median number of strikes was zero for both live and dead prey, which greatly contrasts with the median number of six strikes in light trials (for live or dead prey offered; Fig. 2A). All fish actively swam around the tank in dark trials as they did in light trials and some exhibited sand sifting behavior. A few strikes did occur during dark trials, but one fish was responsible for 21 of the total 23 strikes (on 216 live and dead prey presented in 18 trials). When comparing strikes on live and dead prey, no significant differences were detected in any of the measured variables used to describe prey detection behavior (e.g. prey preference, Table 2; number of prey strikes, Fig. 2A; detection distance, Fig. 3A; detection angle Fig. 4A; and swimming phase at prey detection, Fig. 5A), indicating that live prey could not be distinguished from dead prey.

However, when comparing the few strikes that did occur in dark trials $(n=23)$ to the numerous strikes in light trials ( $n=204$; Fig. 2A), significant differences were observed in some aspects of behavior. In dark trials, prey were detected at a distance one fourth of that in light trials (live and dead combined, light $=10.3 \pm 0.4 \mathrm{~cm}$, dark $=$ $2.3 \pm 0.3 \mathrm{~cm}$; LSD, $P<0.001$; Table 1, Fig. $3 \mathrm{~A}$ ) and more prey were detected during a glide in dark trials ( $60.9 \%$ of strikes) than in light trials $(22.7 \%$ of strikes; LSD, $P=$ 0.002, Table 1, Fig. 5A). Even though prey were detected in a wide range around the body during dark trials, the majority of prey were detected in the same narrow range 
as in light trials $\left( \pm 40^{\circ}\right.$ from body axis, Watson's $U^{2}$-test, $P>0.05$, Fig. $\left.4 \mathrm{~A}\right)$. While differences were observed in several behavioral parameters in light and dark trials, Tramitichromis tended not to feed in the dark and when they did, prey appeared to be found rather indiscriminately as fish explored the experimental arena.

\subsection{Experiment II - Chemical Ablation of the Lateral Line System}

Given the low number of strikes by Tramitichromis sp. in dark trials in Experiment I, only light trials were carried out to determine the effects of lateral line ablation on their prey detection behavior.

The results for all trials - before (pre-cobalt trials), immediately following (cobalt trials), and three weeks after treatment with cobalt chloride (post-cobalt trials)

- were comparable to results for light trials in Experiment I. All fish actively swam around the experimental arena and consumed the majority of live and dead prey presented in pre-cobalt (66.7\% of total prey presented), cobalt $(72.2 \%)$, and postcobalt recovery $(88.9 \%)$ trials. The total number of strikes on live and dead prey was the same among the three trial types (GLMM, $P>0.05$; Table 3, Fig. 2B). Live and dead prey were detected from similar distances in all of these trials (Table 3; Fig. 3B). Prey were detected non-uniformly around the body in all trials (Rayleigh test, $P<$ 0.04; Fig. 4B) and detection angle did not vary with prey type or among sequential trials (Watson's $\mathrm{U}^{2}$-test, $P>0.05$ ), like Experiment I light trials. In pre-cobalt trials, live prey were captured before dead prey (paired $t$-test, $t_{2}=8.66, P=0.013$ ), but this preference for live prey was absent in cobalt trials and post-cobalt trials $(P>0.05$; 
Table 2). As in the light trials in Experiment I, most prey were detected during a pause, and the frequency of prey detection during a pause or glide did not differ among the pre-cobalt, cobalt, and post-cobalt trials (GLMM, $P>0.05$; Table 3, Fig. $5 B)$.

3.3. Comparison of feeding behavior in Tramitichromis and Aulonocara stuartgranti

Interesting similarities and contrasts were found in prey detection behavior in Tramitichromis sp. and Aulonocara stuartgranti. Both species swam around the tank in light and dark trials using a saltatory search strategy, but Tramitichromis tended to swim higher above the sand while searching for prey and pitched forward more (e.g. $\sim 45^{\circ}$ versus $\sim 30^{\circ}$ for $A$. stuartgranti) during prey strikes. In addition, Tramitichromis did not demonstrate the swimming reversals (e.g. swam backwards) upon prey detection that $A$. stuartgranti did, and A. stuartgranti did not use the sand sifting strategy used by Tramitichromis.

In light trials, Tramitichromis and A. stuartgranti detected similarly high numbers of live and dead prey (GLMM, $P>0.05$, Table 4, Fig. 2A), and demonstrated a preference for live prey (Tramitichromis: paired $t$-test, $t_{5}=8.851, P<0.001, A$. stuartgranti: paired $t$-test, $t_{5}=5.551, P=0.003$; Table 2 ). In addition, both species detected more prey during a pause rather than during a glide, and did so with frequencies that were not statistically different (GLMM, P>0.05; Table 4, Fig. 5A). Interestingly, Tramitichromis detected live prey at longer distances than A. stuartgranti (LSD, $P=0.006$; Fig. 3A), but both species detected dead prey at 
distances that were not statistically different $(P>0.05)$. Detection angles were significantly different for Tramitichromis and A. stuartgranti (Watson $\mathrm{U}^{2}$-test, $U^{2}=$ 0.468, $P<0.001$; Fig. 4A); Tramitichromis detected the majority of prey in a narrower range of angles $\left( \pm 40^{\circ}\right.$ from body axis) than did $A$. stuartgranti $\left( \pm 90^{\circ}\right.$ from body axis).

In dark trials, Tramitichromis also demonstrated different prey detection behaviors than A. stuartgranti. Only half of the Tramitichromis ( $n=3$ of 6 fish) struck at prey while all $A$. stuartgranti $(n=6$ fish) struck at prey. When prey was detected, Tramitichromis struck at fewer live prey than did A. stuartgranti (LSD, $P=0.006)$, but the number of strikes on dead prey was not statistically different in the two species $(P>0.05 ;$ Fig. 2A). Furthermore, although both species tended to detect more prey during a glide than during a pause in dark trials, Tramitichromis detected fewer prey during a glide than $\operatorname{did} A$. stuartgranti (LSD, $P=0.020$; Fig. 5A). In addition, Tramitichromis detected prey at shorter distances than did A. stuartgranti (both prey types combined, LSD, $P<0.001$; Fig. 3A). Detection angles were not statistically different in dark trials (Watson's $\mathrm{U}^{2}$-test, $P>0.05$ ) and both species found prey nonuniformly around their bodies (Fig. 4A). The results suggest that Tramitichromis is a visual predator in contrast to A. stuartgranti, which depends on lateral line input in prey detection, especially in the dark.

\section{Discussion}

The results of Experiments I and II showed that the combination of lateral line, olfactory, and tactile cues was not sufficient to elicit a prey strike response by Tramitichromis in the absence of visual cues, but that in light trials, a combination of 
sensory inputs may provide some additional information when used in tandem with vision. This study has demonstrated that closely related taxa that feed on the same prey in the same sensory environment, but have two morphologically (and likely functionally) distinct lateral line systems, use different sensory systems to detect their prey under different light conditions in the laboratory.

\subsection{Feeding behavior of Tramitichromis}

The experimental design in Experiments I and II ensured that different combinations of sensory cues were available to the fish allowing multimodal sensory input to be considered in the interpretation of the results. In Experiment I light trials, all stimuli generated by the movement of the brine shrimp were present and all sensory systems in Tramitichromis were intact (e.g. vision, lateral line system, olfaction). In addition, the significance of prey movements for prey detection - the visual motion stimulus, hydrodynamic flow, and spread of an odor plume generated by the motion of the brine shrimp - was addressed by providing both live and dead prey in all trials. Visual cues were absent in dark trials in Experiment I, but lateral line and olfactory systems were still intact (hydrodynamic and olfactory cues were available). In Experiment II (light trials only), the ability to detect hydrodynamic cues was eliminated by temporarily inactivating the lateral line system in cobalt trials, but visual and olfactory cues were still available. A dependence on more than one sensory modality was inferred when feeding behavior was not as robust in trials in which input to one or more sensory modalities was eliminated compared to trials in which all 
sensory systems were available.

Tramitichromis demonstrated the most robust feeding behavior when all sensory cues were available (Experiment I light trials). In these trials, Tramitichromis demonstrated a preference for live prey, which were detected from greater distances than were dead prey. The visual motion stimulus generated by live brine shrimp likely strengthened the visual stimulus necessary for prey detection and was responsible for the generation of robust prey detection behavior at longer distances. More prey detections occurred during a pause than a glide in light trials, when the prey could be localized in a more stable visual field. Even though the olfactory system was intact and olfactory cues were available during light and dark trials in Experiments I and II, behaviors characteristic of olfactory mediated prey detection (e.g. following and/or locating the source of an odor by zig-zagging through its odor plume, Hara, 1993) were not observed. These results all indicate that visual detection of prey is critical for feeding in Tramitichromis, and that they were relatively unsuccessful in detecting prey in dark trials likely because they could not see the prey. Finally, in Experiment II, feeding behavior was similar before, immediately following, and after the recovery from lateral line ablation using cobalt chloride, providing evidence that Tramitichromis does not appear to depend on its lateral line system for prey detection. Morphological confirmation of lateral line ablation by cobalt chloride was accomplished by fluorescently staining three juvenile Tramitichromis sp. with 4-Di-2ASP $(63 \mu \mathrm{M}, 5 \mathrm{~min}$; also see Fig. 1) following a three hour treatment with either cobalt chloride in calcium free tank water $(0.1 \mathrm{mM})$, or in calcium free tank water $(\mathrm{E}$. Becker, 2013). A lack of hair cell staining in the central region of the neuromasts in 
Tramitichromis sp. was similar to that observed in juvenile Aulonocara stuartgranti treated with cobalt chloride ( 0.05 and $0.1 \mathrm{mM}$, Schwalbe et al, 2012).

Tramitichromis feeds on benthic invertebrates in the sand at the rock-sand interface in Lake Malawi (Fryer, 1959; Koning, 2007), a community that is dominated by ostracods, hydracarins, and chironomid larvae and also includes hydropsychid caddisfly, heptageneid mayfly, and dryopoid beetle nymphs (Abdallah and Barton, 2003). Tramitichromis is known for plunging into the sand, engulfing a mouthful of sand, and sifting it through their gill rakers, but how they determine where to initiate this behavior is not known. Given the results of the current study, it is likely that the fish can see minute changes in the substrate (e.g. a slightly exposed invertebrate or movements by invertebrates in the substrate), perhaps in combination with olfactory cues, to find these prey. Tactile cues may also elicit prey strikes and/or sand sifting behavior, but lateral video recordings of behavioral trials suggest otherwise because Tramitichromis swam several centimeters above the substrate and tended not to contact the substrate with their pelvic fins.

Finally, the ability of one of the six Tramitichromis to detect both live and dead prey in dark trials cannot be easily explained. Tramitichromis intermedius does have spectral sensitivity peaks that are somewhat higher than other Lake Malawi cichlids examined (including A. jacobfreibergi, Parry et al., 2005), but among all retinal cell types, the longest wavelength of maximum absorbance is only about 570 $\mathrm{nm}$ (for the double cones). However, two recent studies have demonstrated that cichlids show positive phototactic behavior (Oreochromis mossambicus, Shcherbakov et al., 2012) and strong foraging responses (Pelvicachromis taeniatus, Meuthen et al., 
2012) in near-IR light. Thus, it is possible that this one Tramitichromis sp. was able to successfully detect prey in dark trials illuminated with a light source in the near IR range.

\subsection{Comparison of Prey Detection Behaviors in Two Benthic Feeding Cichlids}

This study has shown that Tramitichromis and A. stuartgranti use two distinct methods for detecting the same prey, likely due to the relative roles of their sensory systems. Both species exhibited a saltatory search strategy (which cycles between moving through an area and pausing to locate prey or reposition before the next forward movement) and different sensory systems are possibly important during a pause or glide in light and dark trials. Both Tramitichromis and A. stuartgranti appeared to visually scan for prey during a pause in light trials, when the visual field was stable. In light trials, Tramitichromis detected more prey in a narrow range of angles relative to the body axis suggesting that they may possess adequate binocular vision to localize prey (as shown in other teleosts, Sivak, 1978; Bianco et al., 2011; Miyazaki et al., 2011). In contrast, A. stuartgranti detected prey in a wider range of angles suggesting that binocular vision was not employed. However, they struck at a higher proportion of prey during a pause in light trials, suggesting that stabilization of the visual field favored successful prey detection. In dark trials, A. stuartgranti detected prey as swimming velocity decreased during a glide, allowing localization of prey as it came within the operational range of its lateral line system.

The temporary ablation of the lateral line system with cobalt chloride had 
different effects on the two species. In Tramitichromis, prey detection behavior did not change with the elimination of lateral line input, while for A. stuartgranti, there was a reduction in the number of prey strikes in light trials and the complete elimination of prey detections in dark trials (Schwalbe et al., 2012). It is concluded that Tramitichromis does not depend on lateral line input for successful prey detection in contrast to A. stuartgranti, which depends on both vision and the lateral line system in light trials, and uses its lateral line system to detect prey in the dark. The correlation of this behavioral data with the difference in lateral line canal morphology in Tramitichromis and A. stuartgranti suggest that the widened lateral line canals are an adaptation for prey detection, especially in the absence of visual cues.

\subsection{Could sensory biology contribute to the feeding ecology of African cichlids?}

There has been a long history of discussion about the role of feeding mechanisms in the definition of cichlid trophic niches (Fryer and Iles, 1972; Liem, 1973, 1980; McKaye and Marsh, 1983; Albertson et al., 2003) and the ways in which trophic niche differentiation and ecological segregation occur among African cichlids (Goldschmidt et al., 1990; Reinthal, 1990; Sturmbauer et al., 1992; Hori et al., 1993; Bouton et al., 1997; Genner et al., 1999a, b; Duponchelle et al., 2005; Martin and Genner, 2009; Genner and Turner, 2012). In their landmark monograph, Fryer and Iles (1972) reviewed the feeding biology and evolution of cichlid fishes of the African Rift Lakes, but the ecological concepts of habitat partitioning and mechanisms underlying the evolution of trophic diversity among cichlids has only been examined in detail 
more recently (reviewed in Genner and Turner, 2005; Albertson, 2008). For instance, within the mbuna (the rock-dwelling cichlid flock), it has been hypothesized that finescale niche partitioning occurs among species that forage on a combination of algae, aufwuchs, phytoplankton, and other seasonally available food (Reinthal, 1990; Bouton et al., 1997; Genner et al., 1999b). However, there appears to be a continuum in the degree of niche overlap among these species depending on whether or not shared resources are limiting (Bouton et al., 1997; Genner et al., 1999b; Duponchelle et al., 2006), but a high degree of overlap may occur regardless of the availability of shared resources (Martin and Genner, 2009).

Recent field observations by other investigators and results from the current study permit some speculation about the sorts of behavioral and ecological interactions that may be occurring between species of Tramitichromis and Aulonocara. A small number of stomach content analyses show potential for diet overlap in these taxa (Fryer, 1959; Konings, 2007). Species of Tramitichromis and Aulonocara have lakewide distributions (Konings, 2007), presenting the opportunity for spatial overlap. Where they co-occur, Aulonocara might experience interference competition from Tramtichromis given its prey search strategies. For instance, members of these two genera have been observed foraging in the same areas where Tramitichromis (and other sand sifters) can interrupt foraging by Aulonocara (which hover just above the sand searching for prey) by just swimming nearby (M. Kidd, personal communication). Furthermore, the sand plunging behavior of Tramitichromis, removes and likely disrupts other invertebrates in the sand, altering the topography of the bottom sediments, which may prevent Aulonocara from detecting prey by 
swimming just above sand surface. These two taxa also occupy different depth ranges (Tramitichromis spp.: $<15$ m, Konings, 2007; Aulonocara spp.: 5-120 m, Konings, 1990, 2007). Species of Aulonocara may escape competition in shallower waters by foraging in deeper water. Genner and Turner (2012) assigned several species of Aulonocara to an assemblage of "deep benthic feeders" and suggested that these fishes have sensory adaptations (including modification of the cranial lateral line canal system) that should enable them to detect prey at the depth at which they are found. This is supported by experimental work that demonstrated that $A$. stuartgranti uses its lateral line system in prey detection, especially in the dark (Schwalbe et al., 2012). Furthermore, the ability of species of Aulonocara to detect prey non-visually may allow them to forage crepuscularly and/or nocturnally (not yet documented in the field), thus facilitating spatial and temporal segregation between Aulonocara species and other cichlids that feed on benthic invertebrates in the sand, including species of Tramitichromis.

Future studies that involve the integration of the analysis of laboratory-based sensory biology with field-based ecological studies will allow tests of hypotheses that: 1) evolutionary changes in the morphology and physiological capabilities of a sensory system (such as widened canals) are adaptations that allow species to occupy novel trophic niches, and 2) that species use different combinations of sensory cues in the same sensory environment to spatially or temporally partition similar resources in a common habitat. 


\section{Acknowledgements}

We thank Emily Becker and Rebecca Scott who contributed Fig. 1A, B, and Douglas Moore (Orthopedics Research Lab, Rhode Island Hospital) and Timothy Alberg, who generated and analyzed $\mu \mathrm{CT}$ data in Fig. 1C, D. Dr. Nathan Bird provided comments that improved earlier versions of the manuscript. Edward Baker (Facilities Manager, RI NSF EPSCoR Marine Life Science Facility), Emily Becker, Joshua Hower, Brandon Fuller, Callie Veelenturf, and Rebecca Scott were responsible for fish husbandry. This research was funded by the University of Rhode Island College of the Environment and Life Sciences and the National Science Foundation (NSF) grant IOS 0843307 to JFW, and was supported in part by NSF EPSCoR Cooperative Agreement EPS-1004057. 
Table 1. Generalized linear mixed model (GLMM) results for Tramitichromis feeding on live and dead prey during light and dark trials (Experiment I) comparing number of prey strikes, detection distance, and swimming phase during prey detection (pause vs. glide).

\begin{tabular}{|c|c|c|c|c|c|c|c|c|c|}
\hline \multirow[b]{2}{*}{ Source } & \multicolumn{3}{|c|}{ Number of Prey Strikes } & \multicolumn{3}{|c|}{ Detection Distance } & \multicolumn{3}{|c|}{ Pause vs. Glide } \\
\hline & $F$ & d.f. & $P$ & $F$ & d.f. & $P$ & $F$ & d.f. & $P$ \\
\hline Light/Dark & 273.28 & 1,68 & $<0.001$ & 40.89 & 1,213 & $<0.001$ & 10.39 & 1,213 & 0.001 \\
\hline Prey & 3.83 & 1,68 & n.s. & 2.52 & 1,213 & n.s. & 1.29 & 1,213 & n.s. \\
\hline Light/Dark $\times$ Prey & 4.68 & 1,68 & 0.034 & 0.25 & 1,213 & n.s. & 0.003 & 1,213 & n.s. \\
\hline
\end{tabular}


Table 2. Mean prey preference scores for Tramitichromis (Experiments I and II) and A. stuartgranti (Experiment I only, data from Schwalbe et al., 2012) feeding on live and dead prey in light and dark (Experiment I only) trials following Taplin (2007). If the fish demonstrated a preference for a type of prey (indicated by a significant lower preference score), it was always for live prey (paired $t$ test, $* P<0.05, * * P<0.01, * * * P<0.001)$.

\begin{tabular}{|c|c|c|c|c|c|c|}
\hline & & & \multicolumn{2}{|c|}{ Light Trials } & \multicolumn{2}{|c|}{ Dark Trials } \\
\hline Species & \multicolumn{2}{|l|}{ Experiment } & Live & Dead & Live & Dead \\
\hline Tramitichromis & \multirow{2}{*}{\multicolumn{2}{|c|}{ Experiment I }} & $5.74 * * *$ & 7.26 & 6.54 & 6.46 \\
\hline Aulonocara stuartgranti & & & $5.49 * *$ & 7.52 & $4.78^{* *}$ & 8.22 \\
\hline \multirow{3}{*}{ Tramitichromis } & \multirow{3}{*}{ Experiment II } & Pre-Cobalt & $5.25^{*}$ & 7.75 & & \\
\hline & & Cobalt & 6.08 & 6.92 & & \\
\hline & & Post-Cobalt & 6.67 & 6.33 & & \\
\hline
\end{tabular}


Table 3. Generalized linear mixed model (GLMM) results for Tramitichromis feeding on live and dead prey during light trials after cobalt chloride treatment (Experiment II) comparing number of prey strikes, detection distance, and swimming phase during prey detection (pause vs. glide).

\begin{tabular}{|c|c|c|c|c|c|c|c|c|c|}
\hline \multirow[b]{2}{*}{ Source } & \multicolumn{3}{|c|}{ Number of Prey Strikes } & \multicolumn{3}{|c|}{ Detection Distance } & \multicolumn{3}{|c|}{ Pause vs. Glide } \\
\hline & $F$ & d.f. & $P$ & $F$ & d.f. & $P$ & $F$ & d.f. & $P$ \\
\hline Trial & 1.38 & 2,12 & n.s. & 2.24 & 2,76 & n.s. & 0.000 & 2,75 & n.s. \\
\hline Prey & 2.87 & 1,12 & n.s. & 0.07 & 1,76 & n.s. & 0.001 & 1,75 & n.s. \\
\hline Trial $\times$ Prey & 0.96 & 2,12 & n.s. & 1.95 & 2,76 & n.s. & 0.000 & 2,75 & n.s. \\
\hline
\end{tabular}


Table 4. Generalized linear mixed model (GLMM) results for Tramitichromis (this study) and A. stuartgranti (data from Schwalbe et al., 2012) feeding on live and dead prey during light and dark trials (Experiment I) comparing number of prey strikes, detection distance, and swimming phase during prey detection (pause vs. glide).

\begin{tabular}{|c|c|c|c|c|c|c|c|c|c|}
\hline \multirow[b]{2}{*}{ Source } & \multicolumn{3}{|c|}{ Number of Prey Strikes } & \multicolumn{3}{|c|}{ Detection Distance } & \multicolumn{3}{|c|}{ Pause vs. Glide } \\
\hline & $F$ & d.f. & $P$ & $F$ & d.f. & $P$ & $F$ & d.f. & $P$ \\
\hline Species & 0.38 & 1,136 & n.s. & 2.34 & 1,444 & n.s. & 0.000 & 1,432 & n.s. \\
\hline Light/Dark & 352.89 & 1,136 & $<0.001$ & 156.46 & 1,444 & $<0.001$ & 0.000 & 1,432 & n.s. \\
\hline Prey & 12.46 & 1,136 & 0.001 & 6.24 & 1,444 & 0.013 & 0.003 & 1,432 & n.s. \\
\hline Light/Dark $\times$ Prey & 0.40 & 1,136 & n.s. & 0.12 & 1,444 & n.s. & 0.000 & 1,432 & n.s. \\
\hline Species $\times$ Light/Dark & 7.69 & 1,136 & 0.006 & 23.17 & 1,444 & $<0.001$ & 0.000 & 1,432 & n.s. \\
\hline Species $\times$ Prey & 1.29 & 1,136 & n.s. & 4.45 & 1,444 & 0.036 & 0.003 & 1,432 & n.s. \\
\hline Species $\times$ Light $/$ Dark $\times$ Prey & 4.07 & 1,136 & 0.046 & 2.11 & 1,444 & n.s. & 0.000 & 1,432 & n.s. \\
\hline
\end{tabular}



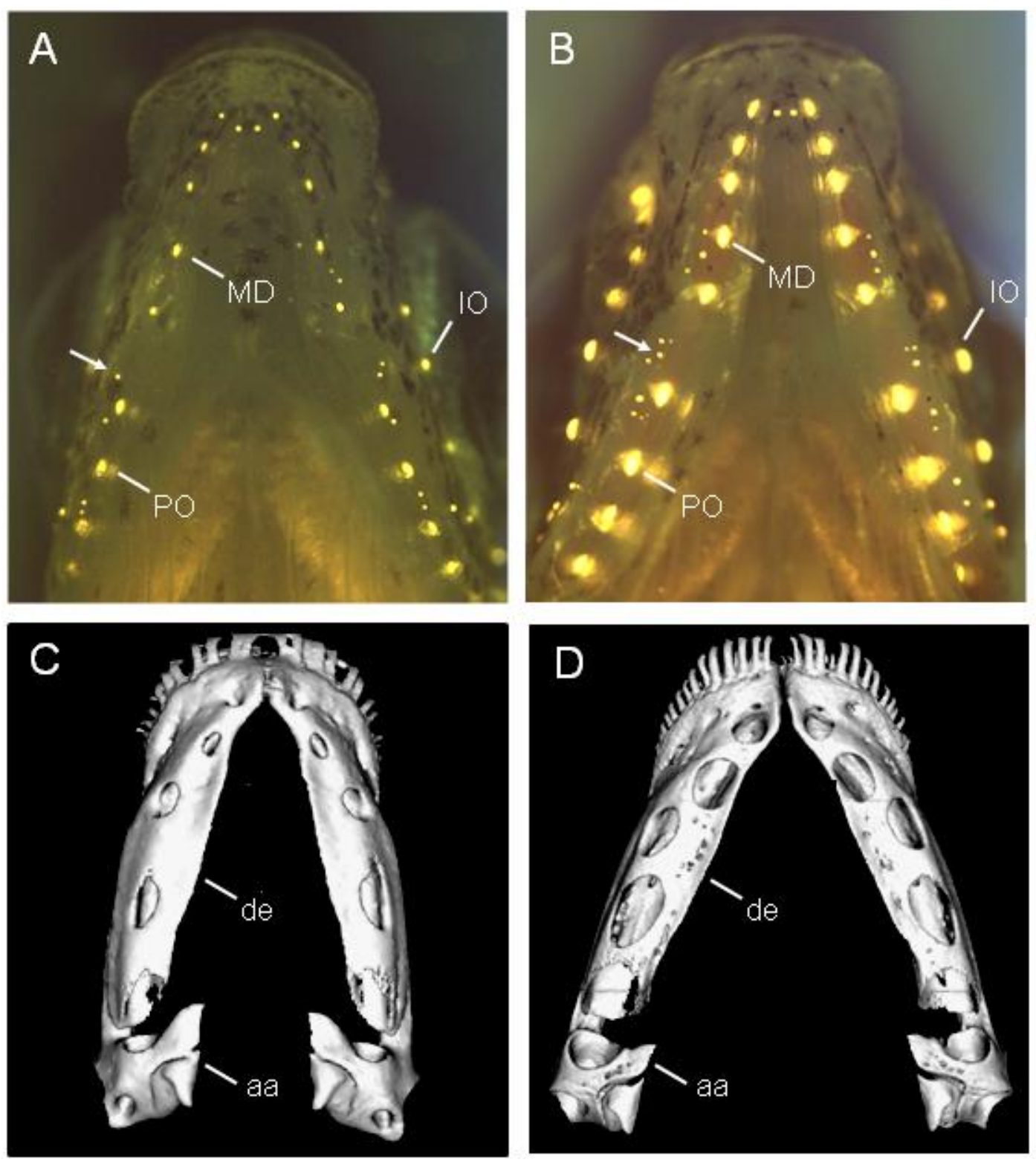

Figure 1. Ventral view of the mandible of Tramitichromis sp. and Aulonocara spp. illustrating the canal and superficial neuromasts and mandibular lateral line canals. (A) Ventral view of a juvenile Tramitichromis sp. (standard length [SL] $=18 \mathrm{~mm}$ ) and (B) A. stuartgranti $(\mathrm{SL}=16 \mathrm{~mm})$ fluorescently stained with 4-Di-2-ASP $(63 \mu \mathrm{M}, 5 \mathrm{~min})$ to reveal the hair cells in the sensory strip in superficial neuromasts (lines and clusters [arrows]) and larger canal neuromasts in the mandibular (MD), preopercular (PO), and infraorbital (IO) canals. MicroCT 3-D reconstruction of the mandible [dentary (de) and angulo-articular (aa) bones] of (C) Tramitichromis sp. (SL $=29 \mathrm{~mm}$ ) showing the bony pores of the MD canal and (D) A. baenschi (SL $=87 \mathrm{~mm})$. 
A

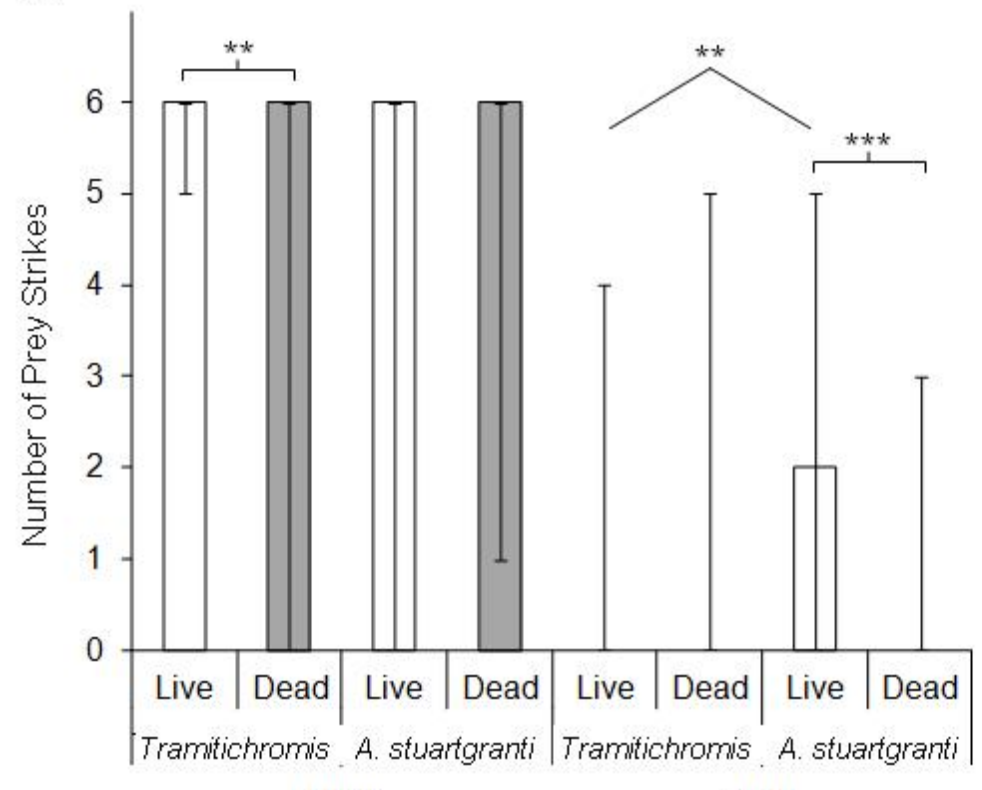

Light
B

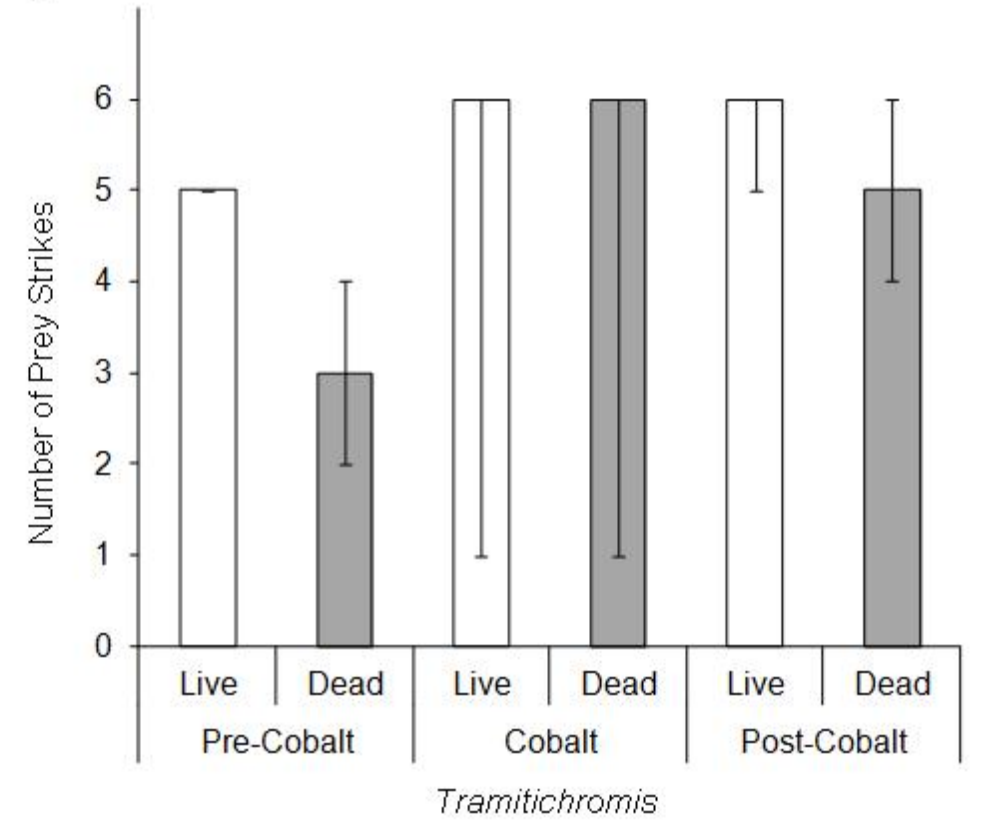

Figure 2. Number of prey strikes (median $\pm \min / \max$ ) on live and dead prey for (A) Tramitichromis (Experiment I) and A. stuartgranti (data from Schwalbe et al., 2012) in light and dark trials, and (B) Tramitichromis (Experiment II, light trials only). LSD, $* * P<0.01,{ }^{* * *} P<0.001$. See text for additional details. 
A

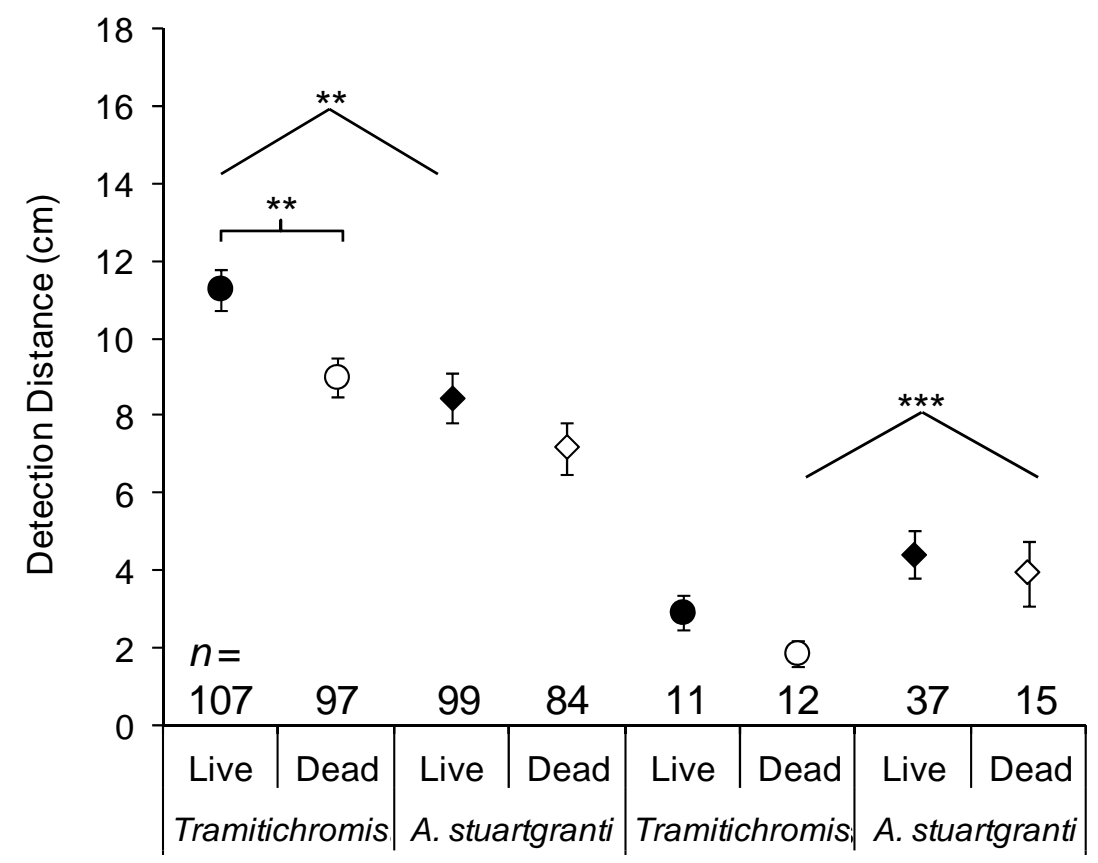

Light

\section{B}

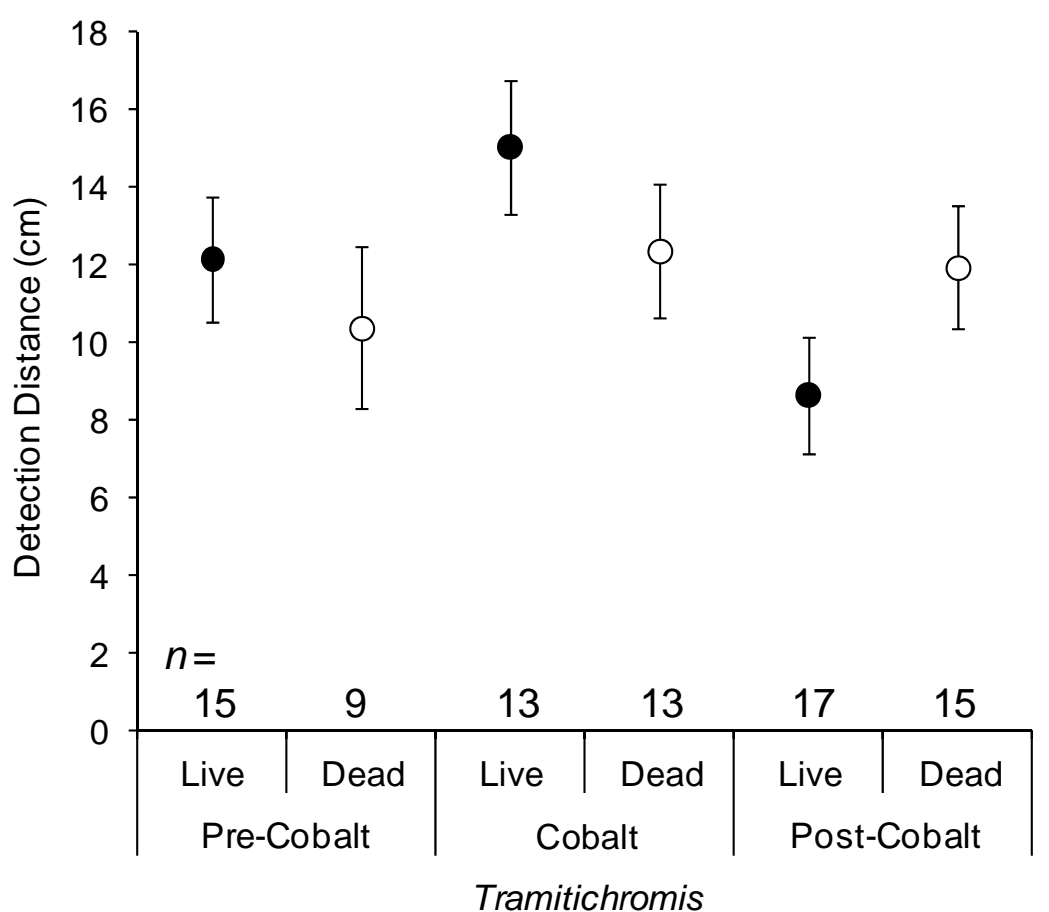

Figure 3. Detection distance (mean $\pm \mathrm{SE}$ ) for live and dead prey for (A) Tramitichromis (Experiment I) and A. stuartgranti (data from Schwalbe et al., 2012) in light and dark trials, and (B) Tramitichromis sp. (Experiment II, light trials only). Non-transformed data are illustrated here (which are biologically relevant), but statistics were carried out on log-transformed data, as appropriate. LSD, ${ }^{* *} P<$ $0.01, * * * P<0.001$. See text for additional details. 
A
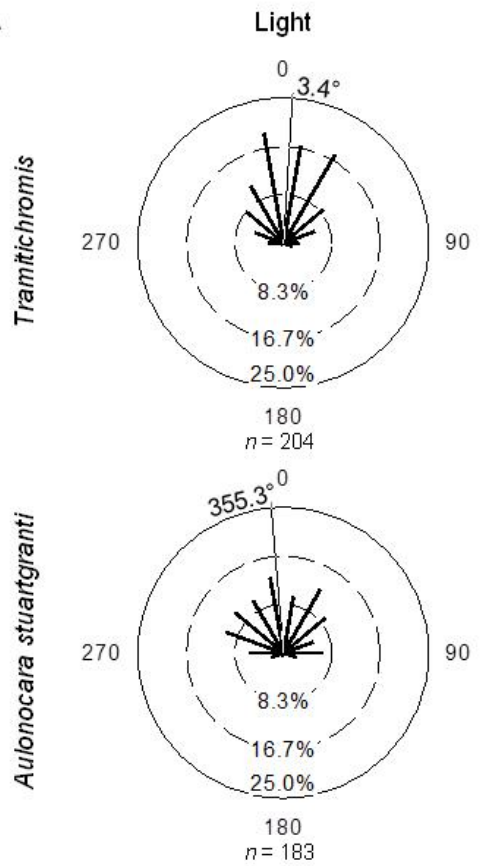

B

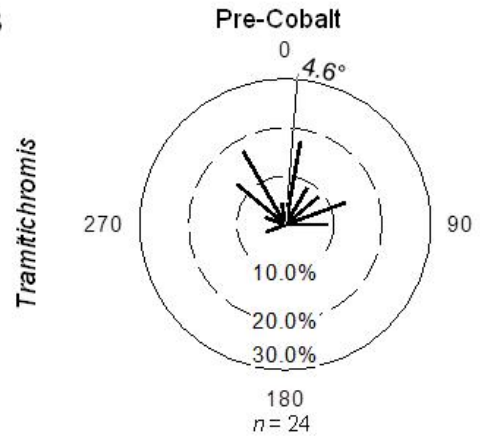

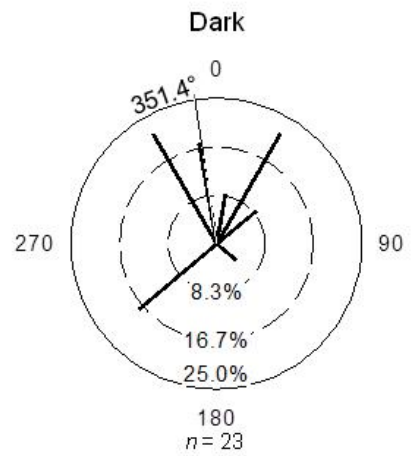
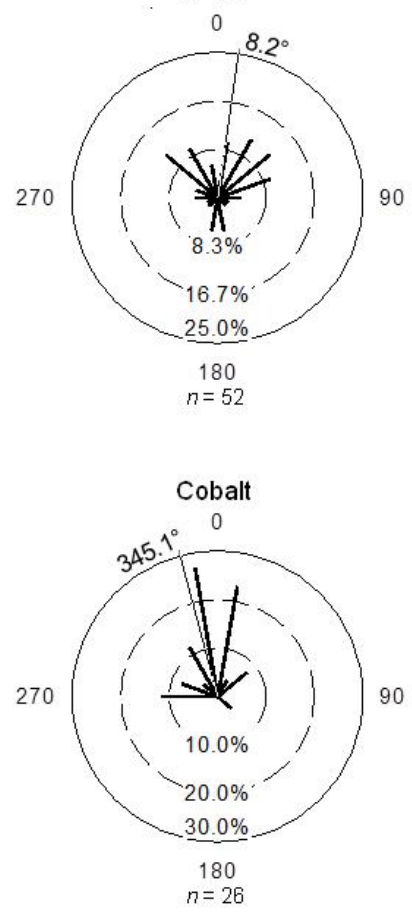

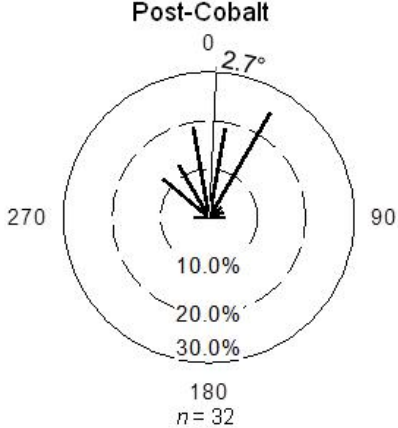

Figure 4. Orientation to prey (live and dead combined) at time of detection for (A) Tramitichromis (Experiment I) and A. stuartgranti (data from Schwalbe et al., 2012) light and dark trials and (B) Tramitichromis (Experiment II, light trials only). Bars represent the proportion of the total number of detection events grouped into $20^{\circ}$ intervals. The narrow line represents mean angle. The center of the polar plot (facing $0^{\circ}$ ) represents the location of the midpoint between the eyes. See text for additional details. 


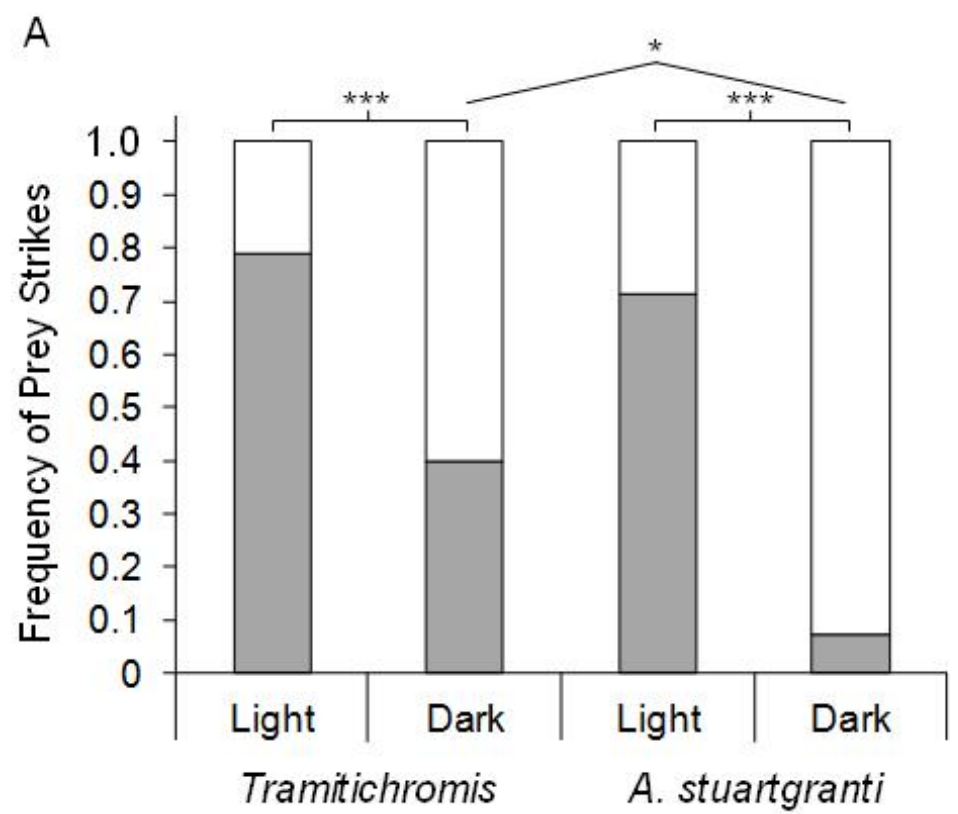

B

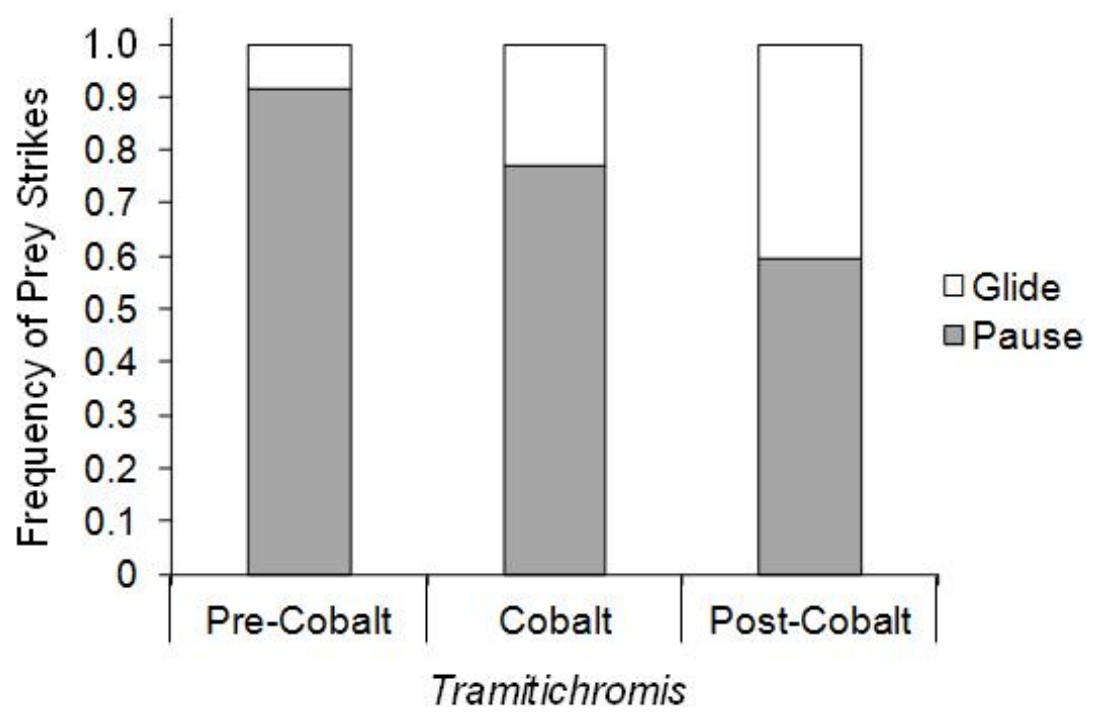

Figure 5. Frequency of prey detections that occurred during the glide or pause phase of swimming leading to prey strikes in (A) Tramitichromis (Experiment I) and A. stuartgranti (data from Schwalbe et al., 2012) light and dark trials, and (B) Tramitichromis (Experiment II, light trials only). LSD, ${ }^{*} P<0.05, * * * P<0.001$. See text for additional details. 


\section{References}

Abdallah, A.M., Barton, D.R., 2003. Environmental factors controlling the distributions of benthic invertebrates on rocky shores of Lake Malawi, Africa. J. Great Lakes Res. 29, 202-215.

Albertson, R.C., 2008. Morphological diversity predicts habitat partitioning in a Lake Malawi cichlid species complex. Copeia 3, 689-698.

Albertson, R.C., Streelman, J.T., Kocher, T.D., 2003. Directional selection has shaped the oral jaws of Lake Malawi cichlid fishes. P. Natl. Acad. Sci-Biol. 100, 5252-5257.

Albertson, R.C., Streelman, J.T., Kocher, T.D., Yelick, P.C., 2005. Integration and evolution of the cichlid mandible: the molecular basis of alternate feeding strategies. PNAS 102, 16287-16292.

Becker, E.A., 2013. The distribution and ontogeny of neuromasts receptor organs and a comparison of methods for chemical ablation of the lateral line system in two cichlid fishes. Master's Thesis, University of Rhode Island.

Becker, E.A., Bird, N.C., Webb, J.F. Relationship of the distribution and ontogeny of neuromasts to the functional evolution of the lateral line system. In preparation.

Bergman, E., 1987. Temperature-dependent differences in foraging ability of two percids, Perca fluviatilis and Gymnocephalus cernuum. Environ. Biol. Fish. $19,45-54$.

Bergman, E., 1988. Foraging abilities and niche breadths of two percids, Perca fluviatilis and Gymnocephalus cernua, under different environmental conditions. J. Anim. Ecol. 57, 443-453.

Bergman, E., 1991. Changes in abundance of two percids, Perca fluciatilis and Gymnocephalus cernuus, along a productivity gradient: relations to feeding strategies and competitive abilities. Can. J. Fish. Aquat. Sci. 48, 536-545.

Bianco, I.H., Kampff, A.R., Engert, F., 2011. Prey capture behavior evoked by simple visual stimuli in larval zebrafish. Front Syst Neurosci. 5, 1-13.

Bleckmann, H., Zelick, R., 2009. Lateral line system of fish. Integr. Zool. 4, 13-25.

Bouton, N., Seehausen, O., van Alphe, J.J.M., 1997. Resource partitioning among rock-dwelling haplochromines (Pisces: Cichlidae) from Lake Victoria. Ecol. Freshw. Fish 6, 225-240.

Branson, B.A., 1961. The lateral-line system in the Rio Grande Perch, Cichlasoma cyanoguttatum (Baird and Girard). Amer. Midl. Nat. 65, 446-458.

Carton, A.G., Montgomery, J.C., 2004. A comparison of lateral line morphology of blue cod and torrentfish: two sandperches of the family Pinguipedidae. Env. Biol. Fish. 70, 123-131.

Coombs, S., Montgomery, J.C., 1992. Fibers innervating different parts of the lateral line system of an Antarctic notothenioid, Trematomus bernacchii, have similar frequency responses, despite large variation in the peripheral morphology. Brain Behav. Evol. 40, 217-233.

Denton, E.J., Gray, J.A.B., 1988. Mechanical factors in the excitation of the lateral lines of fish. In: Atema, J., Fay, R.R., Popper, A.N., Tavolga, W.N. (Eds.), 
Sensory Biology of Aquatic Animals. Springer-Verlag, New York, pp. 595617.

Denton, E.J., Gray, J.A.B., 1989. Some observations on the forces acting on neuromasts in fish lateral line canals. In: Coombs, S., Gorner, P., Münz, H. (Eds.), The Mechanosensory Lateral Line: Neurobiology and Evolution. Springer-Verlag, New York, pp. 229-246.

Dijkgraaf, S. 1963. The functioning and significance of the lateral-line organs. Biol. Rev. 38, 51-105.

Disler, N.N., Smirnov, S.A., 1977. Sensory organs of the lateral-line canal system in two percids and their importance in behavior. J. Fish. Res. Board Can. 34, 1492-1503.

Duponchelle, F., Ribbink, A.J., Msukwa, A., Mafuka, J., Mandere, D., Bootsma, H., 2005. Food partitioning within the species-rich benthic fish community of Lake Malawi, East Africa. Can. J. Fish. Aquat. Sci. 62, 1651-1664.

Fryer, G., 1959. The trophic interrelationships and ecology of some littoral communities of Lake Nyasa with especial reference to the fishes, and a discussion of the evolution of a group of rock-frequenting Cichlidae. P. Zool. Soc. Lond. 132, 153-281.

Fryer, G., Iles, T.D., 1972. The cichlid fishes of the great lakes of Africa: their biology and evolution. Oliver and Boyd, Edinburgh.

Genner, M.J., Turner, G.F., 2005. The mbuna cichlids of Lake Malawi: a model for rapid speciation and adaptive radiation. Fish Fish. 6, 1-34.

Genner, M.J., Turner, G.F., 2012. Ancient hybridization and phenotypic novelty within Lake Malawi's cichlid fish radiation. Mol. Biol. Evol. 29, 195-206.

Genner, M.J., Turner, Backer, S., Hawkins, S.J., 1999a. Niche segregation among Lake Malawi cichlid fishes? Evidence from stable isotope signatures. Ecol. Lett. 2, 185-190.

Genner, M.J., Turner, G.F., Hawkins, S.J., 1999b. Foraging of rocky habitat cichlid fishes in Lake Malawi: coexistence through niche partitioning? Oecologia 121, 283-292.

Goldschmidt, T., Witte, F., de Visser, J., 1990. Ecological segregation in zooplanktivorous haplochromine species (Pisces: Cichlidae) from Lake Victoria. Oikos 58, 343-355.

Hara, T., 1993. Role of olfaction in fish behavior. In: Pitcher, T.J. (Ed.), Behavior of Teleost Fishes, 2nd edn. Chapman and Hall, London, pp. 171-200.

Hofmann, C.M., O'Quin, K.E., Marshall, N.J., Cronin, T.W., Seehousen, O., Carleton, K.L., 2009. The eyes have it: regulatory and structural changes both underlie cichlid visual pigment diversity. PLoS Biol 7, e1000266. doi:10.1371/journal.pbio.1000266

Hori, M., Gashagaza, M.M., Nshombo, M., Kawanabe, H., 1993. Littoral fish communities in Lake Tanganyika: irreplaceable diversity supported by intricate interactions among species. Conserv. Biol. 7, 657-666.

Hulsey, C.D., Mims, M.C., Parnell, N.F., Streelman, J.T., 2010. Comparative rates of lower jaw diversification in cichlid adaptive radiations. J. Evolution. Biol. 23, 1456-1467.

Janssen, J., 1997. Comparison of response distance to prey via the lateral line in the 
ruffe and yellow perch. J. Fish Biol. 51, 921-930.

Konings, A., 1990. Koning's Book of Cichlids and Other Fishes of Lake Malawi. TFH Publications Inc., Neptune City, New Jersey.

Konings, A., 2007. Malawi Cichlids in Their Natural Habitat, 4th edn. Cichlid Press, El Paso, Texas.

Liem, K.F., 1973. Evolutionary strategies and morphological innovations: cichlid pharyngeal jaws. Syst. Biol. 22, 423-441.

Liem, K.F., 1980. Adaptive significance of intra- and interspecific differences in the feeding repertoires of cichlid fishes. Am. Zool. 20, 295-314.

Martin, C.H., Genner, M.J., 2009. High niche overlap between two successfully coexisting pairs of Lake Malawi cichlid fishes. Can. J. Fish. Aquat. Sci. 66, $579-588$.

McKay, K.R., Marsh, A., 1983. Food switching by two specialized algae-scraping cichlid fishes in Lake Malawi, Africa. Oecologia 56, 245-248.

Meuthen, D., Rick, I.P., Thünken, T., Baldauf, S.A., 2012. Visual prey detection by near-infrared cues in a fish. Naturwissenschaften 99, 1063-1066.

Miyazaki, T., Iwami, T., Meyer-Rochow, V.B., 2011. The position of the retinal area centralis changes with age in Champsocephalus gunnari (Channichthyidae), a predatory fish from coastal Antarctic waters. Polar Biol. 34, 1117-1123.

Mogdans, J., Nauroth, I.E., 2011. The Oscar, Astronotus ocellatus, detects and discriminates dipole stimuli with the lateral line system. J. Comp. Phys. A 197, 959-968.

Montgomery, J.C., Coombs, S., Janssen, J., 1994. Form and function relationships in lateral line systems: Comparative data from six species of Antarctic notothenioid fish. Brain Behav. Evol. 44, 299-306.

O’Brien, W.J., Evans, B.I., Browman, H.I., 1989. Flexible search tactics and efficient foraging in saltatory searching animals. Oecologica 80, 100-110.

O'Quin, K.E., Hofmann, C.M., Hofmann, H.A., Carleton, K.L., 2010. Parallel evolution of opsin gene expression in African cichlid fishes. Mol. Biol. Evol. 27, 2839-2854.

Ogle, D.H., Selgeby, J.H., Newman, R.M., Henry, M.G., 1995. Diet and feeding periodicity of ruffe in the St. Louis River Estuary, Lake Superior. T. Am. Fish. Soc. 124, 356-369.

Parry, J.W.L., Carleton, K.L., Spady, T., Carboo, A., Hunt, D.M., Bowmaker, J.K., 2005. Mix and match color vision: tuning spectral sensitivity by differential opsin gene expression in Lake Malawi cichlids. Curr. Biol. 15, 1734-1739.

Peters, H.M., 1973. Anatomie und Entwicklungsgeschichte des Laterallissystems von Tilapia (Pisces, Cichlidae). Z. Morphol. Tiere. 74, 89-161.

Reinthal, P.N., 1990. The feeding habits of a group of herbivorous rock-dwelling cichlid fishes (Cichlidae: Perciformes) from Lake Malawi, Africa. Environ. Biol. Fish. 27, 215-233.

Rezsu, E., Specziar, A., 2006. Ontogenetic diet profiles and size-dependent diet partitioning of ruffe Gymnocephalus cernuus, perch Perca fluviatilis and pumpkinseed Lepomis gibbosus in Lake Balaton. Ecol. Freshw. Fish 15, 339349.

Schleuter, D., Eckmann, R., 2006. Competition between perch (Perca fluviatilis) and 
ruffe (Gymnocephalus cernuus): the advantage of turning night into day. Freshwater Biol. 51, 287-297.

Schleuter, D., Eckmann, R., 2008. Generalist versus specialist: the performances of perch and ruffe in a lake of low productivity. Ecol. Freshw. Fish 17, 86-99.

Schwalbe, M.A.B., Bassett, D.K., Webb, J.F., 2012. Feeding in the dark: lateral-linemediated prey detection in the peacock cichlid Aulonocara stuartgranti. J. Exp. Biol. 215, 2060-2071.

Shcherbakov, D., Knörzer, A., Hilbig, R., Haas, U., Blum, M., 2012. Near-infrared orientation of Mozambique tilapia Oreochromis mossambicus. Zoology 115, 233-238.

Sivak, J.G., 1978. The functional significance of the aphakic space of the fish eye. Can. J. Zool. 56, 513-516.

Sturmbauer, C., Mark, W., Dallinger, R., 1992. Ecophysiology of Aufwuchs-eating cichlids in Lake Tanganyika: niche separation by trophic specialization. Environ. Biol. Fish. 35, 283-290.

Taplin, R.H., 2007. Experimental design and analysis to investigate predator preferences for prey. J. Exp. Mar. Biol. Ecol. 344, 116-122.

van Netten, S.M., 2006. Hydrodynamic detection by cupulae in a lateral line canal: functional relations between physics and physiology. Biol. Cybern 94, 67-85.

Webb, J.F., 1989a. Gross morphology and evolution of the mechanosensory lateral line system in teleost fishes. Brain Behav. Evolut. 33, 34-53.

Webb, J.F., 1989b. Neuromast morphology and lateral line trunk canal ontogeny in two species of cichlids: An SEM study. J. Morph. 202, 53-68.

Webb, J.F., Montgomery, J.C., Mogdans, J., 2008. Bioacoustics and the lateral line system of fishes. In: Webb, J.F., Fay, R.R., Popper, A.N. (Eds.), Fish Bioacoustics. Springer-Verlag, New York, pp. 145-182.

Webb, J.F. 2013. Morphological diversity, development, and evolution of the mechanosensory lateral line system. In: Coombs, S., Bleckmann, H. (Eds.), The Lateral Line System. Springer-Verlag, New York. 


\title{
CHAPTER 3
}

\section{LIGHT ENVIRONMENT INFLUENCES PREY DETECTION BEHAVIOR IN TWO SAND-DWELLING LAKE MALAWI CICHLIDS}

\author{
Margot A. B. Schwalbe* and Jacqueline F. Webb \\ Department of Biological Sciences, University of Rhode Island, \\ 120 Flagg Road, Kingston, RI 02881, USA \\ (*author for correspondence: email: mbergstrom@my.uri.edu) \\ Manuscript in preparation for Journal of Comparative Physiology A
}




\begin{abstract}
Light intensity influences the ability of fishes to visually detect prey, and some fishes use visual and non-visual feeding strategies to adjust to diurnal or depth-associated changes in light environment. Two benthic feeding Lake Malawi cichlids (Aulonocara stuartgranti and Tramitichromis sp.) differ in lateral line canal morphology (widened and narrow canals, respectively) and while $A$. stuartgranti is capable of feeding on live prey in the dark using its lateral line system, Tramitichromis rarely feeds in the dark. The goal of this study was to determine how decreasing light intensity (800 to $0 \mathrm{~lx}$ ) affects feeding behavior in these two species, especially on live and dead prey, and if this is accompanied by a transition between visual and lateral line-mediated feeding behavior. Results demonstrate that $A$. stuartgranti can feed in all light intensities, respond differently to live and dead prey at most light intensities (all but $11 \mathrm{x}$ ), and change its feeding behavior between 1 and 0 lx. In contrast, Tramitichromis sp. fed on live and dead prey until $1 \mathrm{~lx}$, responded to live and dead prey in the same way, and tended not to feed in darkness $(0 \mathrm{~lx})$. These results suggest that the sensory biology of closely related species that exploit a common food resource may have important ecological implications.
\end{abstract}

\title{
Keywords
}

Aulonocara, Tramitichromis, light intensity, detection distance, lateral line 


\section{Introduction}

Light in aquatic habitats varies in quality and quantity over time and space (Kirk 2011) and this influences the ability of visual fish predators to find and capture mobile prey (Vinyard and O’Brien 1976; Confer et al. 1978; Lythgoe 1979; Ryer and Olla 1999; Vogel and Beauchamp 1999; Rickel and Genin 2005). Fishes occupying similar habitats demonstrate variation in visually-mediated prey detection abilities and visual thresholds, which may lead to predatory or competitive advantages under particular light conditions (Vogel and Beauchamp 1999). Further, adaptive specializations of the visual system (including variation in visual pigment sensitivity, Hofmann et al. 2009) and other sensory systems (e.g. lateral line, Livingston 1987; Janssen 1997) may contribute to the ability of fishes to reduce competitive pressure on shared resources.

Many visual fish predators are able to detect prey at low light intensities, but with reduced capabilities when compared to their abilities at higher light intensities. For instance, the distance at which free swimming prey are detected dramatically decreases below a certain light intensity in salmonids (Dunbrack and Dill 1984; Henderson and Northcote 1985) and some freshwater percomorphs (Vinyard and O’Brien 1976; Howick and O'Brien 1983; Richmond et al. 2004). Several marine and freshwater species can feed in both the light and dark by altering their feeding strategies by using visual and non-visual cues, respectively (Townsend and Risebrow 1982; Batty et al. 1986; Diehl 1988; Schwalbe et al. 2012). Morphological and/or physiological specializations of sensory systems, including the lateral line system (Janssen 1997; Schwalbe et al. 2012, reviewed in Webb 2013), olfactory system 
(Parzefall 1993; Montgomery et al. 1999), and gustatory system (Atema 1971), are often found in fishes that inhabit light limited environments where non-visual senses may provide a particular advantage for prey detection.

Widened lateral line canals, one of four cranial lateral line canal morphologies found among bony fishes (Webb 1989), have evolved convergently in $\sim 12$ teleost families and are suggested to be an adaptation for prey detection (Schwalbe et al., 2012; reviewed in Webb 2013). In addition, widened canals may also contribute to predator avoidance especially in hydrodynamically quiet environments because the lateral line system can detect forces generated by the strikes of suction-feeding predators (McHenry et al. 2009). The speciose cichlid fishes of the African Rift Lakes are generally described as visual feeders (Fryer and Iles 1972), but a few genera (e.g., Aulonocara, Alticorpus, Trematocranus, Trematocara, Aulonocranus, Konings, 2007) have widened lateral line canals suggesting the capacity for non-visual prey detection (Konings, 1990). Cichlids provide an important opportunity to compare the relative roles of different sensory modalities in prey detection since other fish with widened canals are generally difficult to maintain in captivity. Recent laboratory studies (Schwalbe et al. 2012, Schwalbe and Webb, accepted) have demonstrated that Aulonocara stuartgranti (widened canals) and Tramitichromis sp. (narrow canals) use vision to locate benthic prey in the light and A. stuartgranti also uses its widened lateral line canals to find live prey in the dark. Fishes in these two genera feed on benthic invertebrates in the sand in Lake Malawi, but occupy different depth ranges (Aulonocara: 5-120 m, Tramitichromis: < 15 m, Fryer and Iles 1972; Konings 1990, 2007). 
Aulonocara and Tramitichromis use different behavioral strategies to detect benthic prey (Konings 2007; Schwalbe et al. 2012; Schwalbe and Webb, accepted). Aulonocara swims just above the substrate to sense hydrodynamic flows generated by benthic invertebrates in or on the substrate in the field (Konings 2007) and in the laboratory (A. stuartgranti, Schwalbe et al. 2013). In contrast, Tramitichromis captures prey in the field by plunging into the substrate, filling its mouth with sand, and then sifting out prey with its gill rakers ("sand sifting," Fryer, 1959; = winnowing, see Laur and Ebeling 1983). This behavior was also observed in the laboratory and in addition, Tramitichromis sp. can also strike at individual prey in the laboratory (Schwalbe and Webb, accepted). Variation in light intensity is predicted to influence prey detection on live and dead prey because Tramitichromis sp. appears to be more dependent on visual cues than A. stuartgranti (Schwalbe et al. 2012, Schwalbe and Webb, accepted). Thus, the goal of this study was to test two hypotheses: (1) decreasing light intensity (800-0 lx) will have different effects on the feeding behaviors of A. stuartgranti and Tramitichromis sp. when detecting live and dead benthic invertebrate prey (tethered adult brine shrimp) and (2) a transition between visual and lateral line-mediated feeding behavior will be indicated by changes in well-defined parameters of prey detection behavior in A. stuartgranti, and not Tramitichromis sp., as light intensity decreases from $800 \mathrm{~lx}$ to darkness $(0 \mathrm{~lx})$. 


\section{Methods}

Study Species

Adult Aulonocara stuartgranti and Tramitichromis sp. (= Tramitichromis for remainder of manuscript, unless otherwise noted) were acquired from commercial suppliers (A. stuartgranti: Bluegrass Aquatics, Louisville, KY, USA; Tramitichromis: Old World Exotic Fish, Inc., Homestead, FL, USA and Life Fish Direct, Draper, UT, USA) and housed in small groups by species in $190 \mathrm{~L}$ aquaria at $26 \pm 1^{\circ} \mathrm{C}$ and $1.0 \pm 0.2$ p.p.t. salinity (using Cichlid Lake Salt, Seachem Laboratories, Inc., Madison, GA, USA). Fish were maintained with standard white fluorescent light on a $12 \mathrm{~h}: 12 \mathrm{~h}$ diurnal cycle and all aquaria were equipped with appropriate mechanical and biological filtration. Fish were fed daily with cichlid pellets (New Life Spectrum Cichlid Formula; New Life International, Inc., Homestead, FL) and supplemented with live adult brine shrimp. Individual fish were not used in feeding experiments if breeding behavior was observed. Animal care and all experimental procedures followed an approved IACUC protocol.

Light Environment in the Experimental Tank

Light in the experimental tank was provided by two fluorescent light fixtures (ballasts, Lithonia Lighting, Model GRW 214 CSW CO M4, Conyers, GA, USA) fitted with full spectrum bulbs (BlueMax lamps, Full Spectrum Solutions, Jackson, MI, USA) 
positioned above the tank and within an opaque curtain enclosure. The curtain (black canvas) was suspended from a rectangular plywood frame $2 \mathrm{~m}$ above the top of the tank in order to control light levels during all behavioral trials around the tank (Fig. 1a). Light intensity was varied by changing the height of the ballasts above the water surface of the tank and using combinations of different neutral density filters mounted over the ballasts (Lee Filters, Burbank, CA, USA). Light intensity (lux [lx] and photosynthetically active radiation [PAR]) and spectrum were measured using a spectrometer (Jaz spectrometer, Ocean Optics, Dunedin, FL, USA) connected to a $2 \mathrm{~m}$ optical fiber (QP400-2-UV/VIS, Ocean Optics) fitted with a cosine corrector (CC-3, Ocean Optics).

Light intensities used in the current study were based on two criteria that incorporate possible intensities present during daily light cycles and at depth in Lake Malawi. First, light levels present during sunrise/sunset to darkness are known for other freshwater habitats (Harden Jones 1956; Ali 1959). Second, direct measurements of light intensities at various depths in Lake Malawi are not available (especially at depths where A. stuartgranti and Tramitichromis are found), so the light intensity at specific depths were calculated with the following equation:

$$
I_{t}=I_{S} \times e^{-\varepsilon \times T}
$$

where $\mathrm{I}_{\mathrm{s}}$ and $\mathrm{I}_{\mathrm{t}}$ are the light intensities directly under the surface (S) and at depth (T); $\varepsilon$ is the light extinction coefficient. If light intensity at the surface of Lake Malawi at midday on a clear sunny day is approximately $2000 \mu \mathrm{mol}$ photons $/ \mathrm{m}^{2} / \mathrm{s}(\sim 108,000 \mathrm{~lx}$, personal communication, SJ Guiliford) and if the light extinction coefficient is either $0.10 \mathrm{~m}^{-1}$ (Patterson et al. 2000) or $0.13 \mathrm{~m}^{-1}$ (Guildford et al. 2007) depending on 
location and season, the light intensity at depth can be estimated under these conditions (Table 1).

Full spectrum bulbs were used as the light source for experiments because they provide the range of wavelengths that correspond to the range of known absorption peaks of retinal photopigments in both Aulonocara and Tramitichromis species. Peak absorptions for A. hueseri are at $415 \mathrm{~nm}$ (violet), $484 \mathrm{~nm}$ (blue-green) and $526 \mathrm{~nm}$ (green; Jordon et al. 2006) and peak absorptions for T. intermedius are at $455 \mathrm{~nm}$ (blue), $532 \mathrm{~nm}$ (green) and $569 \mathrm{~nm}$ (red; Parry et al. 2005). In the experimental tank, the full spectrum bulbs provided major and minor light peaks are at 404, 435, 487, 545, 587, and $611 \mathrm{~nm}$ (Fig. 1b).

\section{Experiments}

A total of 6030 -minute behavioral trials were conducted with A. stuartgranti (30 trials, $n=6$ fish, total length [TL] $=7.5-8.5 \mathrm{~cm}, 4$ females, 2 male) and Tramitichromis (30 trials, $n=6$ fish, $\mathrm{TL}=7.5-9.8 \mathrm{~cm}, 1$ female, 5 males) in order to quantify any variation in behavioral responses to live and dead prey in a range of decreasing light intensities $(800,112,12,1$, and $0 \mathrm{~lx})$. Behavioral trials and subsequent video analysis of several behavioral parameters (number of prey strikes, detection distance and angle, detection-to-strike velocity, proportion of strikes occurring during glide vs. pause phases of prey search, and order of prey strikes) were carried out as in Schwalbe, et al. (2012) and Schwalbe and Webb (accepted) with slight modifications as described below. 
Trials were conducted in an experimental tank $(120 \times 75 \times 60 \mathrm{~cm} ; 560 \mathrm{~L})$ with $5 \mathrm{~cm}$ of sand on the bottom. Light intensity and spectral measurements (with \pm 0.01 accuracy as measured in lx and PAR) were taken directly above the center of each mesh platform (to which live and dead prey were tethered, see below) before and after each trial, and light intensity and spectrum were found to be consistent at all six platforms and trials (Figs. 1b, c). Each fish was acclimated to a particular light intensity for at least 30 minutes prior to the trial in the experimental tank. The transition between photopic (cone-mediated) and scotopic (rod-mediated) vision occurs at approximately $1 \mathrm{~lx}$ and light-adapted fish may take 30 minutes (and up to 3 hours) to become dark-adapted (Ali 1959). Thus, the 30+ minute light adaptation period was judged to be sufficient to allow the fish's visual system to adjust to the light level for a given trial.

Before each trial, adult brine shrimp (Artemia sp.) were tethered in pairs (1 live and 1 dead, freshly frozen) on each of six mesh platforms $(10 \mathrm{~cm} \times 10 \mathrm{~cm})$ placed in a $2 \times 3$ matrix (total of 12 prey) with the top of each platform flush with the sand surface. The water filtration system for the experimental tank was turned off to eliminate hydrodynamic noise. At the start of a trial, a fish was released into the experimental arena from behind an opaque divider and feeding behavior was recorded for 30 min using an HD digital video camera (Sony $\mathbb{C}$ HDR-CX550V, $30 \mathrm{fps}$ ) mounted directly above the tank with a vertical view of the experimental arena. Trials at 1-800 lx were carried out during daylight hours (10:00-18:00) with standard fluorescent room lights on and these lights were shut off for 1 and $12 \mathrm{~lx}$ trials to eliminate extraneous light. Dark trials $(0 \mathrm{~lx})$ were conducted after the overhead lights 
had automatically shut off (>19:00) and infrared illumination ( $840 \mathrm{~nm}$; Speco Provideo, IR-200/24, Amityville, NY) was used to allow video recording of behavior. Each fish was run through five trials, one trial per day and per light intensity, from highest to lowest intensity (e.g. 800,112, 12, 1, and then 0 lx). Trials were carried out in this sequence so that fish were first introduced to the behavioral assay at the highest light intensity so that they would be more likely to respond to the prey at lower light intensities (especially 0 lx, darkness). Trials were conducted over four months and the mean time between the first $(800 \mathrm{~lx})$ and last $(0 \mathrm{~lx})$ trial for a given fish was 12 days. At the end of each trial, unconsumed prey were counted and strike success was confirmed in video recordings. Video was analyzed using Premier Pro (Adobe, CS5) and images from video sequences leading to each prey strike were exported for further analysis. The images were viewed to identify during which phase of search behavior (thrust, glide, or pause) prey detections occurred. In addition, detection distance and detection angle were measured in these images using ImageJ (NIH, v. 1.410). Detection distance was defined as the distance from the tip of a fish's mouth to the prey, measured in the frame immediately before the fish oriented towards it (e.g. before a turn). For each prey strike, detection-to-strike velocity was calculated by dividing detection distance by the time interval between detection and initiation of a strike. Detection angle was defined as the angle between the prey and the tip of the fish's mouth, with reference to the long axis of the fish's body, in the same captured frame in which detection distance was determined. 
Statistical analysis

Generalized linear mixed models (GLMM, using SPSS, IBM, v. 19) with pairwise post-hoc comparisons (least significant differences, LSD, using SPSS) were used to analyze number of prey strikes, detection distance, detection-to-strike velocity, and phase of search behavior during which detections occurred, for each species with reference to the two prey types (live and dead) and light intensity (2-way analysis, prey type $\times$ light intensity). A comparison of these variables between sexes in each species was not completed due to the unequal numbers of males and females used in this study. A second analysis allowed an interspecific comparison of all variables (3way analysis, prey type $\times$ light intensity $\times$ species). This approach allowed the selection of random (individual) and fixed effects (light intensity, prey type, and species) while addressing repeated measures for the same individual. All data were first tested for normality (Kolmogorov-Smirnov test) and only detection distance and detection-to-strike velocity data needed to be $\log _{10}$ transformed to achieve normality.

The order in which live and dead prey were struck at during all trials was analyzed following methods described in Taplin (2007). This analysis assumes that the order in which prey are struck at provides information about prey preference - that prey consumed first are more preferred than prey consumed second, third, etc. and the last prey consumed is the least preferred. While differences in handling time, encounter rates, and relative mobility of prey can potentially complicate the results of this analysis (see Durham et al. 2012, McWilliam et al. 2013), these differences were minimized by offering equal numbers of live and dead brine shrimp tethered to 
platforms and evenly distributed in the experimental tank. The null hypothesis for this analysis was that prey (live and dead brine shrimp) were randomly consumed as the fish moved throughout the experimental tank. Upon consumption, each prey was assigned a rank number based on the order in which it was consumed (first prey consumed $=1$, second prey consumed $=2$, etc.), and any remaining prey were assigned an average of the remaining preference scores and were considered "tied for last." Each fish was assigned its own set of preference scores for live and dead prey at each light intensity and the scores from each fish were considered independent samples and thus grouped by light intensity to test the hypothesis. A preference score equal to 6.5 based on presenting six live and six dead prey (12 total prey) indicated that prey were randomly consumed, while a score $<6.5$ indicated preference for one prey type over the other. Preference scores for live and dead prey at each light intensity for the two species were compared separately using a two-tailed, paired $t$-tests (SPSS).

Detection angles were analyzed with circular statistics using Oriana (v. 3, Kovach Computing Services, Anglesey, UK). Rayleigh tests were performed for each species to test if detections of live and dead prey at the five different light intensities occurred uniformly around the fishes' body (e.g. identify a particular receptive field). Watson's $\mathrm{U}^{2}$ tests were used to determine if detection angles differed with prey type and light intensity, and between the two species. All statistical tests were considered significant at $P<0.05$ and values are given as means \pm s.e.m. 


\section{Results}

Individuals of both species actively swam around the experimental tank at all light intensities, including darkness (0 1x), and Aulonocara stuartgranti struck at 299 prey (of 360 total prey presented, $=83 \%$ ) and Tramitichromis struck at 231 prey $(=64 \%$ ) in all trials. Both A. stuartgranti and Tramitichromis used a saltatory search strategy (a cyclic sequence of caudal fin thrust, glide, and pause) while exploring the tank, and prey were detected during a glide or a pause, but never during a thrust. Aulonocara stuartgranti successfully detected prey as light intensity decreased from 800 to darkness (0 lx), and Tramitichromis successfully detected prey from 800 to $1 \mathrm{~lx}$, but tended not to feed in the dark $(0 \mathrm{~lx})$.

Feeding behavior of Aulonocara stuartgranti

Light intensity influenced the ability of $A$. stuartgranti to detect prey and results of the generalized linear mixed models (GLMMs) identified some variation in prey detection behavior among light intensities and between prey types (Table 2). As light intensity decreased from 800 to $1 \mathrm{~lx}$, A. stuartgranti continued to strike at equally high numbers of live and dead prey (LSD, $P>0.05$; Figs. 2a, 3a), and more prey (52-61\%, live and dead prey combined) were detected during a pause (versus a glide), except at $12 \mathrm{~lx}$ (44\%, Fig. 4a). Detection distance and detection-to-strike velocity decreased as light intensity decreased (Figs. 3c, e), and differences were observed in these two parameters between live and dead prey from $8001 \mathrm{x}$ to $12 \mathrm{~lx}$ (LSD, $P<0.05$; LSD, $P \leq$ 
0.001 ; respectively), but not at $1 \mathrm{~lx}$ (LSD, $P>0.05)$. Further, live prey were detected from greater distances and were approached more rapidly (greater strike-to-velocity velocity) between 800 and $12 \mathrm{~lx}$ than were live prey at $1 \mathrm{~lx}$ (LSD, $P \leq 0.003$; LSD $P<$ 0.001, respectively). In contrast, dead prey were detected from the same distance and were approached at the same velocity as light intensity decreased from 800 to $1 \mathrm{~lx}$ (LSD, $P>0.05$ ). In addition, live and dead prey were detected non-uniformly around the fishes' bodies $\left( \pm 90^{\circ}\right.$ from body axis, Rayleigh test, $\left.P<0.001\right)$ and the distribution of detection angles did not differ among light intensities (Watson's $\mathrm{U}^{2}, P>0.05$ ), with one exception (112 versus 800 lx; Watson's $\mathrm{U}^{2}$ test, $\mathrm{U}^{2}=0.19, P<0.05$; Fig. 5a). Fish tended to prefer live prey between 800 and $1 \mathrm{~lx}$, but only at $112 \mathrm{~lx}$ did significantly more strikes on live prey precede those on dead prey (Taplin's method, paired $t$-test, $t$ $=6.10, P=0.002$; Fig. 6a).

Aulonocara stuartgranti struck at 22 prey $(=30.6 \%$ of prey presented at $0 \mathrm{~lx})$ in the dark $(0 \mathrm{~lx})$ and demonstrated variation in prey detection behaviors compared to behaviors at 800-1 1x (GLMM, Table 2). At 0 lx, fewer live and dead prey were detected (LSD, $P<0.001$; Figs. 2a, 3a) than at 800-1 $1 \mathrm{x}$ and live and dead prey were detected from shorter detection distances (LSD, $P<0.001$, Fig. 3c) and slower detection-to-strike velocities (LSD, $P \leq 0.006$; Fig. 3e) than live and dead prey at 800 $1 \mathrm{~lx}$. Further, more prey (live and dead combined) were detected during a glide at $0 \mathrm{~lx}$ ( $95 \%$ of prey), which was much greater than the number of prey (live and dead combined) detected during a glide at $800-1 \mathrm{~lx}$ (39-56\% of prey, LSD, $P<0.001$; Fig. $4 a)$. 
In the dark $(01 \mathrm{~lx}), A$. stuartgranti demonstrated several differences in behavioral parameters when comparing strikes on live versus dead prey. More live prey were detected than dead prey (live $=2.7 \pm 0.3$, dead $=1 \pm 0.3$; LSD,$P<0.001$; Figs. 2a, 3a) and strikes on live prey preceded those on dead prey at 0 lx (Taplin's method, paired $t$-test, $t=2.85, P=0.036$; Fig. $6 \mathrm{a}$ ). Live prey were detected from greater distances than dead prey (live $=3.22 \pm 0.25 \mathrm{~cm}$, dead $=1.35 \pm 0.25 \mathrm{~cm}$; LSD, $P<0.001$, Fig. $3 c$ ), but both live and dead prey were approached at the same velocity (LSD, $P>0.05$, Fig. 3e). Both live and dead prey were detected uniformly around the fishes' body (e.g. $360^{\circ}$ or $\pm 180^{\circ}$ from body axis, Rayleigh test, $P>0.05$; Fig. 5a) and the distribution of detection angles did not differ between live and dead prey (Watson's $\mathrm{U}^{2}$ test, $P>0.05$ ).

Feeding behavior of Tramitichromis

Tramitichromis readily struck at prey at decreasing light intensities of 800 to $1 \mathrm{~lx}$, but statistical analysis revealed some variation in behavior with respect to prey type and light intensity (Table 2). Despite being active in the dark (0 lx), fish tended not to strike at prey $(n=3$ prey detections of 72 prey presented, $=4.2 \%)$. These strikes appeared to be a result of indiscriminant encounters with the prey as opposed to the result of actively search. Thus, the three strikes on prey at $0 \mathrm{~lx}$ were not included in the analysis with the exception of the analysis of the number of prey strikes.

The number of prey strikes varied with light intensity (800-0 1x; live and dead combined, GLMM, $P<0.001$; Table 2) and more strikes occurred at 800-12 lx than at 
1 and $01 x$ (live and dead combined, LSD, $P \leq 0.003$ ), but the number of strikes was the same for live and dead prey at each light intensity (LSD, $P>0.05$; Figs. 2b, 3b). More prey (live and dead combined) were detected during a pause ( $\geq 60 \%$; Fig. 4b). Detection distance and detection-to-strike velocity varied with light intensity (Table 2; Figs. 3d, f), and differences were not evident in either detection distance or detectionto-strike velocity for the live versus dead prey (LSD, $P>0.05$ ). Live and dead prey were detected non-uniformly, in a narrow range in front of the head $\left( \pm 40^{\circ}\right.$ from body axis, Rayleigh test, $P<0.001$ ), and these distributions were the same for live and dead prey among light intensities (Watson's $\mathrm{U}^{2}, P>0.05$; Fig. 5b). Fish tended to prefer live prey at light intensities between 800 and $1 \mathrm{~lx}$, but significantly more strikes on live prey preceded those on dead prey at only the highest light intensity $(800 \mathrm{~lx}$; Taplin's method, paired $t$-test, $t=13.65, P<0.001$; Fig. 6b).

Species comparison: Aulonocara stuartgranti vs. Tramitichromis

Interesting similarities and difference were revealed when the effect of light intensity on the parameters that define prey detection behavior in A. stuartgranti and Tramitichromis were analyzed (Table 3). An interspecific comparison of detection distance and angle, distance-to-strike velocity, and swimming phase during which detection occurred was not possible at this light intensity since Tramitichromis tended not to feed in the dark ( $n=3$ strikes).

As light decreased from 800 to $12 \mathrm{~lx}$, both A. stuartgranti and Tramitichromis continued to strike at same high numbers of live and dead prey (Table 3), and although 
not significant (GLMM, $P=0.078$; Table 3$)$, A. stuartgranti tended to detect more live and dead prey at $1 \mathrm{~lx}$, and more live prey at $0 \mathrm{~lx}$ than did Tramitichromis (Figs. 3a, b). Both species detected more prey during a pause (versus a glide) at 800 to 1 1x (Fig. 4), and while differences were observed between species (GLMM, $F=10.893, P=$ 0.001), no differences were observed when comparing the results from both species by light intensities (GLMM, P > 0.05). Both species detected prey (live and dead combined) at the same distance and detection-to-strike velocity among light intensities (800-1 1x; LSD, $P>0.05$; Table 2, Fig. 3), but the distribution of detection angles were different (Fig. 5). At intensities from 800 to 1 1x, A. stuartgranti detected prey over a wider range of angles $\left( \pm 90^{\circ}\right.$ from body axis) compared to Tramitichromis $\left( \pm 40^{\circ}\right.$ from body axis; Watson's $\mathrm{U}^{2}$ test, $\left.P<0.05\right)$, with one exception $\left(12 \mathrm{~lx}\right.$, Watson's $\mathrm{U}^{2}$ test, $P>0.05)$.

\section{Discussion}

The results of this study show that light intensity has different effects on the feeding behavior in Aulonocara stuartgranti and Tramitichromis. In addition, A. stuartgranti feed at all light intensities, while Tramitichromis tended not to feed in the dark (0 1x). The species demonstrated similar responses in several behavioral parameters as light decreased from 800 to 1 1x, but for detection angles, in particular, there were differences over this range of light intensities. Further, A. stuartgranti consistently detected live prey from greater distances and approached live prey at higher velocities than dead prey between 800-12 lx, suggesting that $A$. stuartgranti was able to discern 
cues from live versus dead prey more effectively than Tramitichromis over a range of light intensities. The differences in behavioral parameters as light decreased from 1 to 0 lx observed in A. stuartgranti suggest that these fish can change between visual and lateral line-mediated feeding strategies. In the dark $(0 \mathrm{~lx})$ and in the absence of visual cues, the shorter detection distances and slower detection-to-strike velocities likely reduced self-generated hydrodynamic noise, thus enhancing the probability of lateral line-mediated detection of minute flows shed by tethered prey. While intraspecific comparisons (inter-individual variation, including sexual dimorphism) were not included in this study, there may have been differences in the feeding behavior of males and females in one or both species given different reproductive priorities observed in the field (e.g. males defend territories and females mouthbrood their young).

Feeding behavior of Aulonocara stuartgranti and Tramitichromis sp.

Aulonocara stuartgranti uses both its visual system and lateral line system to detect prey, as demonstrated by its ability to feed under all light intensities (in the current study). Chemically ablating the lateral line system negatively influenced feeding behaviors in the light and dark (Schwalbe et al. 2012). This study showed that, while prey were successfully detected at $1 \mathrm{~lx}$, additional light is needed for a strong visual response that likely helps distinguish the two prey types (at 12-800 lx). A transition between sensory modalities occurs between 1-0 lx, as demonstrated by changes in prey detection behaviors (Table 4). The feeding behaviors performed by $A$. 
stuartgranti were similar as light intensities decreased from 800 to $12 \mathrm{~lx}$, and changes in several behavioral parameters (e.g. shorter detection distances, lower detection-tostrike velocities, and differences between prey types were lost) were observed at $1 \mathrm{~lx}$. At this light intensity, live and dead prey were detected from the same distance, approached at the same speed after detection, with no preference for live prey, yet high numbers of live and dead prey were still detected.

The fact that Tramitichromis rarely fed in the dark and that its feeding behavior did not change when its lateral line system was chemically ablated (Schwalbe and Webb, accepted) demonstrates that it strongly depends on vision for prey detection. Tramitichromis was most successful at detecting prey at the higher light intensities (800-12 1x; e.g. captured majority of prey, longest detection distances, fastest detection-to-strike velocities) and can also feed in low light (1 lx), but do not feed in the dark (0 1x; Table 4). Live and dead prey were detected from similar distances by Tramitichromis in this study, which was surprising since Tramitichromis detected live prey from greater distances than dead prey in light trials (Schwalbe and Webb, accepted). While the distance at which Tramitichromis detected live and dead prey in 800-12 1x overlapped the detection distances in the Tramitichromis individuals used in Schwalbe and Webb (accepted), differences may be due to individual variation since fish were from different sources or differences in sample sizes (total possible prey strikes $=72$ per light intensity in current study versus 216 for light trials in Schwalbe and Webb, accepted).

Trials were run from highest to lowest light intensity so that the fish could become accustom to the behavioral assay in a bright light environment. Preliminary 
trials (unpublished data) had demonstrated that $A$. stuartgranti were more likely to respond to tethered prey in dark trials when run through a trial in the light. Learning the experimental procedure appeared to not impact the results for either species because behavior of all fish varied between the first (800 lx) and last trial (0 lx), the results at $800 \mathrm{~lx}$ were different from those observed as light intensity decreased in subsequent trials.

Because Tramitichromis is known to primarily "sand sift" in their natural habitats in Lake Malawi (Fryer 1959), the behavior exhibited by adult Tramitichromis in the lab can be described as a secondary mode of feeding (= picking directly at prey). When Tramitichromis is "sand sifting," it engulfs mouthfuls of sand and presumably determines palatability after the sand and food are already in the buccal cavity. Sand sifting appears to be synonymous with "winnowing" behaviors observed in some surfperches (Laur and Ebeling 1983), which take mouthfuls of substrate to acquire invertebrate prey. Vision likely contributes to the location of patches of preyrich substrate (Holbrook and Schmitt 1984; Schmitt and Holbrook 1984). There is a tradeoff between winnowing/sand sifting and directly striking at prey - fish that take mouthfuls of substrate may capture more prey per bite, but prey tend to be smaller and less diverse, compared to fishes that directly strike at prey in or on the substrate (Schmitt and Coyer 1982; Laur and Ebeling 1983). The sensory system (or systems) that mediate sand sifting behavior in Tramitichromis has yet to be determined, but vision presumably influences where sand sifting is initiated provided the dependence on vision for detecting benthic prey (current study; Schwalbe and Webb, accepted). Thus, it may be more important for Tramitichromis to respond to available cues 
generated by potential prey, but they do not respond to hydrodynamic cues (Schwalbe and Webb, accepted). While there is likely diet overlap between Tramitichromis and A. stuartgranti in Lake Malawi (Fryer 1959; Konings 2007), it would be interesting to determine through diet analyses if these fishes consume prey of different types and sizes in the field provided that one species sand sifts and the other directly strikes at prey.

Both species demonstrated lower detection-to-strike velocities at lower light intensities. Swimming more slowly likely improves the probability of visual prey detection with the stabilization of the visual field, which would be advantageous to both A. stuartgranti and Tramitichromis. In addition, swimming more slowly could also reduce self-generated hydrodynamic noise enabling A. stuartgranti to detect hydrodynamic stimuli at low light levels and in darkness (1-0 lx), where vision is likely less effective for prey detection.

Light intensity influences the distribution of detection angles more in A. stuartgranti than in Tramitichromis and a few factors may account for the variation between the two species. First, the difference in detection angles at 800-1 $1 \mathrm{x}$ and in the dark ( 0 lx) in A. stuartgranti ( $\pm 90^{\circ}$ vs. $\pm 180^{\circ}$ from body axis, respectively) is likely due to a transition between visual and lateral line-mediated feeding behaviors, which was not observed in Tramitichromis since they rarely feed in the dark (0 1x). Prey can probably be detected by A. stuartgranti all around the body with the lateral line system because canal and superficial neuromasts are found on the head, trunk and tail (Webb 1989), whereas the visual field is constrained by eye size, shape, and position on the head (Collin and Shand 2003). Second, fish may monitor different portions of their 
visual fields while searching for prey (as seen in other fish with different visual axes and visual fields determined by concentrated regions of retinal cells, Collin, 1989; Miyazaki et al. 2011). Aulonocara stuartgranti detected prey in a wider range of angles ( $\pm 90^{\circ}$ from body axis) than did Tramitichromis ( $\pm 40^{\circ}$ from body axis), indicating that $A$. stuartgranti may pay attention to a greater volume of water, thus potentially allowing the fish to look for predators while searching for prey with its lateral line system as it hovers above the sand. In contrast, the narrower detection angles demonstrated by Tramitichromis suggest that it may use binocular vision to detect prey (as in other teleosts, Sivak 1978; Blanco-Vives et al. 2011; Miyazaki et al. 2011). If Tramitichromis has a larger aphakic (lensless) space in its eyes compared to A. stuartgranti, then that would allow greater movement of the lens, which would enlarge the binocular field of vision (Sivak 1978). Third, A. stuartgranti tended to detect more prey at $1 \mathrm{~lx}$ than did Tramitichromis, suggesting that it has better visual abilities in low light. Thus, morphological adaptations for increased visual acuity and/or sensitivity would be expected in A. stuartgranti, like those found in known nocturnal teleosts (e.g. large relative eye size, high optical ratio, extremely clear optical media and dorsal tubular eyes [deep sea species] or laterally placed eyes with wider visual fields, reviewed in Warrant 2004; Schmitz and Wainwright 2011). Detection (= reaction) distances for free swimming prey are generally much longer at higher light intensities and do not change with additional increase in light intensity, but detection distance decreases sharply below this critical light intensity (= light intensity at which detection distance is reduced compared to that at higher intensities [lake trout and brook trout, Confer et al. 1978]). The current study has 
shown that the critical light intensity for A. stuartgranti and Tramitichromis feeding on tethered benthic prey in the laboratory is near $12 \mathrm{~lx}$, which is similar to those found in other freshwater teleosts feeding on free-swimming Daphnia (11-50 1x, bluegill, Vinyard and O'Brien 1976; lake trout, brook trout, and bluegill, Confer et al. 1978), amphipods (5-25 1x, Bergstrom and Mensinger 2009), or small fish (5.59-17.83 lx, largemouth bass, Howick and O’Brien 1983; lake trout, Vogel and Beauchamp 1999) and rarely does detection distance increase above that demonstrated at the critical light intensity (as in Arctic grayling, Thymallus arcticus, Schmidt and O’Brien 1982).

The connection between experimental light conditions and ecologically relevant light levels in Lake Malawi

In Lake Malawi, as in other bodies of freshwater, photic conditions are very dynamic and are affected by habitat type, water depth, bottom depth and proximity to the lake bottom (Sabbah et al. 2011), as well as meteorological events, wave action, eutrophication, turbidity, and both diurnal and seasonal changes in light quality and quantity. Full spectrum light is present in the shallower waters, and middle wavelength light (e.g. 450-575 nm) is transmitted best, while shorter and longer wavelengths attenuate rapidly (Dalton et al. 2010). Further, irradiance spectra are affected by substrate type, such that transmission in water above sandy substrates are shifted to longer wavelengths compared to those of rocky habitats (Sabbah et al. 2011).

The extent of visual foraging by species of Aulonocara and Tramitichromis at different depths can be estimated by connecting the behavioral results from the current 
study to calculated light intensities predicted for Lake Malawi based on the two light extinction coefficients and midday sunlight intensity (Table 1). These data suggest that Aulonocara may be able to visually detect prey to 71 to $92 \mathrm{~m}(\geq 121 \mathrm{x})$ and with some visual limitations at approximately 89 to $115 \mathrm{~m}(\sim 1 \mathrm{~lx})$. In fact, some Aulonocara species can be found up to $120 \mathrm{~m}$ (Konings 2007), so these fish may be able to visually detect prey in those depths at midday. Using the same calculations, Tramitichromis may be able to visually detect prey at $1 \mathrm{~lx}$ and thus potentially at 89 to $115 \mathrm{~m}$, but they are typically found in shallow waters ( $<15 \mathrm{~m}$, Konings 1990,2007$)$. The ability to find prey at $1 \mathrm{~lx}$ may be more relevant to Tramitichromis if it feeds crepuscularly near sunrise and/or sunset, rather than at greater depths. It follows that Tramitichromis may be limited to shallow, bright habitats so its ability to visually detect prey is not compromised, whereas Aulonocara is not restricted by light intensity since it can feed at a greater range of light intensities and in darkness.

The diversity of spectral sensitivities found among cichlids likely contributes to sensory adaptations that improve the ability to perceive specific food resources under different light conditions (Hofmann et al. 2009; Sabbah et al. 2010). A few cichlids species are sensitive to infrared light (Pelvicachromis taeniatus, Meuthen et al. 2012; Oreochromis mossambicus, Shcherbakov et al. 2012), which might explain how one Tramitichromis sp. repeatedly fed on tethered prey under infrared illumination in Schwalbe and Webb (accepted). None of the Tramitichromis in the current study captured as many prey as that one fish. Determining if Tramitichromis is sensitive to infrared light warrants further investigation. 
Aulonocara and Tramitichromis species occupy different depth ranges (5-120 m and $<15 \mathrm{~m}$, respectively; Konings 1990, 2007) and are thus exposed to different light environments due to the attenuation of light as depth increases. Over the course of a day, these fish also experience shifts in light from complete or near darkness to full sunlight. Laboratory experiments presented here demonstrate that $A$. stuartgranti is able to feed at a range of ecologically relevant light intensities, including darkness, suggesting it could be a crepuscular and/or nocturnal feeder and/or feed at considerable depths. In contrast, Tramitichromis tends not to feed in the dark, suggesting that it most likely a diurnal, but possibly crepuscular, feeder. The combination of morphological adaptations (e.g. widened lateral line canals) and behavioral evidence for feeding under different light intensities suggests that Aulonocara may avoid competition with other benthic insectivores, such as Tramitichromis, thus facilitating temporal and/or spatial segregation that would reduce competition for a shared, limited food resource. Field observations in Lake Malawi are needed to test this hypothesis.

\section{Acknowledgements}

We thank Karen Carleton (University of Maryland) for expertise in cichlid vision, Edward Baker (Facilities Manager, RI NSF EPSCoR Marine Life Science Facility), Emily Becker, Brandon Fuller, Christopher Holland, Callie Veelenturf, Rebecca Scott, and Benjamin Sevey for assistance with fish husbandry. This research was funded by the National Science Foundation (NSF) grant IOS 0843307 to JFW, the University of 
Rhode Island College of the Environment and Life Sciences, and NSF EPSCoR Cooperative Agreement EPS-0554548 and EPS-1004057. 
Table 1. The relationship of measured light intensity (mean lux and PAR, \pm SE measured immediately after behavioral trials) and predicted depths at which these intensities occur in Lake Malawi. Calculations were based on midday sunlight levels, two light extinction coefficients, $0.10 \mathrm{~m}^{-1}$, Patterson et al. 2000; $0.13 \mathrm{~m}^{-1}$, Guildford et al. 2007), and light intensities under natural conditions (Harden Jones 1955, Ali 1959). Light intensities were achieved by varying the height of two fluorescent fixtures (ballasts) and/or covering these fixtures with several neutral density filters.

\begin{tabular}{lccccc}
\hline \multicolumn{2}{c}{ Light Intensity } & & \multicolumn{2}{c}{ Light Extinction Coefficient } & \\
\cline { 1 - 3 } Lux & $\begin{array}{c}\text { PAR } \\
\text { Mmol photons } / \mathrm{m}^{2} / \mathrm{s}\end{array}$ & & $\begin{array}{c}\varepsilon=10 \mathrm{~m}^{-1} \\
\text { Depth }(\mathrm{m})\end{array}$ & $\begin{array}{c}\varepsilon=0.13 \mathrm{~m}^{-1} \\
\text { Depth }(\mathrm{m})\end{array}$ & $\begin{array}{c}\text { Light intensities under natural } \\
\text { conditions }\end{array}$ \\
\hline $800(800.8 \pm 5.4)$ & $11.0(11.0 \pm 0.10)$ & & 52 & 40 & Very cloudy day \\
$112(112.4 \pm 1.9)$ & $1.5(1.51 \pm 0.03)$ & & 72 & 55 & Twilight \\
$12(12.0 \pm 0.3)$ & $0.2(0.16 \pm 0.01)$ & & 92 & 71 & Twilight \\
$1(1.4 \pm 0.1)$ & $0.03(0.03 \pm 0.01)$ & & 115 & 89 & Full moon/deep twilight \\
$0(0 \pm 0.1)$ & $0(0.000 \pm 0.003)$ & $\mathrm{NA}$ & $\mathrm{NA}$ & New moon \\
\hline
\end{tabular}


Table 2. Prey detection behavior for A. stuartgranti ( $n=6$ fish) and Tramitichromis $(n=6$ fish) feeding on six live and six dead prey at five light intensities (A. stuartgranti: 0-800 lx, Tramitichromis: 1-800 lx). GLMM analyses; $P \leq 0.05$.

\begin{tabular}{lcccccccc}
\hline & \multicolumn{3}{c}{ Aulonocara stuartgranti } & & \multicolumn{3}{c}{ Tramitichromis } \\
\cline { 2 - 3 } \cline { 7 - 8 } & $F$ & d.f. & $P$ & & $F$ & d.f. & $P$ \\
\hline Number of Prey Detections & & & & & & & \\
$\quad$ Light Intensity & 92.397 & 4,50 & $<0.001$ & & 28.402 & 4,50 & $<0.001$ \\
$\quad$ Prey & 11.942 & 1,50 & 0.001 & & 2.636 & 1,50 & 0.111 \\
$\quad$ Light Intensity $\times$ Prey & 3.264 & 4,50 & 0.019 & & 0.151 & 4,50 & 0.962 \\
\hline Detection Distance & & & & & & & \\
$\quad$ Light Intensity & 31.950 & 4,289 & $<0.001$ & & 5.184 & 3,220 & 0.002 \\
$\quad$ Prey & 38.772 & 1,289 & $<0.001$ & & 2.232 & 1,220 & 0.137 \\
$\quad$ Light Intensity $\times$ Prey & 3.241 & 4,289 & 0.013 & & 0.269 & 3,220 & 0.848 \\
\hline Detection-to-Strike Velocity & & & & & & & \\
$\quad$ Light Intensity & 12.989 & 4,289 & $<0.001$ & & 7.736 & 3,220 & $<0.001$ \\
$\quad$ Prey & 17.614 & 1,289 & $<0.001$ & & 4.887 & 1,220 & 0.028 \\
$\quad$ Light Intensity $\times$ Prey & 3.156 & 4,289 & 0.015 & & 0.186 & 3,220 & 0.906 \\
\hline Pause vs. Glide & & & & & & & \\
$\quad$ Light Intensity & 3.249 & 4,289 & 0.013 & & 1.131 & 3,220 & 0.337 \\
$\quad$ Prey & 0.266 & 1,289 & 0.607 & & 15.314 & 1,220 & $<0.001$ \\
$\quad$ Light Intensity $\times$ Prey & 0.378 & 4,289 & 0.824 & & 1.893 & 3,220 & 0.132 \\
\hline
\end{tabular}


Table 3. Comparison of prey detection behavior by A. stuartgranti $(n=6$ fish) and Tramitichromis $(n=6$ fish) feeding on six live and six dead prey at five light intensities. Number of prey strikes compares results between species during trials at $800-0$ lx, while the other three variables compare results at $800-1$ lx, because Tramitichromis tended not to strike at prey in the dark $(0 \mathrm{~lx}, n=3$ strikes $)$. GLMM analyses, $P \leq 0.05$.

\begin{tabular}{|c|c|c|c|c|c|c|c|c|c|c|c|c|}
\hline \multirow[b]{2}{*}{ Source } & \multicolumn{3}{|c|}{ Number of Prey Detections } & \multicolumn{3}{|c|}{ Detection Distance } & \multicolumn{3}{|c|}{ Velocity } & \multicolumn{3}{|c|}{ Pause vs. Glide } \\
\hline & $F$ & d.f. & $P$ & $F$ & d.f. & $P$ & $F$ & d.f. & $P$ & $F$ & d.f. & $P$ \\
\hline Light & 78.294 & 4,100 & $<0.001$ & 29.689 & 4,509 & $<0.001$ & 18.789 & 4,509 & $<0.001$ & 4.224 & 4,509 & 0.002 \\
\hline Prey & 8.638 & 1,100 & 0.004 & 26.310 & 1,509 & $<0.001$ & 15.227 & 1,509 & $<0.001$ & 4.394 & 1,509 & 0.037 \\
\hline Species & 3.168 & 1,100 & 0.078 & 0.236 & 1,509 & 0.627 & 0.034 & 1,509 & 0.853 & 10.893 & 1,509 & 0.001 \\
\hline Light $\times$ Prey & 0.250 & 4,100 & 0.909 & 2.001 & 4,509 & 0.093 & 0.854 & 4,509 & 0.492 & 0.317 & 4,509 & 0.867 \\
\hline Species $\times$ Light & 1.655 & 4,100 & 0.166 & 1.171 & 3,509 & 0.320 & 0.668 & 3,509 & 0.572 & 0.174 & 3,509 & 0.914 \\
\hline Species $\times$ Prey & 0.000 & 1,100 & 1.000 & 2.744 & 1,509 & 0.098 & 3.670 & 1,509 & 0.056 & 8.486 & 1,509 & 0.004 \\
\hline Species $\times$ Light $\times$ Prey & 1.177 & 4,100 & 0.326 & 0.913 & 3,509 & 0.435 & 2.739 & 3,509 & 0.043 & 2.335 & 3,509 & 0.073 \\
\hline
\end{tabular}


Table 4. Summary of behavioral parameters measured in trials for A. stuartgranti ( $n=6$ fish) and Tramitichromis ( $n=6$ fish) at five light intensities with reference to the critical light intensity. See text for discussion of critical light intensity values.

\begin{tabular}{|c|c|c|c|}
\hline $\begin{array}{l}\text { Light } \\
\text { Intensity }\end{array}$ & $\begin{array}{l}\text { Critical Light } \\
\text { Intensity }\end{array}$ & Aulonocara stuartgranti & Tramitichromis \\
\hline $800-12 \mathrm{~lx}$ & Above & $\begin{array}{l}\text { - Captured majority of prey presented }(96 \%) \\
\text { - Longest detection distances, live }>\text { dead prey } \\
\text { - Fastest detection-to-strike velocities, live }>\text { dead prey } \\
\text { - Tended to prefer live prey, preference for live prey at } \\
112 \text { lx only } \\
\text { - More prey detected during a pause vs. a glide } \\
\text { - Wide detection angles, } \pm 90^{\circ} \text { from body axis }\end{array}$ & $\begin{array}{l}\text { - Captured majority of prey presented }(84 \%) \\
\text { - Longest detection distances, live }=\text { dead prey } \\
\text { - Fastest detection-to-strike velocities, live }=\text { dead prey } \\
\text { - Tended to prefer life prey, preference for live prey at } \\
\text { - } 800 \text { lx only } \\
\text { - More prey detected during a pause vs. a glide } \\
\text { - Narrow detection angles, } \pm 40^{\circ} \text { from body axis }\end{array}$ \\
\hline $1 \mathrm{~lx}$ & Below & $\begin{array}{l}\text { - } \text { Captured majority of presented prey }(96 \%) \\
\text { - Shorter detection distances, live }=\text { dead prey } \\
\text { - Slower detection- to-strike velocities, live }=\text { dead prey } \\
\text { - Tended to prefer live prey } \\
\text { - More prey detected during a pause vs. a glide } \\
\text { - Wide detection angles, } \pm 90^{\circ} \text { from body axis }\end{array}$ & $\begin{array}{l}\text { - } \text { Fewer prey tended to be detected }(65 \%) \\
\text { - Shortest detection distances, live }=\text { dead prey } \\
\text { - Slowest detection-to-strike velocities, live }=\text { dead prey } \\
\text { - Tended to prefer live prey } \\
\text { - More prey detected during a pause vs. a glide } \\
\text { - Narrow detection angles, } \pm 40^{\circ} \text { from body axis }\end{array}$ \\
\hline
\end{tabular}

- Struck at prey in the dark (30.6\%), live $>$ dead prey

- Rarely feeds in the dark

- Shortest detection distances, live $>$ dead prey

- Slowest detection-to-strike velocities, live = dead prey

- Detected more prey in a glide vs. a pause

- Detected prey uniformly around the body, $\pm 180^{\circ}$ from body axis or $360^{\circ}$ 

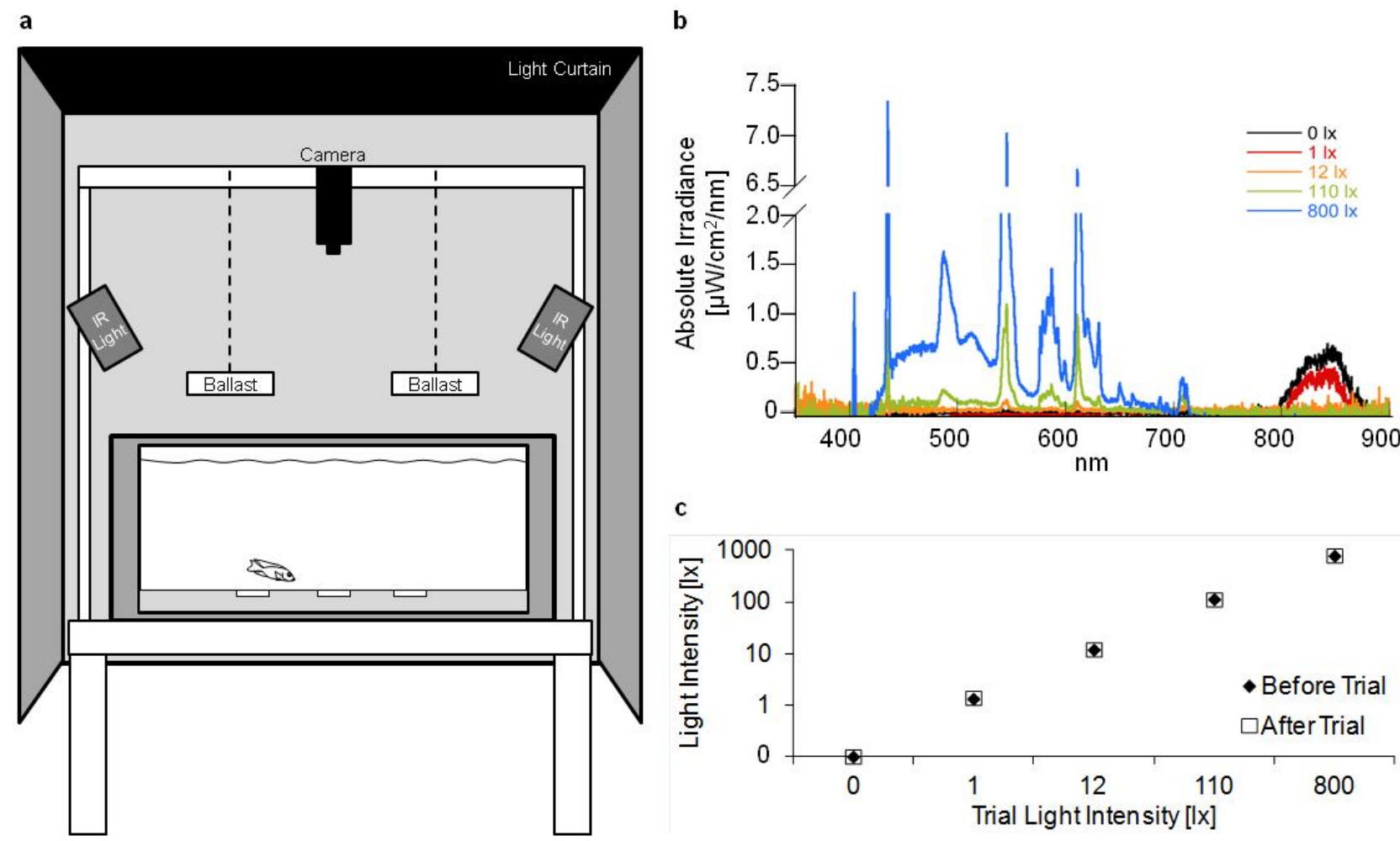

Figure 1. Experimental tank used to record feeding behavior of A. stuartgranti and Tramitichromis. a Diagram of experimental tank with front panel of light curtain removed. Light sources originate from two fluorescent light fixtures (ballast, artificial full spectrum light) and two infrared (IR) lights. b Sample light spectra generated by fluorescent lights in behavioral trials. The area between 2-6.5 $\mu \mathrm{W} / \mathrm{cm}^{2} / \mathrm{nm}$ was removed so the portion containing $0-2 \mu \mathrm{W} / \mathrm{cm}^{2} / \mathrm{nm}$ could be extended, and thus demonstrating that peaks between 400-700 nm occurring in 1-800 lx trials were consistent while intensity was decreased with the addition of neutral density filters (see Table 1). The peak at $840 \mathrm{~nm}$ (in 0 and 1 lx trials only) is from two IR lights. c Mean ( \pm s.e.m.) light intensities measured before and after trials, light intensity did not differ before and after trials at any of the light intensities (students $t$-test, $P>0.05$ ). 
a

Aulonocara stuartgranti

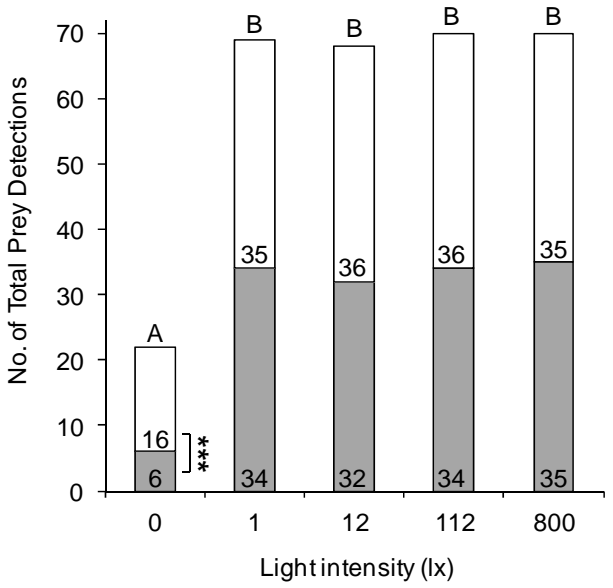

b

Tramitichromis

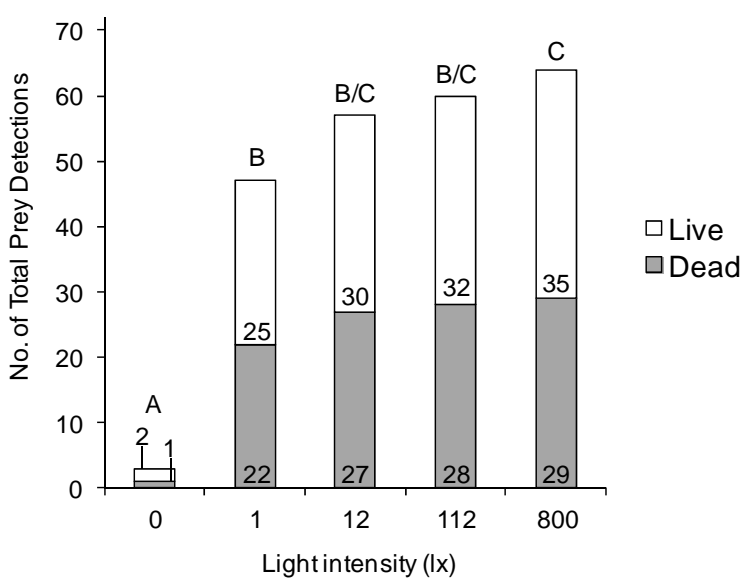

Figure 2. Total number of prey detections by prey type (live $=$ white bars and dead $=$ grey bars) for $\mathbf{a} A$. stuartgranti ( $n=6$ fish) and $\mathbf{b}$ Tramitichromis ( $n=6$ fish) at five light intensities. Letters above bars show statistically significant groupings (LSD, $P<$ $0.05)$ and combinations of letters $(\mathrm{B} / \mathrm{C})$ represent the lack of statistical differences from either $\mathrm{B}$ or $\mathrm{C}$. Asterisks indicates a significant difference between the number of prey detections on live vs. dead prey by $A$. stuartgranti at $01 x$ (LSD, $P<0.001$ ). See text for additional details. 
Aulonocara stuartgranti

a

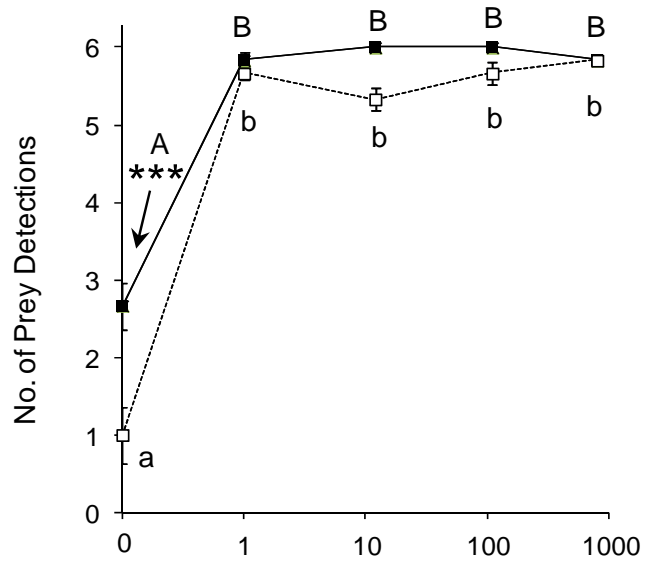

C

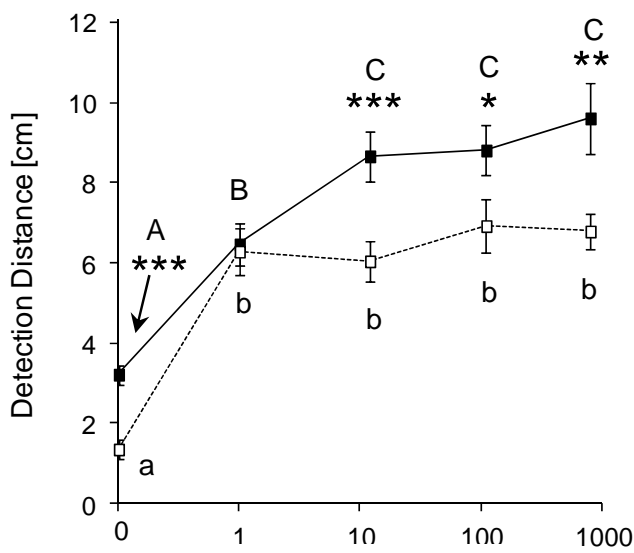

e

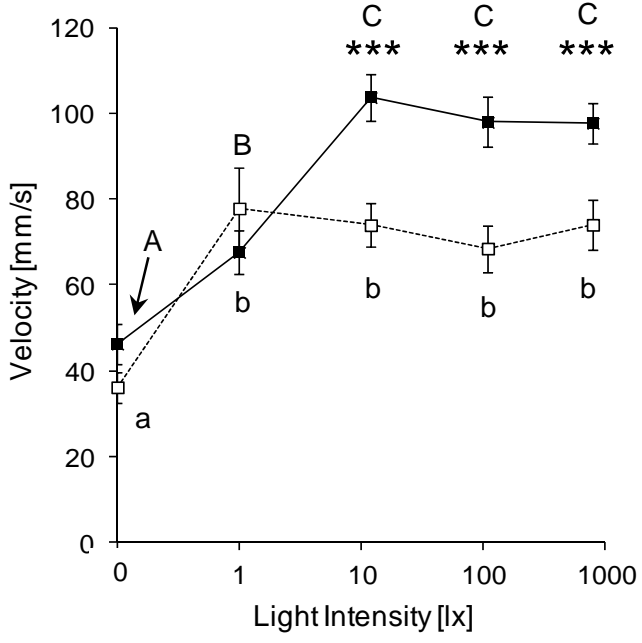

Tramitichromis
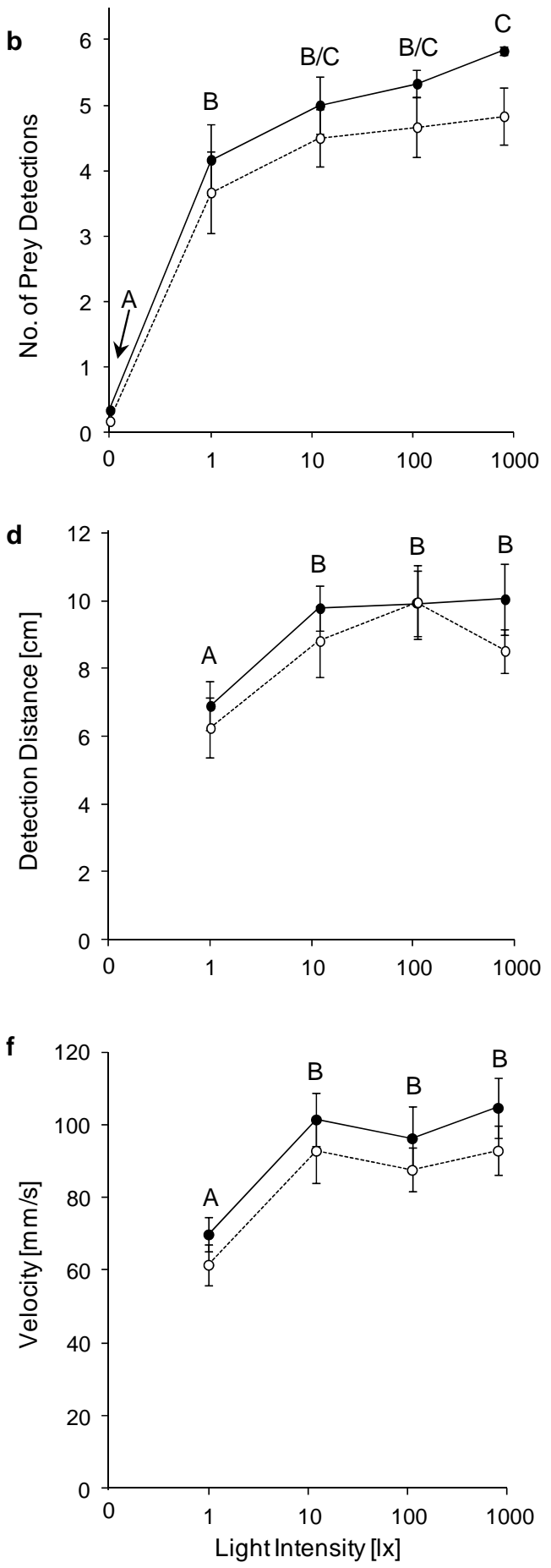

Figure 3. Three parameters defining prey detection behavior in A. stuartgranti $(n=6$ fish) and Tramiticrhomis ( $n=6$ fish) on six live and six dead prey at five light intensities. (a, c, e) Mean ( \pm s.e.m.) number of prey detections, detection distance, and detection-to-strike velocity for A. stuartgranti feeding on live $(\rightarrow-)$ and dead $(---\square--$ 
) prey and $(\mathbf{b}, \mathbf{d}, \mathbf{f})$ Tramitichromis feeding on live $(-\bullet)$ and dead ( $\cdots-\cdots-\cdots)$ prey. Results for detection distance and detection-to-strike velocity for Tramitichromis at 0 lx was not included due to a small sample size ( $n=3$ strikes). Letters above bars show statistically significant groupings $(\mathrm{LSD}, P<0.05)$ and combinations of letters $(\mathrm{B} / \mathrm{C})$ represent the lack of statistical differences from either B or C. For A. stuartgranti, capital letters represent differences among light intensity for live prey, whereas lowercase letters represent differences among light intensities for dead prey. No differences were observed between prey types in Tramitichromis (LSD, $P>0.05$ ), so capital letters represent results for live and dead prey combined. Asterisks indicate differences between live and dead prey in A. stuartgranti (LSD, * $P<0.05$, ** $P<$ $0.01, * * * P<0.001)$. See text for additional details. 
a

Aulonocara stuartgranti

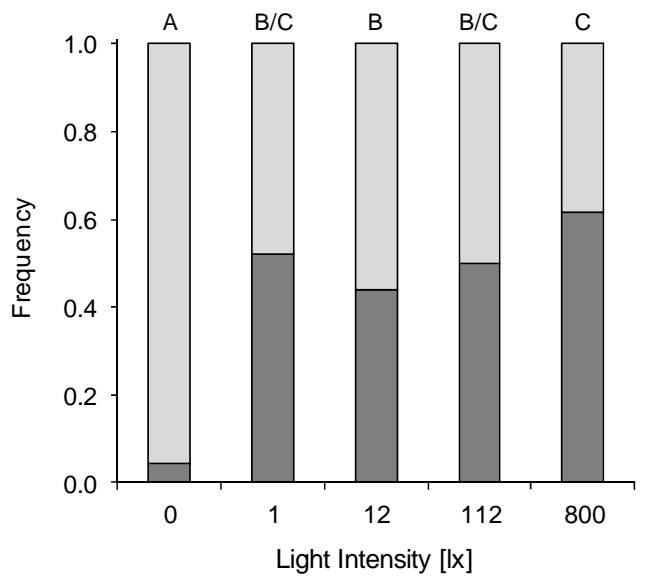

b

Tramitichromis

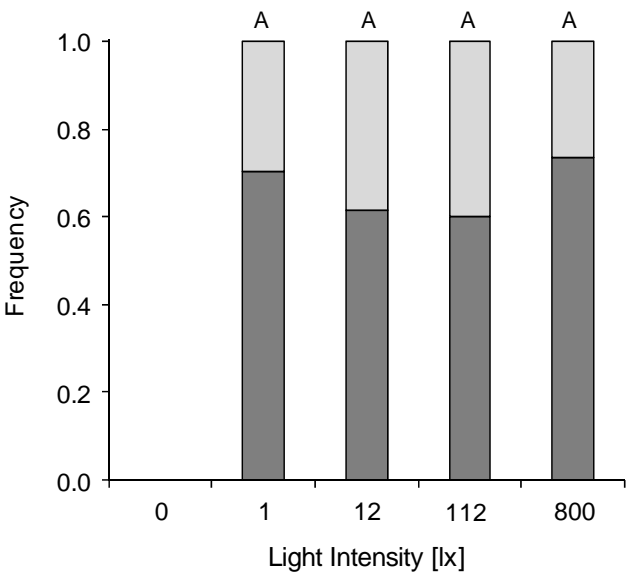

口Glide

aPause

Figure 4. Frequency of prey strikes (live and dead prey combined, 12 total prey/trial) during glide and pause phases of swimming at five light intensities in a Aulonocara stuartgranti ( $n=6$ fish) and b Tramitichromis ( $n=6$ fish). Letters above bars show statistically significant groupings (LSD, $P<0.05)$ and combinations of letters $(B / C)$ represent the lack of statistical differences from either $\mathrm{B}$ or $\mathrm{C}$. 
a

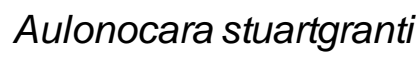

0 lx

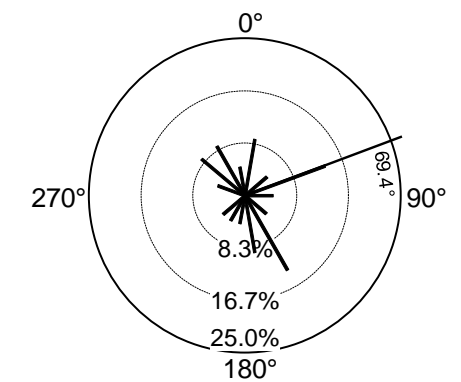

1 IX

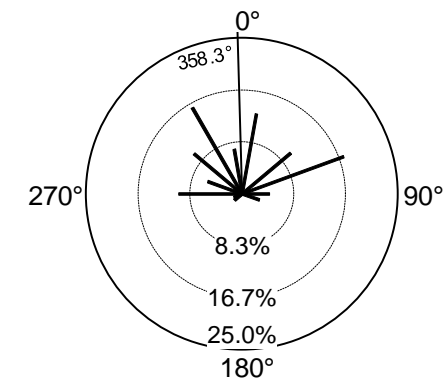

12 Ix

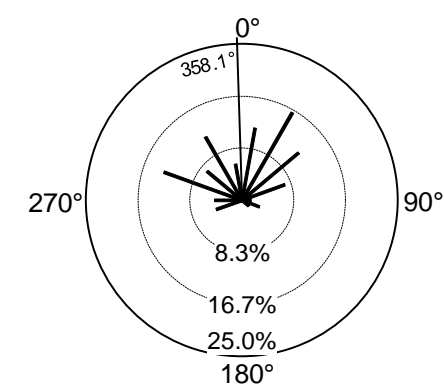

112 Ix
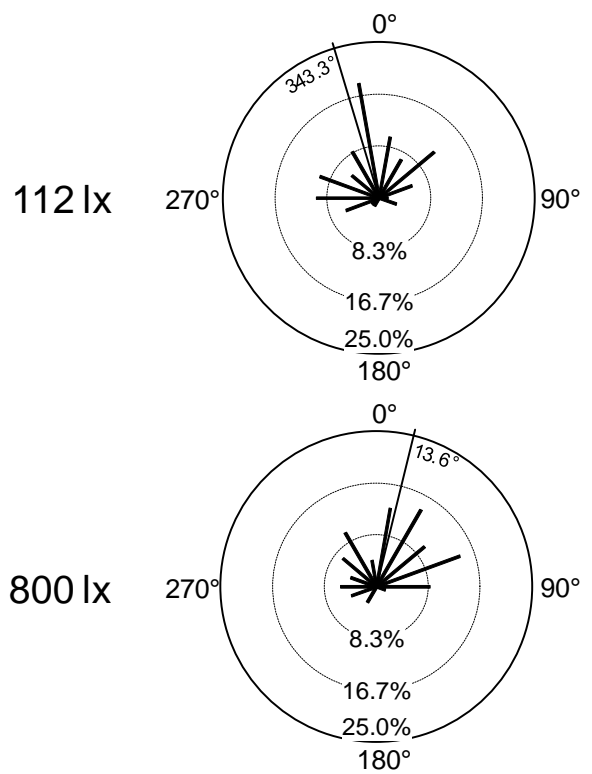

b Tramitichromis
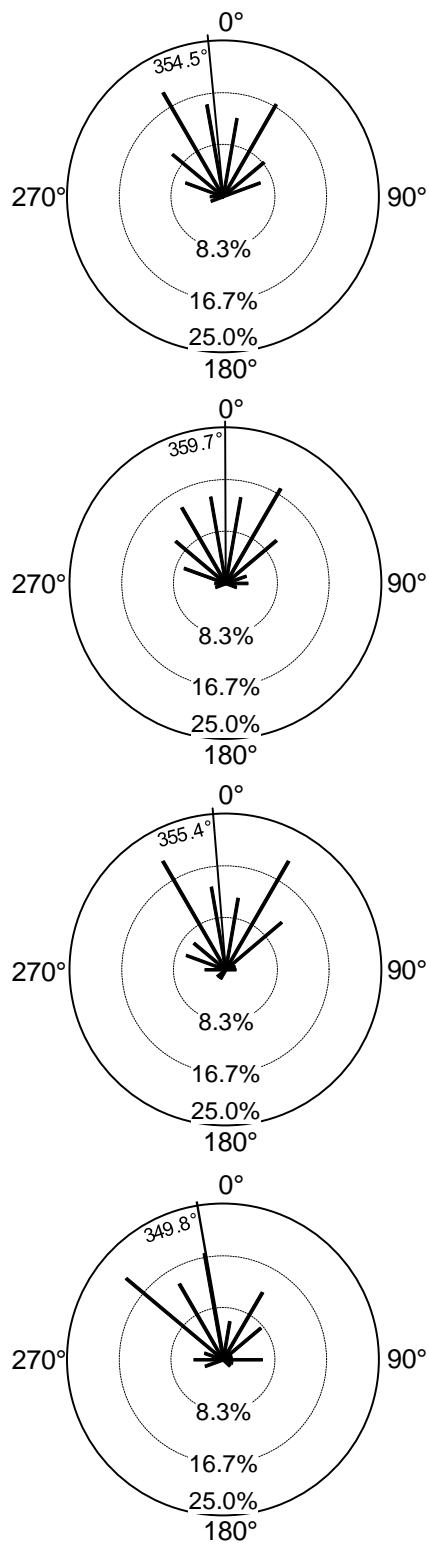

Figure 5. Detection angle for live and dead prey combined (=12 total prey/trial) at five light intensities for $\mathbf{a}$ A. stuartgranti ( $n=6$ fish) and $\mathbf{b}$ Tramitichromis $(n=6$ 
fish). Black lines represent the proportion of the number of detections of prey grouped into $20^{\circ}$ intervals. The thin line represents the mean angle for all trials. Fish snout is at the center and fish is facing $0^{\circ}$. All fish detected prey non-uniformly around their head and body (Rayleigh test, $P<0.001$ ), except for $A$. stuartgranti at $0 \mathrm{~lx}$ (Rayleigh test, $P$ $>0.05$ ). Results for Tramitichromis at $0 \mathrm{~lx}$ were not included because of the small number of strikes $(n=3)$ that occurred. See text for additional statistical details. 

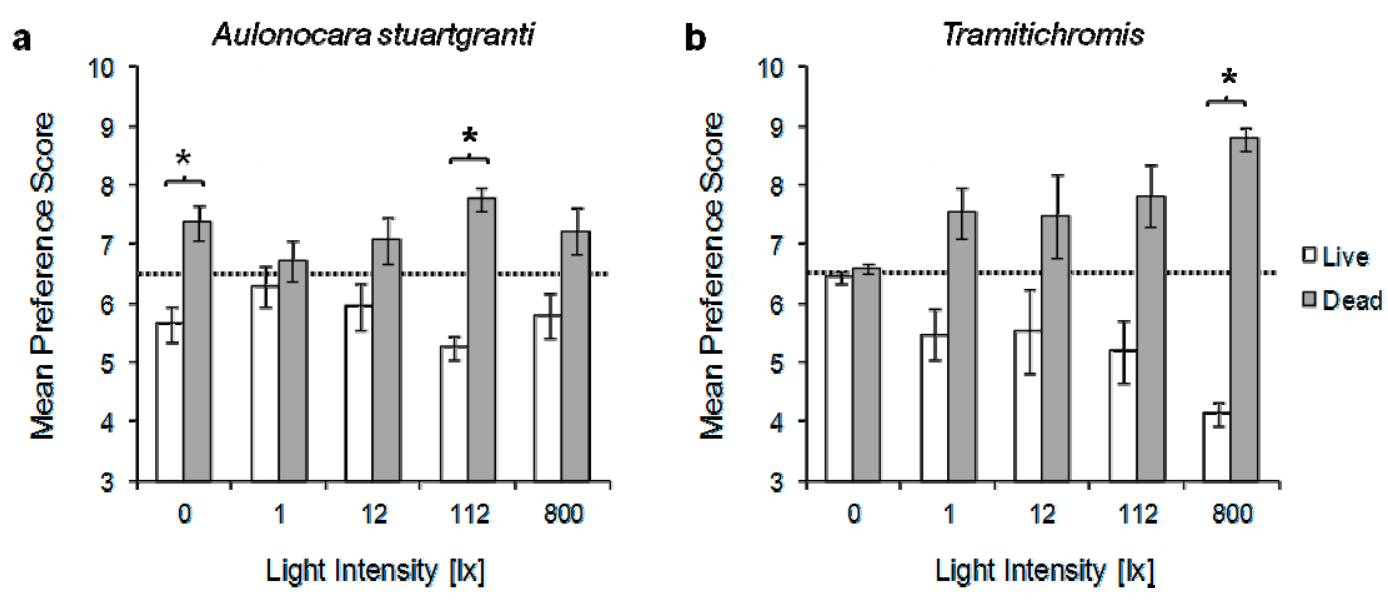

Figure 6. Mean ( \pm s.e.m.) prey preference scores (following Taplin 2007) for a $A$. stuartgranti ( $n=6$ fish) and $\mathbf{b}$ Tramitichromis ( $n=6$ fish) feeding on six live (white bars) and six dead (gray bars) tethered adult brine shrimp in each trial, for trials at five light intensities. Preferences scores were calculated by taking the mean of the rank order in which prey were captured. The dotted line indicates the mean preference score with no preference for either prey type $(=6.5$ ). Scores less than 6.5 (below dotted line) indicate a preference, and significant differences (paired $t$-test, $P<0.05$ ) in preference scores for live vs. dead prey are indicated by an asterisk $(*)$. Both $A$. stuartgranti and Tramitichromis tended to show preferences for live prey at all light intensities, with the exception of A. stuartgranti at $1 \mathrm{~lx}$ and Tramitichromis at $0 \mathrm{~lx}$. 


\section{References}

Ali MA (1959) The ocular structure, retinomotor and photobehavioral responses of juvenile pacific salmon. Can J Zoology 37:965-996

Atema J (1971) Structures and functions of the sense of taste in the catfish (Ictalurus natalis). Brain Behav Evolut 4:273-294

Batty RS, Blaxter JHS, Libby DA (1986) Herring (Clupea harengus) filter-feeding in the dark. Mar Biol 91:371-375

Bergstrom MA and Mensinger AF (2009) Interspecific resource competition between the invasive round goby and three native species: logperch, slimy sculpin, and spoonhead sculpin. T Am Fish Soc 138:1009-1017

Blanco-Vives B, Aliago-Guerrero M, Cañavate JP, García-Mateos G, Martín-Robles AJ, Herrera-Pérez P, Muñoz-Cueto JA, Sánches-Vázquez FJ (2011) Metamorphosis induces a light-dependent switch in Senegalese sole (Solea senegalensis) from diurnal to nocturnal behavior. J Biol Rhythms 27:135-144

Collin SP (1989) Topographic organization of the ganglion cell layer and intraocular vascularization in the retinae of two reef teleosts. Vision Res 29:765-775

Collin SP, Shand J (2003) Retinal sampling and the visual field in fishes. In: Collin SP, Marshall NJ (eds) Sensory Processing in Aquatic Environments. Springer, New York, pp 139-169

Confer JL, Howick GL, Corzette MH, Kramer SL, Ftizgibbon S, Landesberg R (1978) Visual predation by planktivores. Oikos 31:27-37

Dalton BE, Cronin TW, Marshall NJ, Carleton KL (2010) The fish eye view: are cichlids conspicuous? J Exp Biol 213:2243-2255

Diehl S (1988) Foraging efficiency of three freshwater fishes: effects of structural complexity and light. Oikos 53:207-214

Dunbrack RL, Dill LM (1984) Three-dimensional prey reaction field of the juvenile coho salmon (Oncorhynchus kisutch). Can J Fish Aquat Sci 41:1176-1182

Durham SR, Dietl GP, Visaggi CC (2012) The mismeasure of behavior: a natural history revision of prey preference in the banded tulip snail. J Shellfish Res 31:101-109

Fryer G (1959) The trophic interrelationships and ecology of some littoral communities of Lake Nyasa with especial reference to the fishes, and a discussion of the evolution of a group of rock-frequenting Cichlidae. P Zool Soc Lond 132:153-281

Fryer G, Iles TD (1972) The cichlid fishes of the great lakes of Africa: their biology and evolution. Oliver and Boyd, Edinburgh

Guildford SJ, Bootsma HA, Taylor WD, Hecky RE (2007) High variability of phytoplankton photosynthesis in response to environmental forcing in oligotrophic Lake Malawi/Nyasa. J Great Lakes Res 33:170-185

Harden Jones, FR (1956) The behaviour of minnows in relation to light intensity. J Exp Biol 33:271-281

Henderson MA, Northcote TG (1985) Visual prey detection and foraging in sympatric cutthroat trout (Salmo clarki clarki) and dolly varden (Salvelinus malma). Can J Fish Aquat Sci 42:785-790 
Hofmann CM, O’Quin KE, Marhsall NJ, Cronin TW, Seehausen O, Carleton KL (2009) The eyes have it: regulatory and structural changes both underlie cichlid visual pigment diversity. PLOS Biol 7(12): e1000266

Holbrook SJ, Schmitt RJ (1984) Experimental analyses of patch selection by foraging black surfperch (Embiotoca jacksoni Agazzi). J Exp Mar Biol Ecol 79:39-64

Howick GL, O'Brien WJ (1983) Piscivorous feeding behavior of largemouth bass: experimental analysis. Can J Fish Aquat Sci 42:785-790

Janssen J (1997) Comparison of response distance to prey via the lateral line in the ruffe and yellow perch. J Fish Biol 51:921-930

Kirk JTO (2011) Light and photosynthesis in aquatic ecosystems, 3rd edn. Cambridge University Press, New York

Konings A (1990) Koning's Book of Cichlids and Other Fishes of Lake Malawi. TFH Publications Inc., Neptune City, New Jersey

Konings A (2007) Malawi Cichlids in Their Natural Habitat, 4th edn. Cichlid Press, El Paso, Texas

Laur DR, Ebeling AW (1983) Predator-prey relationships in surfperches. Env Biol Fish 8:217-229

Livingston ME (1987) Morphological and sensory specializations of five New Zealand flatfish species, in relation to feeding behaviour. J Fish Biol 31:775795

Lythgoe JN (1979) The ecology of vision. Clarendon Press, Oxford

McHenry MJ, Feitl KE, Strother JA, Van Trump WJ (2009). Larval zebrafish rapidly sense the water flow of a predator's strike. Biol Lett 5:477-479

McWilliam RA, Minchinton TE, Ayre DJ (2013) Despite prolonged association in closed populations, an intertidal predator does not prefer abundant local prey to novel prey. Biol J Linn Soc 108:812-820

Meuthen D, Rick IP, Thünken T, Baldauf SA (2012) Visual prey detection by nearinfrared cues in a fish. Naturwissenschaften 99:1063-1066

Miyazaki T, Iwami T, Meyer-Rochow VB (2011) The position of the retinal area centralis changes with age in Champsocephalus gunnari (Channichthyidae), a predatory fish from coastal Antarctic waters. Polar Biol 34:1117-1123

Montgomery JC, Diebel C, Halstead MBD, Downer J (1999) Olfactory search tracks in the Antarctic fish Trematomus bernacchii. Polar Bio 21:151-154

Parry JWL, Carleton KL, Spady T, Carboo A, Hunt DM, Bowmaker JK (2005) Mix and match color vision: tuning spectral sensitivity by differential opsin gene expression in Lake Malawi cichlids. Curr Biol 15:1734-1739

Parzefall J (1993) Behavioural ecology of cave-dwelling fishes, 2nd ed. In: T. Pitcher (ed) Behaviour of Teleost Fishes. Chapman \& Hall, London, pp. 573-608

Patterson G, Hecky RE, Fee EJ (2000) Effect of hydro- logical cycles on planktonic primary productivity in Lake Malawi/Niassa. Adv Ecol Res 31:421-430

Richmond HE, Hrabik TR, Mensinger AF (2004) Light intensity, prey detection and foraging mechanisms of age 0 year yellow perch. J Fish Biol 65:195-205

Rickel A, Genin A (2005) Twilight transitions in coral reef fish: the input of lightinduced changes in foraging behaviour. Anim Behav 70:133-144

Ryer CH, Olla BL (1999) Light-induced changes in the prey consumption and behavior of two juvenile planktivorous fish. Mar Ecol Prog Ser 181:41-51 
Sabbah S, Lamela Larai R, Gray SM, Hawryshyn CW (2010) Functional diversity in the color vision of cichlid fishes. BMB Biol 8:133

Sabbah S, Gray SM, Boss ES, Fraser JM, Zatha R, Hawryshyn CW (2011) The underwater photic environment of Cape Maclear, Lake Malawi: comparison between rock- and sand-botton habitats and implications for cichlid fish vision. J Exp Biol 214:487-500

Schmidt D, O’Brien WJ (1982) Planktivorous feeding ecology of arctic grayling (Thymallus arcticus). Can J Fish Aquat Sci 39:475-482

Schmitt R, Coyer JA (1982) The foraging ecology of sympatric marine fish in the genus Embiotoca (Embiotocidae): importance of foraging behavior in prey size selection. Oecologia 55:369-378

Schmitt R, Holbrook SJ (1984) Ontogeny of prey selection by black surfperch Embiotoca jacksoni (Pisces: Embiotocidae): the roles of fish morphology, foraging behavior, and patch selection. Mar Ecol-Prog Ser 63:6-12

Schmitz L, Wainwright PC (2011) Nocturnality constrains morphological and functional diversity in the eyes of reef fishes. BMC Evol Biol 11:338

Schwalbe MAB, Bassett DK, Webb JF (2012) Feeding in the dark: lateral-linemediated prey detection in the peacock cichlid Aulonocara stuartgranti. J Exp Biol. 215:2060-2071

Schwalbe MAB, Webb, JF (Accepted) Sensory basis for detection of benthic prey in two Lake Malawi cichlids. Zoology

Shcherbakov D, Knörzer A, Hilbig R, Haas U, Blum M (2012) Near-infrared orientation of Mozambique tilapia Oreochromis mossambicus. Zoology 115:233-238

Sivak JG (1978) The functional significance of the aphakic space of the fish eye. Can J Zool 56:513-516

Taplin RH (2007) Experimental design and analysis to investigate predator preferences for prey. J Mar Biol Ecol 344:116-122

Townsend CR, Risebrow AJ (1982) The influence of light level on the functional response of a zooplanktonivorous fish. Oecologia 53:293-295

Vinyard GL, O'Brien WJ (1976) Effects of light and turbidity on reaction distance of bluegill (Lepomis macrochirus). J Fish Res Board Can 33:2845-2849

Vogel JL, Beauchamp DA (1999) Effects of light, prey size, and turbidity on reaction distances of lake trout (Salvelinus namaycush) to salmonid prey. Can J Fish Aquat Sci 56:1293-1297

Warrant EJ (2004) Vision in the dimmest habitats on Earth. J Comp Physiol A 190:765-789

Webb JF (1989) Gross morphology and evolution of the mechanosensory lateral line system in teleost fishes. Brain Behav Evolut 33:34-53

Webb JF (2013) Morphological diversity, development, and evolution of the mechanosensory lateral line system. In: Coombs S, Bleckmann H (eds) The Lateral Line System. Springer-Verlag, New York 
CHAPTER 4

\title{
DETECTION OF ARTIFICIAL WATER FLOWS BY THE LATERAL LINE SYSTEM AS A CONDITIONED BEHAVIORAL RESPONSE IN THE PEACOCK CICHLID, AULONOCARA STUARTGRANTI
}

\author{
Margot A. B. Schwalbe, Benjamin Sevey, and Jacqueline F. Webb \\ Department of Biological Sciences, University of Rhode Island, \\ 120 Flagg Road, Kingston, RI 02881, USA \\ (*author for correspondence: email: mbergstrom@my.uri.edu) \\ Manuscript in preparation for Journal of Experimental Biology
}




\section{SUMMARY}

Artificially produced water flows are used as an alternative to complex, natural stimuli to establish behavioral roles of the lateral line system, including prey detection. A novel apparatus was developed to deliver water flows emanating from the substrate that mimic natural prey so the behavioral sensitivity of a fish that uses its widened cranial lateral line canals for prey detection could be determined. Peacock cichlids (Aulonocara stuartgranti) were trained to respond to two types of flows (Type I "pulse," Type II - "dampened"). Two experiments addressed the following questions:

1) How do differences in flow type and/or flow rate influence behavioral responses? 2) At what minimum flow rate will fish stop responding to the artificial stimulus? and 3) How does temporarily ablating the lateral line affect the behavioral response to flow and how does behavior recovery after treatment? Results demonstrated that $A$. stuartgranti detected both Type I and II at all flow rates presented $\left(1.9-38.0 \mathrm{~mL} \mathrm{~min}^{-}\right.$

$\left.{ }^{1}\right)$, therefore the behavioral threshold could not be determined. The temporary inactivation of the lateral line with cobalt chloride greatly reduced the ability of $A$. stuartgranti to detect flows, and behaviors returned to pretreatment levels within seven days. This is the first study in which an apparatus that emits artificial stimuli from the substrate was used to evaluate flow detection capabilities of a species that depend on its widened lateral line canals to locate benthic prey.

\section{KEYWORDS}

Mechanoreception, neuromast, particle image velocimetry, teleost, food reward 


\section{INTRODUCTION}

The mechanosensory lateral line system is found in all fishes and larval and adult aquatic amphibians and mediates critical behaviors, including prey detection, predator avoidance, schooling, rheotaxis, and obstacle avoidance (reviewed in Coombs and Montgomery, 1999; Webb, 2013). Using natural stimuli to learn about the roles of the lateral line system in behavior is ideal, especially when establishing its role in predator-prey interactions (Hoekstra and Janssen, 1986; Pohlmann et al., 2004; Palmer et al. 2005), but interpreting the complexity of natural stimuli can be challenging. As an alternative, artificially produced water flows have been used in a small number of teleost and elasmobranch fishes by using a vibrating sphere or dipole source (mottled sculpin, Cottus bairdi, Coombs and Janssen, 1990; goldfish, Carassius auratus and oscar, Astronotus ocellatus, Nauroth and Mogdans, 2009), a piston pump (zebrafish, Danio rerio, McHenry et al., 2009), surface waves (killifish, Aplocheilus lineatus, Bleckmann, 1980; African clawed toad, Xenopus laevis, Elepfandt, 1982), and water jets (C. bairdi, Janssen et al., 1990; round stingray, Urobatis halleri, bat ray, Myliobatis californica, and pelagic stingray, Pteroplatytrygon violacea, Jordan et al., 2009; X. laevis, Roberts et al., 2009). It is difficult to present a biologically relevant artificial stimulus that captures the complexity of stimuli generated by, for instance, the movements of free swimming prey or the filter feeding currents generated by stationary prey. Nevertheless, artificial water flows are controllable, repeatable, and quantifiable stimuli that are amenable to analysis. In addition, the use of artificial stimuli can allow a reliable and quantifiable assessment of the role of the lateral line 
system in the detection of water flows by temporarily inactivating the system using chemical or pharmacological agents (Claas et al., 1993; Coombs et al., 2001; Mogdans and Nauroth, 2011).

The lateral line system of teleost fishes consists of neuromast receptor organs that are contained in an evolutionarily conserved set of pored canals on the head and trunk (canal neuromasts) or that sit on the surface of the skin (superficial neuromasts). The diversity of this system is defined by morphological variation in neuromasts (e.g. neuromast size, shape, and length, hair cell density and orientation) and cranial lateral line canals (e.g. four canal patterns - narrow, widened, reduced, and narrow branched; Webb, 1989), which makes the analysis of its function and behavioral roles even more challenging. A small number of theoretical and experimental studies have investigated the morphological and functional differences between narrow (the most common morphology among teleosts) and widened canals (the least common morphology, Denton and Grey, 1988, 1989; Janssen, 1997, Schwalbe and Webb, accepted). Widened canals tend to be found in benthic fishes and/or fishes that live in hydrodynamically quiet or light-limited environments (Coombs et al., 1988; Janssen, 1997), and have been suggested to be an adaptation for prey detection (Schwalbe et al., 2012; reviewed in Webb, 2013). However, experimental studies remain lacking due to the limited distribution of widened canals among bony fishes and their inaccessibility for laboratory study.

Among the cichlids of the African Rift Lakes, Aulonocara (peacock cichlids) is one of a just a few genera with widened lateral line canals, and is also commercially available and easily maintained in the laboratory. Aulonocara has been described as 
having 'deep pits' (Fryer, 1959), 'an acoustic system on the enlarged suborbital bones which consists of swollen pit organs' (Meyer et al., 1987), 'enlarged cephalic pores' (Konings, 1990), or an 'enlarged lateral line system...visible externally as pits and grooves especially on the lower part of the head' (Konings, 2007). In addition, Aulonocara have been observed in the field to use an unusual feeding strategy in which they swim just above the substrate and strike directly at buried invertebrates and have thus been described as 'sonar feeders' (Konings, 2007). A recent study has demonstrated that $A$. stuartgranti uses this same prey search strategy in the laboratory, and detects water flows generated by tethered adult brine shrimp with its lateral line system (Schwalbe et al., 2012). However, the movements of live prey generate both hydrodynamic and visual stimuli, which confound the analysis of the relative roles of vision and the lateral line system in prey detection.

A new artificial stimulus delivery system (the "apparatus") was designed to present hydrodynamic stimuli without visual cues and to generate two different types of water flows that originate from the substrate, which are thus biologically relevant to benthic feeders, such as Aulonocara. In the absence of a non-conditioned response to these artificial water flows, it was necessary to design a protocol for training fish to respond to these flows. Experiments using trained fish addressed the following questions: 1) How do differences in flow type and/or flow rate influence behavioral responses to flow? 2) At what minimum flow rate will fish stop responding to the artificial stimulus? and 3) How does temporarily ablating the lateral line with cobalt chloride affect the behavioral response to flow and how does behavior recovery after treatment? 


\section{MATERIALS AND METHODS}

Adult Aulonocara stuartgranti (Meyer \& Riehl) were $\mathrm{F}_{2}$ 's of fish purchased from a commercial supplier (Bluegrass Aquatics, Louisville, KY) and were housed in small groups in $190 \mathrm{~L}$ aquaria with appropriate mechanical and biological filtration. During training and experiments, fish were maintained individually or in divided aquaria at 26 $\pm 1{ }^{\circ} \mathrm{C}$ and 1 ppt salinity (Cichlid Lake Salt, Seachem Laboratories, Inc., Madison, GA) with a 12:12 hr light:dark cycle. Fish were fed daily with cichlid pellets (New Life Spectrum Cichlid Formula; New Life International, Inc., Homestead, FL). If a brood was in the mouth of a female on a particular day, that fish were not used. Animal care and all experimental procedures followed an approved IACUC protocol.

\section{Apparatus Designed to Deliver Water Flows from the Substrate}

An artificial stimulus delivery system (the "apparatus") was designed to generate hydrodynamic stimuli that rise from the sand and mimic the sorts of water movements generated by benthic invertebrates, on which Aulonocara feeds. A peristaltic pump (Model 07551-00, Cole Parmer, Vernon Hills, IL, USA) was used to move water through a simple network of chemically inert tubing (internal diameter $=1 \mathrm{~cm}, \mathrm{HDPE}$ tubing, Cole Parmer, Vernon Hills, IL, USA). The tips of the tubing were inserted into each of six holes drilled into a sheet of Plexiglas $(61 \times 46 \times 1.3 \mathrm{~cm})$. Each of these six "active" holes fitted with tubing was paired with an "inactive" hole that was fitted with a small piece of isolated tubing ( $\sim 5 \mathrm{~cm}$ long) that was not connected to the pump. 
The active and inactive holes were always in the same relative positions (e.g. the active hole was to the left of the inactive hole) and this arrangement also replicated the positioning of the pairs of tethered live and dead prey presented to fish in previous studies (7 cm apart, Schwalbe et al., 2012; Schwalbe and Webb, accepted). The Plexiglas sheet (with network of tubing below it) was placed just above the bottom of a large experimental tank (375 L; Fig. 1A) covered with sand so that the openings of all of the holes were flush with the surface of the sand. Holes were plugged with silicone stoppers when not in use. Water was drawn from a bucket of tank water by the rotations of the pump head (Model 77250-62, Cole Parmer) and forced through the network of tubing beneath the Plexiglas sheet (Fig. 1 B). Tank water was used as a source of water to ensure the effect of olfactory cues from different water sources and the water was frequently changed to eliminate cues associated with variation in water temperature (e.g., tank water temperature $=26^{\circ} \mathrm{C}$, room temperature $=21^{\circ} \mathrm{C}$ ). A manual toggle switch turned the pump on and off and was equipped with a small light bulb that indicated when the pump was running. In order to reduce mechanical noise in the experimental tank, the pump was placed on a separate table next to the tank and the tubing that emerged from the pump was fed through a PVC pipe extending from the water surface to below the sand where it connected to the apparatus. An opaque divider was also positioned $\sim 20 \mathrm{~cm}$ away from the PCV pipe to separate it from the experimental arena over the apparatus and further reduce vibrations (Fig. 1). 


\section{Generation and Visualization of Two Types of Hydrodynamic Flows}

Two different types of flow were generated by the apparatus. A "pulsed" flow (Type I) was produced by the normal operation of the pump, when the tubing positioned around the pump head was cyclically compressed against the rollers as it was rotated by the peristaltic pump. A "dampened" flow (Type II) was created by reducing the magnitude of flow pulses with a dampener (Model 07596-20, Cole Parmer) placed inline after the pump (at position of "disconnect coupling" in Fig. 1A).

Flow rate (measured as $\mathrm{mL} \mathrm{min}^{-1}$ ) could be regulated by adjusting digital controls on the pump and was verified by measuring the volume of water that passed through the apparatus over a given amount of time. Mean flow velocities (in $\mathrm{mm} \mathrm{s}^{-1}$ ) generated by the apparatus were calculated using $\mathrm{V}=\mathrm{Q} / \mathrm{A}$, where $\mathrm{V}$ is water velocity,

$\mathrm{Q}$ is flow rate (set by the pump, $\mathrm{mL} \mathrm{min}^{-1}$ ), and internal cross-sectional area of tubing $\left(=31.67 \mathrm{~mm}^{2}\right)$. Several velocities (and thus pump flow rates) were selected based on the known range of water flows generated by invertebrates (e.g., foraging copepod: 2$6 \mathrm{~mm} \mathrm{~s}^{-1}$, van Duren and Videler, 2003; tethered krill: $\sim 50 \mathrm{~mm} \mathrm{~s}^{-1}$, Yen et al., 2003; swimming copepodid: $\sim 12 \mathrm{~mm} \mathrm{~s}^{-1}$, Catton et al., 2007; midge larvae in burrow: 14 $\mathrm{mm} \mathrm{s}^{-1}$; Morad et al., 2010; tethered brine shrimp: 2-7 $\mathrm{mm} \mathrm{s}^{-1}$, Schwalbe et al., 2012). The pump settings were identical and tubing diameter was the same for Type I and Type II flows so the calculated mean flow velocities were the same for both flows at each selected flow rate (Table 1).

Type I and Type II flows were visualized and quantified using digital particle image velocimetry (DPIV) revealing the hydrodynamic structure and peak flow velocity of the two flow types at five flow rates $\left(1.9-38.0 \mathrm{~mL} \mathrm{~min}^{-1}\right)$. The apparatus 
(Plexiglas sheet and tubing) was moved into a large tank $(150 \mathrm{~L})$ filled with water seeded with near neutrally buoyant, silver coated reflective particles $(12-14 \mu \mathrm{m}$ diameter; Potters Ind., Inc.) at a density of $0.1 \mathrm{~g} \mathrm{~L}^{-1}$. A light beam from a continuous 1000 mW krypton-ion laser (Spyder III Krypton, Wicked Lasers, Kowloon, Hong Kong) was focused into a $2 \mathrm{~mm}$ thick and $10 \mathrm{~cm}$ wide vertical sheet that illuminated the diameter of each hole. A high-speed, high-resolution (1024x512 pixels) Photron APX camera was positioned perpendicular to the laser sheet to record particle movement at 60 frames s$^{-1}$ while the peristaltic pump was running. Images were processed using $\mathrm{DaVis} 7.0$ software (LaVision) using sequential cross-correlation without pre-processing. An initial correlation window of $16 \times 16$ pixels was selected with multi-pass with decreasing smaller size to a final interrogation window of $12 \times 12$ pixels with $50 \%$ overlap.

\section{Training Fish to Respond to Artificial Water Flows}

Aulonocara stuartgranti did not show an unconditioned response to water flows generated by the apparatus (data not shown), so fish were individually trained to detect and respond to hydrodynamic stimuli generated by the apparatus using a food reward protocol. A four step training process was carried out with a total of five fish (total length [TL]=76-94 mm, 2 males, 3 females) each of which took 4-6 weeks to be successfully trained (Table 2). First, a fish in its home tank was trained to follow a plastic feeder wand (R2 Target Feeder Wand, R2 Fish School, Orlando, FL, USA) that dispensed a food reward (1 pellet per reward, cichlid pellets; New Life Spectrum Cichlid Formula) from a small slot at its tip. After following the wand $\geq 80 \%$ of the 
time, a fish progressed to the second step in which it was gently transferred to the experimental tank (with net and bucket) and rewarded with food after following the wand in the experimental tank. Once a fish followed the wand $\geq 80 \%$ of the time in the experimental tank, the wand was then used to position fish over an active hole in the apparatus with Type I flow at $28.5 \mathrm{~mL} \mathrm{~min}^{-1}$ (all other holes plugged). A food reward was presented after a fish held its position over the active hole for $\geq 3$ seconds. The active hole was randomly selected from among the six active holes and changed randomly after every three rewards (by moving the silicone plugs, while the fish remained in the tank) to reduce bias to a particular hole. In the fourth step, fish were expected to seek out the active hole with flow (Type I flow at $28.5 \mathrm{~mL} \mathrm{~min}^{-1}$ ), position its lower jaw over the hole (same behavior demonstrated when detecting live prey, Schwalbe et al., 2012), and stay over the hole (a "hover") for $\geq 3 \mathrm{sec}$, after which it received a food reward. The location of the active hole was randomly changed every three rewards or every 15 minutes (whichever came first). A fish often needed to repeat these last two training steps in the experimental tank until it demonstrated a response to a water flow $\geq 70 \%$ of the time.

Fish were trained five times per week until they demonstrated $\geq 70 \%$ successful responses to active holes, and then two to three times per week to maintain this behavior (with step four only). Fish became less interested in finding the active hole with flow upon satiation and it was determined that a maximum of twelve pellets per day allowed the fish to maintain high levels of motivation in the experimental tank. During training and experiments, one of two experimenters was visible to the fish through the window of the tank and movements were kept to a minimum. Over time, 
the fish appeared to only acknowledge the experimenter when receiving a food reward from the feeder wand. Two experiments followed upon the completion of the training protocol.

\section{Effect of Flow Type and Flow Rate on Flow Sensing Behavior}

In the first experiment, four trained fish (TL=76-94 mm, 2 males, 2 females) were run through a series of behavioral trials using Type II flows with decreasing flow rate (38.0, 19.0, 9.5, 4.8, and $1.9 \mathrm{~mL} \mathrm{~min}^{-1}$ with corresponding calculated flow velocities of $20,10,5,2.5$, and $1 \mathrm{~mm} \mathrm{~s}^{-1}$, respectively) and then the trial series was replicated. Then another series of trials (also with one replicate) was carried out using Type I flows two weeks later. Each fish participated in one trial per day, so up to four trials were carried out per day (using four different fish) and trials were carried out over a total of 56 days. Trials were completed in this stepwise manner to identify the behavioral thresholds for each flow type.

One flow rate and one flow type was used per trial. Each trial was composed of twelve rounds - nine rounds with flow emanating from the active hole and three rounds with diverted flow (pump disconnected from tubing at the "disconnect coupling," and flowing into a bucket; Fig. 1A), so that no flow emanated from the active hole. In both cases, the inactive hole was open, but flow was not present. By presenting fish with two open holes (active and inactive), visual cues that might bias the response to flows were eliminated. In each round in which flow emanated from the active hole, fish were expected to locate the flow coming from the open, active hole and ignore its paired open, inactive hole and fish were not expected to respond to 
either hole in the diverted flow rounds. If fish did respond to active holes in diverted flow rounds, they may have been responding to the location of the open hole (the hole on the left) and not to flow. In addition, acoustic noise from the running pump was present in the diverted flow rounds, but mechanical noise was greatly reduced. Since the tubing was disconnected from the Plexiglas sheet before the tubing entered the tank, vibrations from the pump that traveled through the tubing were minimized. However, vibrations by the pump may have been transmitted to the floor, but its platform could have absorbed some of these vibrations from the floor.

During each trial composed of twelve rounds, a fish had nine opportunities to find flow emitted from an active hole and an addition fifteen opportunities to demonstrate false positive responses (= responses to nine inactive holes during rounds with flow, three active holes with diverted flow, and three inactive holes with diverted flow). Thus, tests using two different flow types, each at five different flow rates, twelve rounds per trial, two trial replicates, and two hole types, a total of 480 responses per fish were possible among all trials $(=1,920$ total possible responses for all four fish).

The order of fish used and the choice of all active and inactive hole pairs were randomly selected before trials began on a given day. Silicone plugs were removed from the first active and inactive holes and then a fish was then gently moved into the experimental tank (via net and bucket) and acclimated for $\sim 5 \mathrm{~min}$. After the fish started to explore the tank (demonstrating normal behavior), the pump was turned on to start a round. A round with flow ended after the fish correctly identified the active hole, or after three minutes if the fish did not respond to the flow. Each diverted flow 
round lasted for three minutes. At the end of each round, the pump was shut off and the flow coming from the active hole was allowed to dissipate and/or the position of the active and inactive holes was changed (by manually plugging and unplugging holes). Food rewards were immediately given to a fish after it remained over an active hole with flow for $\geq 3 \mathrm{~s}$ and no food reward was given for responses to inactive holes in rounds with flow or to either active or inactive holes in diverted flow rounds (= any hole without flow).

Trials were recorded with two high definition video cameras (Sony, HDRCX550V, 30 frames per second) that were positioned to provide dorsal and lateral views of the experimental arena. Dorsal views allowed a description of swimming behavior throughout the tank and lateral views captured the fishes' behavior relative to the holes in the substrate. The light bulb attached to the pump's manual switch was within view of the dorsally positioned camera so that it recorded the bulb turning on and off, marking the beginning and end of each round. Behavioral responses to the active and inactive holes were defined (see Results) and scored based on information from both dorsal and lateral views. Video was analyzed in Adobe Premier Pro (CS5, Adobe Systems, San Jose, CA, USA).

Several general linear mixed models (GLMMs, SPSS, v.19, IBM, Armonk, NY, USA) were used to detect variation in responses towards active versus inactive holes in rounds with flow and active and inactive holes in rounds with diverted flow. Due to the categorical nature of this data, analyses designed for normally distributed data were not possible. Thus, GLMM analyses were run with either a binomial distribution (data points were for either a "response" or a "non-response") or a 
multinomial distribution (six possible responses, search without bite $=$ lowest rank, to hover with bite $=$ highest rank, see Results for description of each behavior and Table 3) with logit link functions. By doing so, these GLMM models predicted the probabilities of the possible outcomes for a categorically distributed dependent variable (e.g. number of responses or type of responses), given a set of independent variables (hole type, flow rate, and/or flow type). These models also account for repeated measures from the same individual.

Different GLMM models were used to test for the significance of one, two or three independent variables. First, one-way analyses were run to determine if the number and type of responses differed between active and inactive holes in rounds with flow and with diverted flow, for each flow rate, by flow type. This allowed a test of differences between hole types and thus positional bias. Next, two-way analyses were carried out to determine if decreasing the flow rate influenced the number and type of responses to active and inactive holes, in rounds with flow and with diverted flow, for each flow type. Then, a three-way analysis was performed to test if the number and type of responses varied between the active and inactive holes, in rounds with flow and with diverted flow, among all flow rates, and for both flow types. After examining the results from the GLMM tests, pairwise post-hoc comparisons (using least significant differences, LSD) were carried out to detect differences in the number of "responses" and "non-responses", for active versus inactive holes, in rounds with flow and with diverted flow, for each flow rate, and flow type. These post-hoc comparisons were not possible using the GLMM results for response type. Intraspecific comparisons of these variables were not completed due the low number 
of fishes used ( $N=4$ fish). Differences were considered to be significant at $P<0.05$ for all statistical tests. Values are given as mean $\pm \mathrm{SE}$ unless otherwise specified.

\section{Effect of Lateral Line Ablation on Flow Sensing Behavior}

The lateral line system can be temporarily inactivated using cobalt chloride $\left(\mathrm{CoCl}_{2}\right.$; Karlsen and Sand, 1987) and this treatment does not affect other sensory systems (olfaction: Yoshii and Kurihara, 1983; taste, Pohlmann et al., 2004; vision: Liao, 2006). This method has been successfully used in previous studies to determine that $A$. stuartgranti uses its lateral line system, especially in the dark, to detect live benthic invertebrate prey (Schwalbe et al., 2012). Here, five trained fish (same four fish used in the experiment described above, with the additional of one female, $\mathrm{TL}=89 \mathrm{~mm}$ ) were treated with $\mathrm{CoCl}_{2}$ to temporarily deactivate the lateral line system and the assess the recovery of flow sensing behavior. This experiment was carried out more than three months after the previous experiment, so fish required training 2-3 times per week to maintain the conditioned response to water flows (Step 4 only, Table 2).

All fish were run through daily trials identical to the experiment described above (e.g. nine rounds with flow and three rounds with diverted flow) except flow type and flow rate was kept constant throughout this experiment. Type I flow at 4.8 $\mathrm{mL} \min ^{-1}$ was used in all trials because it was the lowest flow rate that appeared to generate consistent behavioral responses in the previous experiment. First, each fish was run through a trial on each of the two days before treatment (Days -2 and -1 ) to establish a behavioral baseline. Next, fish were treated with $0.1 \mathrm{mM}$ cobalt (II) chloride heptahydrate (Sigma-Aldrich, St Louis, MO, USA) for three hours in a bucket 
of conditioned tap water (calcium $=60 \mathrm{mg} \mathrm{L}^{-1}$, Hach hardness test kit, Loveland, CO, USA; experimental and home tanks $=220-260 \mathrm{mg} \mathrm{Ca}^{++} \mathrm{L}^{-1}$; as in Schwalbe et al., 2012, Schwalbe and Webb, accepted) and a trial followed within two hours of the treatment. After that, trials were conducted daily until Day 11, and then on Days 14, 18 and 21 to document the recovery of flow sensing behavior. A total of 2,040 responses were possible since five fish were run through one trial per day that consisted of twelve rounds (=120 responses per day for hole types) over 17 days.

Generalized linear mixed models (GLMMs, SPSS) were performed to analyze the results of this experiment using the same approaches as in the previous experiment. The number of responses and type of behavioral responses were analyzed using GLMMs with binomial or multinomial distributions with logit link functions, respectively. One-way analyses were performed to determine if there was variation in number of responses between the active and inactive holes in rounds with flow and with diverted flow by day, and 2-way analyses tested for differences between active and inactive holes in rounds with flow and with diverted flow among all days (Day -2 to Day 21). Given the low number of responses to inactive holes in rounds with flow and to active and inactive holes in rounds with diverted flow (= no flow), the type of responses (See Results for description of each behavior and Table 3) were only analyzed for the active holes in rounds with flow to identify differences in behavior before and after $\mathrm{CoCl}_{2}$ treatment (Day-2 to Day 21).

In order to provide morphological confirmation of behavioral data, several additional adult $A$. stuartgranti $(N=7, \mathrm{TL}=75-108 \mathrm{~mm}$, all males) were treated with $\mathrm{CoCl}_{2}$ for three hours (as above) and were stained with a fluorescent mitochondrial 
stain, $63 \mu \mathrm{M}$ 4-DI-2-ASP (4-(4-Diethylaminostyryl)-1-methylpyridinium iodide, Sigma-Aldrich, St Louis, MO, USA) in tank water for five minutes, on Day 0 (immediately after treatment) or on Days 3,6, 7, or 9 post-treatment. As a control, one male fish $\left(\mathrm{TL}=114 \mathrm{~mm}\right.$ ) was placed in tank water for three hours (without $\mathrm{CoCl}_{2}$ ) and then stained with 4-DI-2-ASP (as above). Each fish was anesthetized with $0.33 \%$ buffered MS-222 (Ethyl 3-aminobenzoate methanesulfonate salt, Sigma-Aldrich, St Louis, MO, USA), dissected to visualize canal neuromasts, and then images of superficial and canal neuromasts on the lateral and ventral surfaces of the head were captured using a Nikon dissecting microscope (Model SMZ1500) equipped with epifluorescence (GFP-B, Ex 470/40) and Spot camera (Model 25.2 Mp Color Mosaic; Spot software v 5.0).

\section{RESULTS}

\section{DPIV Characterization of Type I and Type II Flows}

The Type I and II flows generated by the peristaltic pump (Fig. 2) were neither laminar nor uniform in structure, and both produced a mean peak velocity greater than the calculated mean flow velocities (Table 2). The DPIV analysis showed the two types of flow differed in hydrodynamic structure over time. The dampener used to generate the Type II flow slightly decreased the mean peak velocity at most experimental flow rates, but these velocities were not substantially less than the velocities in Type I flow. However, the pulses (=areas of periodic regions of higher velocity flow) observed of Type I flows appeared to form sooner (e.g. $0.25 \mathrm{~s}$ faster at 
$9.5 \mathrm{~mL} \mathrm{~min}^{-1}$ ), had slightly greater peak velocities in the center of the pulses, and took longer to dissipate than the pulses in Type II flows (Fig. 2). The range of flow velocities generated at the six different active holes in the apparatus appeared to be consistent among flow rates $\left(\mathrm{mL} \mathrm{min}^{-1}\right)$ for the two different flow types.

\section{Definition of Behavioral Responses to Flow}

Fish actively explored the tank and approached all 12 holes (open and plugged) in the apparatus during all trials. Fish demonstrated a range of behaviors when reacting to the open active (with flow) and inactive holes (no flow) and these were defined as either "responses" or "non-responses" based on how long they stayed over an open hole ("responses" $\geq 3$ s; "non-responses" $<3$ s; summarized in Table 3). "Responses" were assigned an additional rank based on three recognizable behaviors observed among all individuals and if fish bit at the tubing, which was an unconditioned response (= six ranks). For "responses," a "hover" response was labeled when fish remained stationary for $\geq 3$ seconds with its lower jaw directly over the hole. A "shift" response was recorded when a fish moved its lower jaw from side to side directly above the hole for $\geq 3$ seconds. A "search" response was noted when a fish repeatedly paused with its lower jaw just above the open hole, then swam away ( $>1$ body length), and quickly returned to the hole. Behaviors, from highest to lowest rank, were defined as follows: a hover response with at least one bite at the tubing, a hover response without bite, a shift response with at least one bite, a shift response without bite, a search response with at least one bite, and a search response without bite. "Nonresponses were defined as either a "check" when a fish briefly paused for $<3 \mathrm{~s}$ with its 
lower just positioned over the hole and then swam away or when a fish did not swim near an open hole, or swam over an open hole, but neither oriented towards the hole nor reduced swimming speed while approaching the hole.

\section{Effect of Flow Rate and Flow Type on Flow Sensing Behavior}

Fish responded to both Type I and Type II flows and variations were observed for each flow type in the number (Fig. 3) and type (Fig. 4) of responses to active and inactive holes with flow and with diverted flow (= no flow). While flow rate had little effect on the number of responses for either flow type, fish responded to the two flow types with different combinations of behaviors. Fish responded to the active holes with flow at all flow rates (including the lowest flow rate of $1.9 \mathrm{~mL} \mathrm{~min}^{-1}$ ), so the behavioral threshold for responses to Type I or Type II flows was not determined.

Few differences were observed in the behavioral responses to Type I and Type II flows. For instance, for Type II flows, variation was found in the number of responses and type of behavioral responses for active and inactive holes in rounds with flow and with diverted flow for each flow rate (GLMMs, Table 4). Overall, the number of responses to the active holes in rounds with flow was greater (69.2-89.2\%) than the number of responses to the inactive holes in rounds with flow and both the active and inactive holes in diverted flow rounds (all without flow, $<50 \%$, LSD, $P \leq 0.007$; Fig. 3B). As flow rate decreased, the number of responses to the active and inactive holes in rounds with flow and with diverted flow did not vary with flow rate (Table 5). The type of responses did not vary among flow rates for active and inactive 
holes (Table 5) and the majority of the types of responses to active holes with flow were the second highest rank (hover response; Fig. 4B).

For Type I flows, the number of responses to active and inactive holes during rounds with flow and with diverted flow varied among all flow rates (Table 4). In general, the number of responses to active holes with flow was greater (94.4-97.2\%) than the number of responses to the inactive holes in rounds with flow and active and inactive holes in diverted flow rounds (all without flow, $<42 \%$, LSD, $P \leq 0.007$; Fig. 3A). As flow rate decreased, the number of responses to any of the active and inactive holes with and without flow did not vary (Table 5). The types of responses did not vary among flow rates for active and inactive holes in any round (Table 5; Fig. 4A) and the majority of the types of responses to active holes with flow were the highest rank (hover responses with bites).

When comparing the results from Type II to Type I flows, the number of responses to active and inactive holes in rounds with flow and with diverted flow varied (GLMM, Table 6), with more responses to active holes with flow compared to the other three types of holes without flow, regardless of flow type or flow rate (LSD, $P<0.001)$. Interestingly, the number of responses to active and inactive holes in rounds with flow and with diverted flow for each flow rate were the same (GLMM, $F=0.301$, $P=0.989$; Table 7), but fish responded to more active holes with flow in trials with Type I flows than in trials with Type II flows (LSD, $P<0.001$ ). Further, the way fish responded to active holes with flow varied (GLMM, $F=27.455, P<0.001$; Table 7). Fish responded most frequently to Type I flows with the highest ranked response (hover response with bites), while hover responses (second highest rank) were more 
common in responses to Type II flows. However, this variation was not significant when comparing the two flow types with respect to flow rates (GLMM, $F=0.658$, $P=0.893$; Table 7).

\section{Effect of Lateral Line Ablation on Flow Sensing Behavior}

As in the previous experiment, fish actively explored the tank and investigated all of the active and inactive holes of the apparatus in rounds with flow and with diverted flow. Prior to treatment with cobalt chloride $\left(\mathrm{CoCl}_{2}\right.$; Days -2 and -1$)$, fish responded in the same way to active holes with flow as in the previously described experiment with Type I flow at $4.8 \mathrm{~mL} \mathrm{~min} \mathrm{~m}^{-1}$ (e.g. similar number and types of responses, Figs. $3 \mathrm{~A}, 4 \mathrm{~A}, 5,6)$. Immediately following $\mathrm{CoCl}_{2}$ treatment (Day 0 ), the number of responses to the active holes with flow was greatly reduced and was similar to the number of responses to the three hole types without flow before and after the recovery from $\mathrm{CoCl}_{2}$ treatment (GLMM, Table 8). After Day 1 post-treatment and each day thereafter, the number of responses to active holes with flow was greater than that for inactive holes in rounds with flow and for both active and inactive holes in rounds with diverted flow (Table 8). The number of responses to the active holes with flow was significantly lower on Days 0-2 compared to pretreatment (Days -2 and -1) and to the number of responses after Day 3 (GLMM, Table 9; LSD, $P<0.05$; Table 10). Interestingly, fish responded with different types of responses to the active holes with flow over time (Table 9). Fish performed more search and shift responses than hover responses (with and without bites) when identifying the active hole with flow on Days 0-6, which greatly contrasts the responses on Days 7 to 21 , where fish most commonly 
responded to the active holes with flow with the highest ranked responses (hover response with bites; Fig. 6).

Staining with 4-Di-2-ASP (a mitochondrial stain) revealed the sensory strip (where hair cells are located) of both canal and superficial neuromasts (Fig. 7A). A dramatic reduction in fluorescence was observed immediately following $\mathrm{CoCl}_{2}$ treatment (Day 0; Fig. 7B). On Day 3 post-treatment, superficial neuromasts appeared to fluoresce with the same intensity as those in control fish (no $\mathrm{CoCl}_{2}$ treatment; data not shown). On Days 3 and 6 post-treatment, fluorescence of hair cells in the sensory strip had partially returned with gaps between hair cells when compared to control fish (Fig. 7C, D). By Days 7 and 9, the intensity of fluorescence had returned to levels seen in control fish (Fig. 7E, F).

\section{DISCUSSION}

This study demonstrated for the first time that teleost fishes can be trained to respond to biologically relevant, artificial water flows coming from the substrate and can distinguish between flows with different hydrodynamic structures. Furthermore, it showed that an artificial water flow stimulus can be used to investigate the role of the lateral line system in feeding on benthic prey. The novel apparatus allowed the evaluation of the role of the lateral line system in the detection of a stimulus mimicking a benthic "prey" in the absence of visual and olfactory cues. Experiments using the apparatus also documented the time course of recovery of the lateral line system following treatment with cobalt chloride $\left(\mathrm{CoCl}_{2}\right)$ - behavioral changes were 
immediate and flow sensing behavior returned within a day after treatment, but the full return of the behavior to pretreatment levels were not observed until a week following treatment. Fluorescent staining of neuromasts provided a morphological confirmation of the effect of $\mathrm{CoCl}_{2}$ (absence of fluorescence where hair cells are located in the neuromasts) that was correlated with the return of flow sensing behavior.

\section{Using Artificial Stimuli as a Proxy for Natural Prey}

The responses of A. stuartgranti to the stimuli generated by the apparatus have shown that artificial stimuli can mimic biologically relevant cues and evoke natural responses from fish. Aulonocara stuartgranti demonstrated differences in behavioral responses when presented with two different flow types. While the number of responses was high for both Type I and II flows, fish hovered and bit at the tubing more frequently when presented with Type I flows than Type II flows. This suggests that Type I flow was particularly relevant to $A$. stuartgranti and likely mimicked their natural prey (benthic invertebrates; Koning, 2007), since it elicited strike responses (e.g. biting) while hovering over the active hole with flow. Similarly, mottled sculpins, Cottus bairdi, showed different unconditioned responses to a "pulsed flow" (generated by a syringe connected to a minishaker), while "laminar flow" (generated by gravity fed system) did not elicit the bite response (Janssen et al., 1990).

The role of the lateral line system in prey detection behavior in A. stuartgranti has been investigated in other studies that used live prey (tethered adult brine shrimp, Schwalbe et al., 2012; Schwalbe and Webb, accepted). The use of the apparatus in the current study allowed the elimination of the complex stimuli generated by the live, 
mobile prey in order to focus on the importance of hydrodynamic stimuli in prey detection behavior. The movement of live tethered brine shrimp generated water movement, as well as visual stimuli and additional spread of an odor plume, while no additional stimuli were generated by freshly dead tethered brine shrimp.

Determination of the roles of these different sensory systems was addressed by performing behavioral trials in the light and dark, and with or without a functional lateral line system (cobalt chloride $\left[\mathrm{CoCl}_{2}\right]$ ablation, same method as current study) that eliminated the contribution of vision and/or the lateral line system during prey detection in a stepwise manner. While olfaction was not eliminated during these experiments, $\mathrm{CoCl}_{2}$ treated fish did not strike at any prey in the dark indicating that olfactory cues were insufficient to trigger strikes on prey. The apparatus used in the current study was intended to minimize most sensory cues (e.g. visual, olfactory, thermal, mechanosensory noise generated by the running pump), except hydrodynamic stimuli. Tubing could be seen at the level of the sand, but there was no visual difference between the pair of active and inactive holes that was open in all rounds. Olfactory cues were reduced by pumping tank water through chemically inert tubing. The fish clearly responded to a range of flow rates and two flow types that were generated by the apparatus, thus indicating that hydrodynamic cues are critical for prey detection behavior in A. stuartgranti.

Fish explored all twelve of the holes in the apparatus (including unused plugged holes) by briefly "checking" the holes (pausing with their lower jaws positioned over a hole, $<3 \mathrm{~s}$ ), and they occasionally responded to some holes in the absence of flow. Fish may have been pausing longer over these holes attempting to 
detect flow, especially in the case of the "active" holes in rounds with diverted flow that were in the same position as holes with flow in other rounds. The position of active and inactive holes was consistent throughout these experiments (e.g. active holes were always on the left, inactive holes were always on the right), so fish may have learned to check the holes on the left more frequently than those on the right. This positional bias may have contributed to the greater number of responses to "active" holes in rounds with diverted flow than to inactive holes in rounds with flow and with diverted flow. It is unlikely that fish responded to the acoustic noise and/or mechanical vibrations generated by the pump because it was running in all trials. The number of responses to "active" holes in rounds with diverted flow was always significantly lower than to active holes with flow (Fig. 3).

Most studies using artificial stimuli did not have to train fish to respond to the mechanically generated water flow because artificial stimuli evoked unconditioned lateral line-mediated behaviors. For example, the mottled sculpin, C. bairdi, has an orienting response to free swimming prey (Hoekstra and Janssen, 1985) that could be elicited by stimulation with a dipole source generated by a vibrating sphere (Coombs and Janssen, 1990). The killifish (or striped panchax), Aplocheilus lineatus, can discriminate surface waves generated by struggling terrestrial invertebrates at the water surface, which was determined by using oscillating a probe to generate various wave frequencies (Bleckmann et al., 1981). Aulonocara stuartgranti uses a unique feeding strategy in which they swim just above the substrate and detect flows generated by invertebrates buried in the sand (in the field, Koning, 2007, and laboratory, Schwalbe et al., 2012), but they did not demonstrate an unconditioned 
response to the artificial water flows generated by the apparatus used in the current study and thus required training. Once the training protocol began, fish quickly responded to the feeding wand, although it took some time for them to associate the hydrodynamic flow with a food reward ( $\sim 1$ month). Upon the completion of training, fish repeatedly responded to the artificial water flows at rates similar to that of fish responding (unconditioned or conditioned) to other artificial stimuli $(\sim 70-100 \%$, Coombs et al., 2001; 32-60\%, Jordan et al., 2009; 68\%, McHenry et al., 2009; 80\%, Mogdans and Nauroth, 2011).

\section{Flow sensing in Aulonocara stuartgranti}

The water flow stimuli generated by the apparatus effectively demonstrated that $A$. stuartgranti is sensitive to flows that have different hydrodynamic structure and have velocities as low as $\sim 1 \mathrm{~mm} \mathrm{~s}^{-1}$. This is slower than flows generated by copepods and copepodids (van Duren and Videler, 2003; Catton et al., 2007), tethered krill (Yen et al., 2003), midge larvae in burrows (Morad et al., 2010), and tethered brine shrimp (Schwalbe et al., 2012). Aulonocara stuartgranti likely detect natural and artificial flows coming from the substrate using canal neuromasts located within its ventrally directed mandibular, lower preopercular and perhaps infraorbital canals, as well as the superficial neuromasts found in clusters on the surface of the lower jaw (current study, Schwalbe et al. 2012, Becker, 2013). The functional properties of the widened lateral line canals are predicted to mediate the ability to detect such flows. Widened canals are characterized by weak ossification of the canal roof, large pores, and large canal neuromasts (Webb, 1989) and the epithelium covering the canals may behave as a 
tympanum to enhance sensitivity of lower frequencies (Denton and Gray, 1988, 1989; Coombs et al., 1992).

The investigation of intraspecific differences in feeding behavior between male and female A. stuartgranti warrants further experiments because sexual dimorphism is common in African cichlids (reviewed in Kocher, 2004). While there have not been any reports of differences between adult males and females with reference to lateral line canal morphology in any species (e.g. differences in internal canal diameter, neuromast size, etc.), variation may indeed occur between male and female cichlids with widened canals. Jaw shapes do vary between males and females of the same species and adaptations to female mouthbrooding are thought to contribute to deviations between the sexes (Oliveira and Almada, 1995; Herler et al., 2010), which may be correlated with variation in prey capture success. Further, male and female cichlids have contrasting reproductive priorities observed in the field (e.g. males defend territories and females mouthbrood), and this may influence feeding strategies.

Aulonocara stuartgranti was able to detect flows at all flow rates presented during experiments, so behavioral thresholds could not be determined. Fish were trained at a flow rate that was intermediate between the highest and lowest flow rates used in the experiment. Experiments were then conducted using flow rates from highest to lowest to attempt to identify the behavioral threshold for flow detection, which could not be determined. The apparatus could be altered by increasing or decreasing tubing diameter to alter flow velocities while maintaining the same flow rate $\left(\mathrm{mL} \mathrm{min}^{-1}\right)$, but the mechanical properties of the peristaltic pump may limit the amount of water that is forced through the apparatus. The number of pulses generated 
by the pump was proportional to the number of rotations completed by the pump head and pulse cycles were longer at lower flow rates. The use of a different type of pump could generate flows $<1.0 \mathrm{~mm} \mathrm{~s}^{-1}$ that would allow the identification of behavioral thresholds by $A$. stuartgranti.

Aulonocara stuartgranti consistently responded to both flow types with different types of responses, despite the fact that substantial variations were not observed in the DPIV analyses (e.g. hydrodynamic structure and mean peak velocities). The DPIV results indicated that the dampener had only a small effect on the structure and mean peak velocity in Type II flow compared to that of Type I flow. Yet, these subtle differences, or some other component not captured by the DPIV analysis, were distinguishable by the fish as illustrated by differences in their behavior when responding to the two types of flow.

\section{Behavioral and Morphological Recovery Following Lateral Line Ablation}

The correlated results from behavioral trials and fluorescent staining following treatment with $\mathrm{CoCl}_{2}$ provide further support that the effects of $\mathrm{CoCl}_{2}$ are reversible (Karlsen and Sand, 1987) and that recovery likely result from hair cell regeneration. Fish responded to flows a day after treatment and fluorescence returned in smaller superficial neuromasts within three days following $\mathrm{CoCl}_{2}$ treatment (current study, Becker, 2013). However, neither behavior nor staining of larger canal neuromasts (which have many more hair cells) was restored to pretreatment levels by seven days post-treatment. 
The variation in behavioral responses in $\mathrm{CoCl}_{2}$ treated fish during recovery may be explained by different recovery rates of superficial (=velocimeters) and canal neuromasts (=accelerometers, Coombs et al., 2001), as indicated by the increase of fluorescence staining during the recovery period. Superficial and canal neuromasts in A. stuartgranti have different morphologies and functional roles, and recover from $\mathrm{CoCl}_{2}$ treatment at different rates (superficial neuromasts $\leq 3$ days, canal neuromasts $\leq$ 7 days; current study, Becker, 2013). The types of behavioral responses to the active holes with flow changed over the course of the experiment - the majority of responses to the active holes with flow on Days -2 and -1 were hover responses with bites (= highest ranked response), followed lower ranked responses (more search responses with bites and shift responses with and without bites) on Days 0-6, and hover responses with bites became the most frequent response on Day $7+$. Since fish were trained to respond to flow, they likely responded to the active holes with flow regardless if the flow was detected by superficial and/or canal neuromasts. If superficial neuromasts became active within a day following treatment (as seen in the fluorescent staining), the search and shifting behaviors may have improved the fishes' ability to detect flow by moving its lower jaw from side to side, and thus exposing more re-activated superficial neuromasts to the flow. Once the canal neuromasts had recovered, the shift behavior was not as frequently performed. Thus, the behavioral responses observed during the first few days after $\mathrm{CoCl}_{2}$ treatment may have been due to the detection of flow by superficial neuromasts, and not the combination of canal and superficial neuromasts, which likely occurred before and after the recovery of treatment (and normal prey detection behaviors). 


\section{Conclusion}

The use of the novel apparatus in this study demonstrated that fish can be trained to detect flows emanating from the substrate. This system provides biologically relevant, hydrodynamic stimuli to benthic feeders without visual and olfactory cues. In addition, this system could be used to investigate the behavioral sensitivity of flows emanating from the substrate in other benthic feedering teleosts, including Ericymba buccata, a minnow with widened canals that feed from the benthos (Hoyt, 1970); flatfishes, already known for morphological and sensory specializations used in prey detection (Livingston, 1987); and Eurasian ruffe, Gymnocephalus cerunus, a percid with widened canals (Janssen, 1997). A comparison of the sensitivity and nature of behavioral responses to the apparatus among fishes with widened canals would provide more insight on the functional significance of this interesting and unique lateral line phenotype.

\section{ACKNOWLEDGEMENTS}

We thank Kevin Borsay for designing and Adam Arrighi for constructing and testing the artificial stimulus delivery system, Brett Bergstrom for constructing the manual switch for the peristaltic pump, Dr. Cheryl Wilga for her expertise with DPIV and for allowing us to use her equipment, and Edward Baker (Facilities Manager, RI NSF EPSCoR Marine Life Science Facility), Emily Becker, Christopher Holland, and Rebecca Scott for their assistance in fish husbandry. This research was funded by the 
National Science Foundation (NSF) grant IOS 0843307 to JFW, the University of

Rhode Island College of the Environment and Life Sciences, and by NSF EPSCoR Cooperative Agreement EPS-1004057. 
Table 1. Flow rates ( $\mathrm{mL} \mathrm{min}^{-1}$, pump setting) generated by the peristaltic pump, velocities calculated and also visualized with DPIV, and mean peak velocity \pm SE) coming from six different active holes in the apparatus. DPIV revealed that flows generated by the pump did not demonstrate uniform velocities (as predicted by calculations), especially as flow rates increased, due to the generation of regions of high velocity (pulses) for flow types I and II. See text for additional details.

\begin{tabular}{lccc}
\hline & & \multicolumn{2}{c}{ Peak Velocity } \\
\cline { 3 - 4 } $\begin{array}{l}\text { Flow Rate } \\
\left(\mathbf{m L ~ m i n}^{-1}\right)\end{array}$ & $\begin{array}{c}\text { Calculated Velocity } \\
\left(\mathbf{m m ~ s}^{-\mathbf{1}}\right)\end{array}$ & $\begin{array}{c}\text { Type I } \\
\left(\mathbf{m m ~ s}^{-1}\right)\end{array}$ & $\begin{array}{c}\text { Type II } \\
\left(\mathbf{m m ~ s}^{-\mathbf{1}}\right)\end{array}$ \\
\hline 1.9 & 1.0 & $1.17 \pm 0.05$ & $0.87 \pm 0.04$ \\
4.8 & 2.5 & $3.6 \pm 1.7$ & $2.7 \pm 0.3$ \\
9.5 & 5.0 & $9.0 \pm 0.6$ & $6.3 \pm 0.7$ \\
19.0 & 10.0 & $20.6 \pm 1.0$ & $19.4 \pm 1.1$ \\
38.0 & 20.0 & $44.95 \pm 2.0$ & $47.1 \pm 2.0$ \\
\hline
\end{tabular}


Table 2. Positive reinforcement training protocol used to condition five $A$. stuartgranti to flows coming from the apparatus.

\begin{tabular}{lcl}
$\begin{array}{l}\text { Training } \\
\text { Phase }\end{array}$ & $\begin{array}{c}\text { Length } \\
\text { (days) }\end{array}$ & \multicolumn{1}{c}{ Description } \\
\hline Step 1 & $2-3$ & $\begin{array}{l}\text { Fish learns to accept food from wand, follows wand in } \\
\text { home tank. }\end{array}$ \\
\hline Step 2 & $2-4$ & $\begin{array}{l}\text { Fish acclimates to transportation between home and } \\
\text { experimental tank, accepts food from wand, follows wand } \\
\text { in experimental tank. }\end{array}$ \\
\hline Step 3 & $5-7$ & $\begin{array}{l}\text { Fish positioned over an active hole with flow using the } \\
\text { wand in experimental tank, fish received food from wand } \\
\text { after remaining over the hole for } \geq 3 \text { s. }\end{array}$ \\
\hline Step 4 & $\begin{array}{l}\text { Fish rewarded with food from wand after it correctly seeks } \\
\text { out and identifies the active hole with flow by remaining } \\
\text { over the hole for } \geq 3 \mathrm{~s} .\end{array}$ \\
\hline
\end{tabular}


Table 3. Definitions of behavioral responses and non-responses displayed by A. stuartgranti ( $N=5$ fish) to open holes (active and inactive, in flow and diverted flow rounds) from highest to lowest rank. See additional details in text.

\begin{tabular}{lll}
\hline \multirow{2}{*}{ Type } & \multicolumn{1}{l}{ Category } & \\
\hline & Hover + Bite & Fish paused with lower jaw over open hole, remained stationary, bit at hole \\
\cline { 2 - 3 } \begin{tabular}{ll} 
Responses \\
\multirow{2}{*}{\begin{tabular}{l} 
Hover $)$ \\
\cline { 2 - 3 }
\end{tabular}}
\end{tabular} & Shift + Bite & Fish paused over open hole, moved its lower jaw from side to side, bit at hole \\
\cline { 2 - 3 } & Shift & Fish paused over open hole, moved its lower jaw from side to side \\
\cline { 2 - 3 } & Search + Bite & Fish repeatedly paused over, swam away from, and quickly returned to open hole, bit at hole \\
\hline $\begin{array}{l}\text { Non-Responses } \\
(<3 \mathrm{~s})\end{array}$ & Check & Fish repeatedly paused over, swam away from, and quickly returned to open hole \\
\cline { 2 - 3 } & No response & Fish did not go near, orient towards, or reduce its swimming speed when close to open hole \\
\hline
\end{tabular}


Table 4. Comparison of number of behavioral responses and types of responses by $A$. stuartgranti ( $N=4$ fish) to four hole types (active and inactive in rounds with flow and "active" and inactive in rounds with diverted flow) at each flow rate, for Types I and II flow. One -way GLMM analyses, $P \leq 0.05$.

\begin{tabular}{|c|c|c|c|}
\hline \multicolumn{4}{|l|}{ Type I } \\
\hline Flow Rate (mL $\left.\min ^{-1}\right)$ & $\mathbf{F}$ & d.f. & $\mathbf{P}$ \\
\hline \multicolumn{4}{|l|}{ Number of Responses } \\
\hline 1.9 & 21.728 & 3,188 & $<0.001$ \\
\hline 4.8 & 22.018 & 3,188 & $<0.001$ \\
\hline 9.5 & 22.582 & 3,188 & $<0.001$ \\
\hline 19.0 & 13.657 & 3,188 & $<0.001$ \\
\hline 38.0 & 19.468 & 3,188 & $<0.001$ \\
\hline \multicolumn{4}{|l|}{ Types of Responses } \\
\hline 1.9 & 2.630 & 15,172 & 0.001 \\
\hline 4.8 & 3.840 & 15,172 & $<0.001$ \\
\hline 9.5 & 1.788 & 15,172 & 0.040 \\
\hline 19.0 & 2.320 & 12,176 & 0.009 \\
\hline 38.0 & 2.738 & 18,168 & $<0.001$ \\
\hline \multicolumn{4}{|l|}{ Type II } \\
\hline Flow Rate (mL min-1) & $\mathbf{F}$ & d.f. & $\mathbf{P}$ \\
\hline \multicolumn{4}{|l|}{ Number of Responses } \\
\hline 1.9 & 15.423 & 3,188 & $<0.001$ \\
\hline 4.8 & 21.382 & 3,188 & $<0.001$ \\
\hline 9.5 & 19.637 & 3,188 & $<0.001$ \\
\hline 19.0 & 15.637 & 3,188 & $<0.001$ \\
\hline 38.0 & 10.103 & 3,140 & $<0.001$ \\
\hline \multicolumn{4}{|l|}{ Types of Responses } \\
\hline 1.9 & 2.139 & 18,168 & 0.007 \\
\hline 4.8 & 3.679 & 18,168 & $<0.001$ \\
\hline 9.5 & 1.851 & 18,168 & 0.023 \\
\hline 19.0 & 2.176 & 18,168 & 0.006 \\
\hline 38.0 & 3.980 & 9,132 & $<0.001$ \\
\hline
\end{tabular}


Table 5. Comparison of number of behavioral responses and type of responses by $A$. stuartgranti ( $N=4$ fish) to four hole types (active and inactive in rounds with flow and "active" and inactive in rounds with diverted flow) among flow rates, for Types I and II flow. Two-way GLMM analyses, $P \leq 0.05$.

\begin{tabular}{lccc}
\hline $\begin{array}{l}\text { Type I } \\
\text { Source }\end{array}$ & F & d.f. & P \\
\hline $\begin{array}{l}\text { Number of Responses } \\
\quad \text { Flow Rate }\end{array}$ & 1.524 & 4,874 & 0.193 \\
$\quad$ Hole Type & 67.813 & 3,874 & $<0.001$ \\
$\quad$ Flow Rate $\times$ Hole Type & 0.445 & 12,874 & 0.945 \\
\hline Types of Responses & & & \\
$\quad$ Flow Rate & 0.121 & 24,774 & 1.000 \\
$\quad$ Hole Type & 0.430 & 18,774 & 0.982 \\
$\quad$ Flow Rate $\times$ Hole Type & 0.165 & 72,774 & 1.000 \\
\hline Type II & & & \\
Source & F & d.f. & P \\
\hline Number of Responses & \multicolumn{3}{c}{} \\
$\quad$ Flow Rate & 0.0099 & 4,912 & 0.983 \\
$\quad$ Hole Type & 42.984 & 3,912 & $<0.001$ \\
$\quad$ Flow Rate $\times$ Hole Type & 0.976 & 12,912 & 0.470 \\
\hline Types of Responses & \multicolumn{3}{|}{} \\
$\quad$ Flow Rate & 0.000 & 24,812 & 1.00 \\
$\quad$ Hole Type & 3.631 & 18,812 & $<0.001$ \\
$\quad$ Flow Rate $\times$ Hole Type & 0.158 & 72,812 & 1.000 \\
\hline
\end{tabular}


Table 6. Comparison of number of behavioral responses and types of responses by $A$. stuartgranti ( $N=4$ fish) to four hole types (active and inactive in rounds with flow and "active" and inactive in rounds with diverted flow) among flow rates and flow types. Three-way GLMM analysis, $P \leq 0.05$.

\begin{tabular}{lccc}
\hline Source & F & d.f. & P \\
\hline Flow Type & 0.002 & $1,1,786$ & 0.963 \\
Flow Rate & 0.707 & $4,1,786$ & 0.587 \\
Hole Type & 63.392 & $3,1,786$ & $<0.001$ \\
Flow Type $\times$ Flow Rate & 0.209 & $4,1,786$ & 0.933 \\
Flow Type $\times$ Hole Type & 8.019 & $3,1,786$ & $<0.001$ \\
Flow Rate $\times$ Hole Type & 0.569 & $12,1,786$ & 0.868 \\
Flow Type $\times$ Flow Rate $\times$ Hole Type & 0.301 & $12,1,786$ & 0.989 \\
\hline
\end{tabular}


Table 7. Comparison of types of responses by A. stuartgranti ( $N=4$ fish) to active holes in rounds with flow among flow rates and flow types. Two-way GLMM analysis, $P \leq 0.05$.

\begin{tabular}{lccc}
\hline Source & F & d.f. & P \\
\hline Flow Type & 27.455 & 6,627 & $<0.001$ \\
Flow Rate & 0.363 & 30,627 & 0.999 \\
Flow Type $\times$ Flow Rate & 0.658 & 24,627 & 0.893 \\
\hline
\end{tabular}


Table 8. Comparison of number of behavioral responses by A. stuartgranti ( $N=5$ fish) to four hole types (active and inactive in rounds with flow and "active" and inactive with diverted flow) at each day before and after treatment with $\mathrm{CoCl}_{2}$ (Day -2 to Day 21). One-way GLMM analyses, $P \leq 0.05$.

\begin{tabular}{lccc}
\hline Day & F & d.f. & P \\
\hline Day -2 & 12.784 & 3,116 & $<0.001$ \\
Day -1 & 11.379 & 3,116 & $<0.001$ \\
Day 0 & 0.000 & 3,116 & 1.000 \\
Day 1 & 3.917 & 3,116 & 0.010 \\
Day 2 & 8.912 & 3,116 & $<0.001$ \\
Day 3 & 16.326 & 3,116 & $<0.001$ \\
Day 4 & 13.437 & 3,116 & $<0.001$ \\
Day 5 & 15.895 & 3,116 & $<0.001$ \\
Day 6 & 11.610 & 3,116 & $<0.001$ \\
Day 7 & 12.825 & 3,116 & $<0.001$ \\
Day 8 & 4.944 & 3,44 & 0.005 \\
Day 9 & 8.882 & 3,116 & $<0.001$ \\
Day 10 & 10.304 & 3,116 & $<0.001$ \\
Day 11 & 9.600 & 3,116 & $<0.001$ \\
Day 14 & 13.883 & 3,116 & $<0.001$ \\
Day 18 & 8.219 & 3,116 & $<0.001$ \\
Day 21 & 7.143 & 3,68 & $<0.001$ \\
\hline
\end{tabular}


Table 9. Comparison of number of behavioral responses and type of responses by $A$. stuartgranti ( $N=5$ fish) to active holes in rounds with flow among days before and after treatment with $\mathrm{CoCl}_{2}$ (Day-2 to Day 21). One-way GLMM analyses, $P \leq 0.05$.

\begin{tabular}{lccccccc}
\hline & \multicolumn{3}{c}{ Number of Responses } & & \multicolumn{3}{c}{ Type of Responses } \\
\cline { 2 - 4 } \cline { 6 - 8 } Source & F & d.f. & P & & F & d.f. & P \\
\hline Day & 9.033 & 16,685 & $<0.001$ & & 1.935 & 96,600 & $<0.001$ \\
\hline
\end{tabular}


Table 10. Comparisons of number of responses by A. stuartgranti ( $N=5$ fish) to active holes with flow by day, which included before (Days -2, -1), immediately after (Day 0 ), and during the recovery of treatment of $\mathrm{CoCl}_{2}$ (Days 1-21). Post hoc pairwise comparisons, LSD. $*=P<0.05$.

\begin{tabular}{|c|c|c|c|c|c|c|c|c|c|c|c|c|c|c|c|c|c|}
\hline & -2 & -1 & 0 & 1 & 2 & 3 & 4 & 5 & 6 & 7 & 8 & 9 & 10 & 11 & 14 & 18 & 21 \\
\hline-2 & & $*$ & $*$ & $*$ & $*$ & - & - & - & - & - & - & - & - & - & - & - & - \\
\hline-1 & & & $*$ & $*$ & - & - & - & - & $*$ & $*$ & $*$ & - & $*$ & $*$ & - & - & $*$ \\
\hline 0 & & & & - & $*$ & $*$ & $*$ & $*$ & $*$ & $*$ & $*$ & $*$ & $*$ & $*$ & $*$ & $*$ & $*$ \\
\hline 1 & & & & & $*$ & $*$ & $*$ & $*$ & $*$ & $*$ & $*$ & $*$ & $*$ & $*$ & $*$ & $*$ & $*$ \\
\hline 2 & & & & & & $*$ & $*$ & $*$ & $*$ & $*$ & $*$ & $*$ & $*$ & $*$ & - & $*$ & $*$ \\
\hline 3 & & & & & & & - & - & $*$ & - & $*$ & - & - & - & - & - & $*$ \\
\hline 4 & & & & & & & & - & - & - & - & - & - & - & - & - & - \\
\hline 5 & & & & & & & & & $*$ & - & $*$ & - & - & - & - & - & $*$ \\
\hline 6 & & & & & & & & & & - & - & - & - & - & - & $*$ & - \\
\hline 7 & & & & & & & & & & & - & - & - & - & - & - & - \\
\hline 8 & & & & & & & & & & & & - & - & - & - & - & - \\
\hline 9 & & & & & & & & & & & & & - & - & - & - & - \\
\hline 10 & & & & & & & & & & & & & & - & - & - & - \\
\hline 11 & & & & & & & & & & & & & & & - & - & - \\
\hline 14 & & & & & & & & & & & & & & & & - & - \\
\hline 18 & & & & & & & & & & & & & & & & & $*$ \\
\hline 21 & & & & & & & & & & & & & & & & & \\
\hline
\end{tabular}



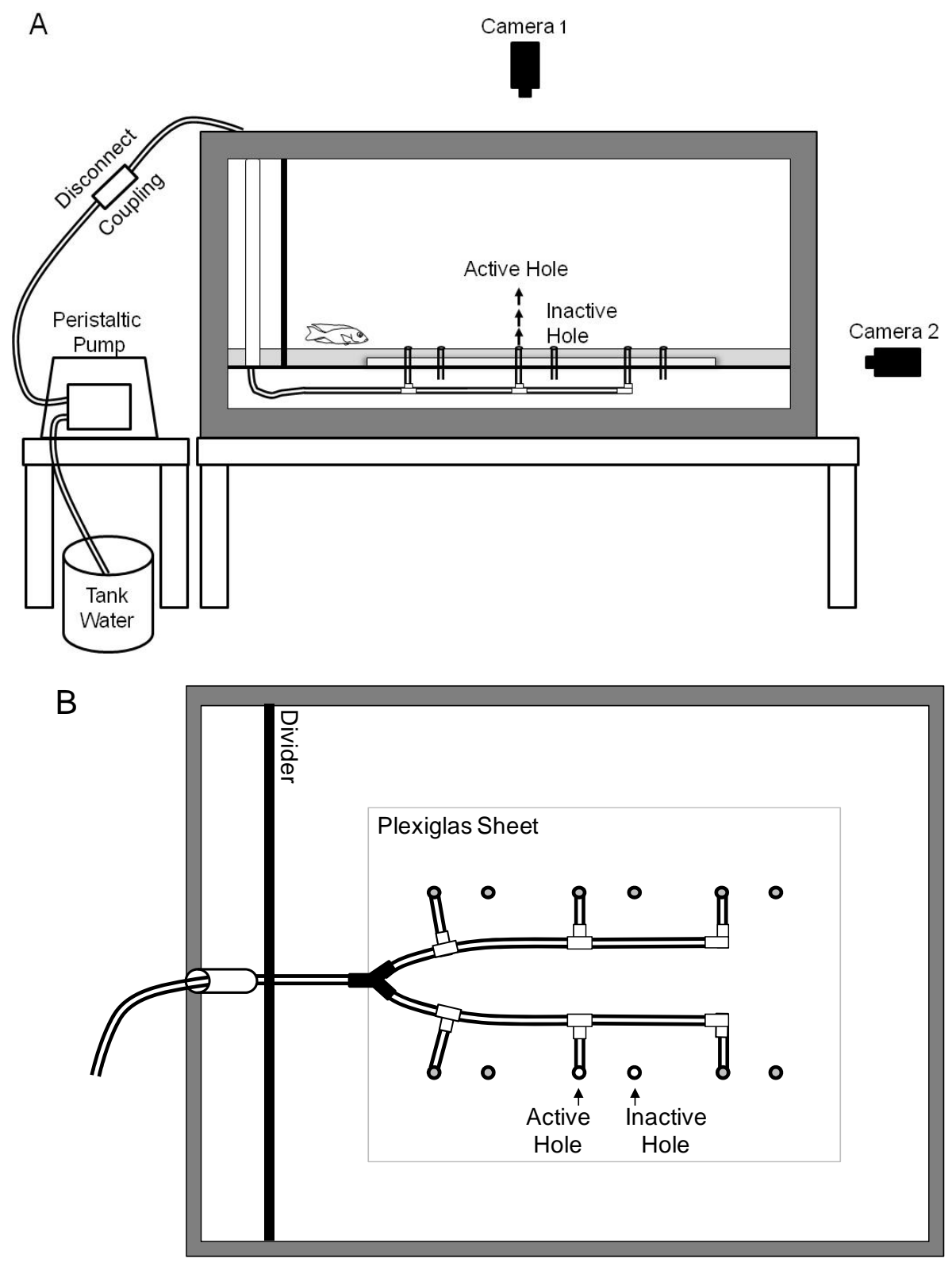

Figure 1. Artificial stimulus delivery system designed for this study. (A) Configuration of the apparatus in the experimental tank and peristaltic pump on an adjacent table. Six active holes were connected to the pump and inactive holes, consisting of short pieces of tubing, terminated below the Pleixglas sheet in the false bottom. Camera 1 was positioned directly over the tank, while Camera 2 was placed laterally at the level of the sand and in front of the tank window. (B) Dorsal view of the apparatus in the experimental tank. One pair of holes was open at a time (arrows) during rounds with flow and all other holes were plugged with silicone stoppers (grey holes). The tubing and Plexiglas sheet are visible here, but were covered with sand and not visible to the fish during experiments. 

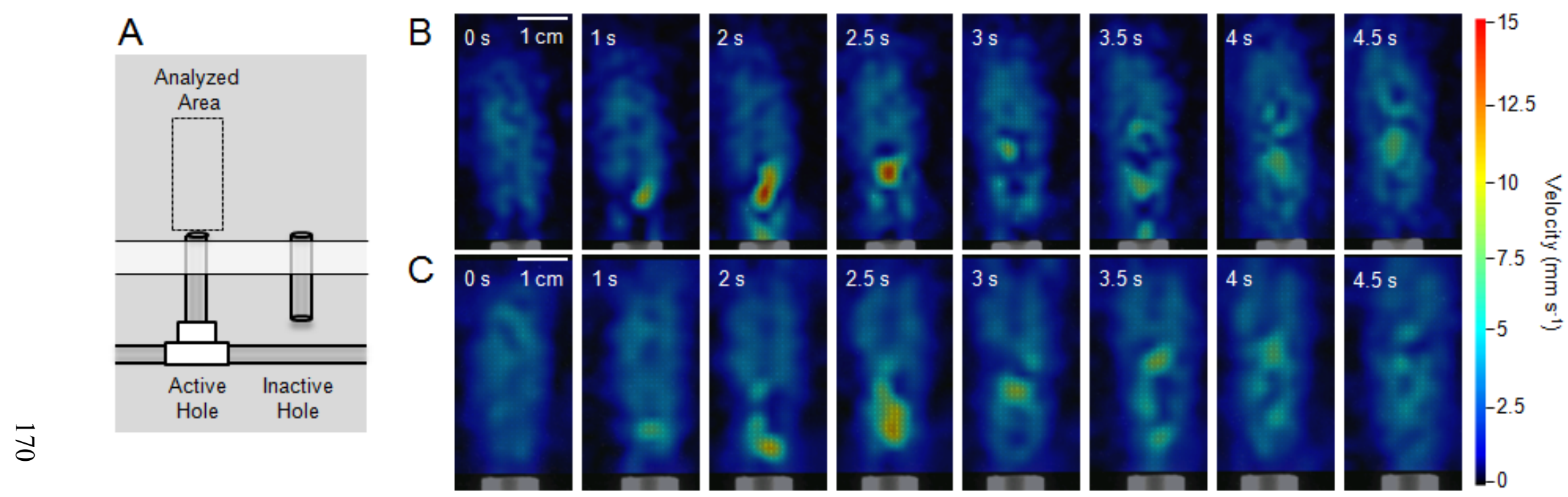

Figure 2. Visualization of flow from apparatus using digital particle image velocimetry (DPIV). (A) Flows were analyzed as they emerged vertically from each active hole ( $2 \mathrm{~cm} \mathrm{x} 4 \mathrm{~cm}$ area, indicated by the dashed box). (B) Type I flow and (C) Type II flow showing velocity vector fields (arrows) and color maps of flow magnitudes (color scale) above an active hole (red = maximum, 15 $\mathrm{mm} \mathrm{s}^{-1}$; dark blue $=$ minimum) over $4.5 \mathrm{~s}$ at a flow rate of $9.5 \mathrm{~mL} \mathrm{~min}^{-1}$, which represents one pump cycle (e.g., "pulse"). 
A

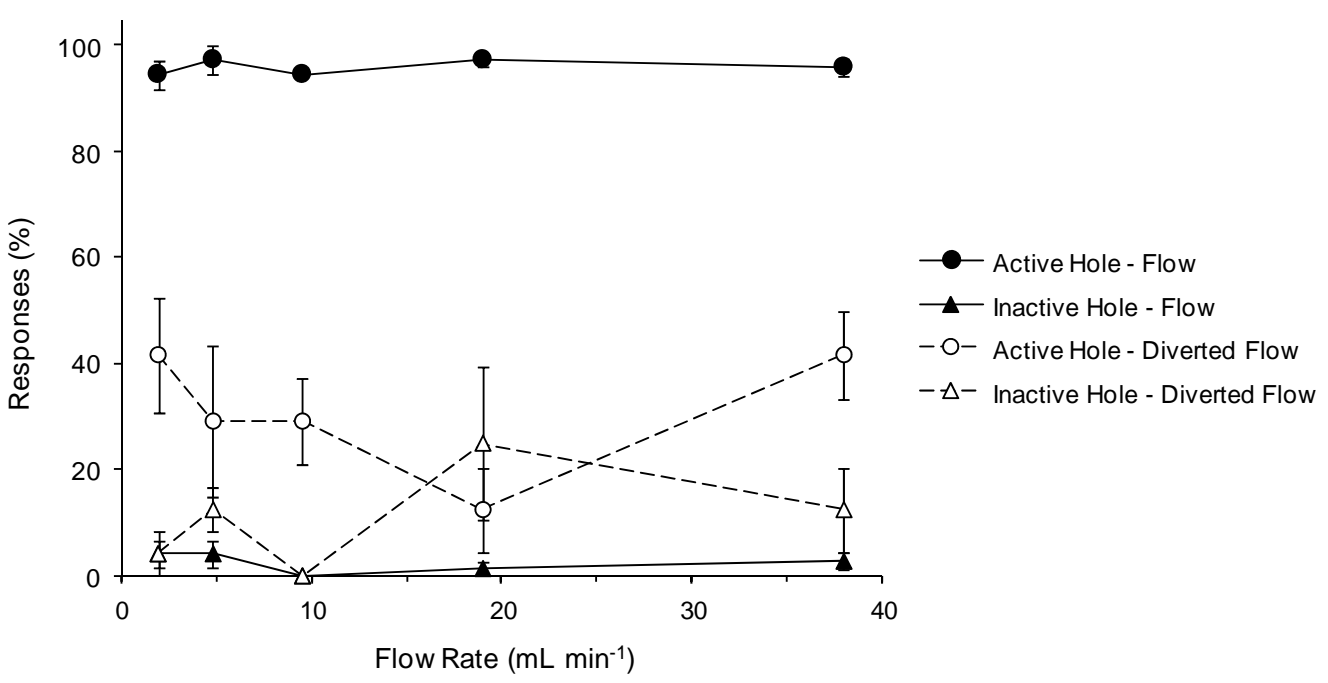

B

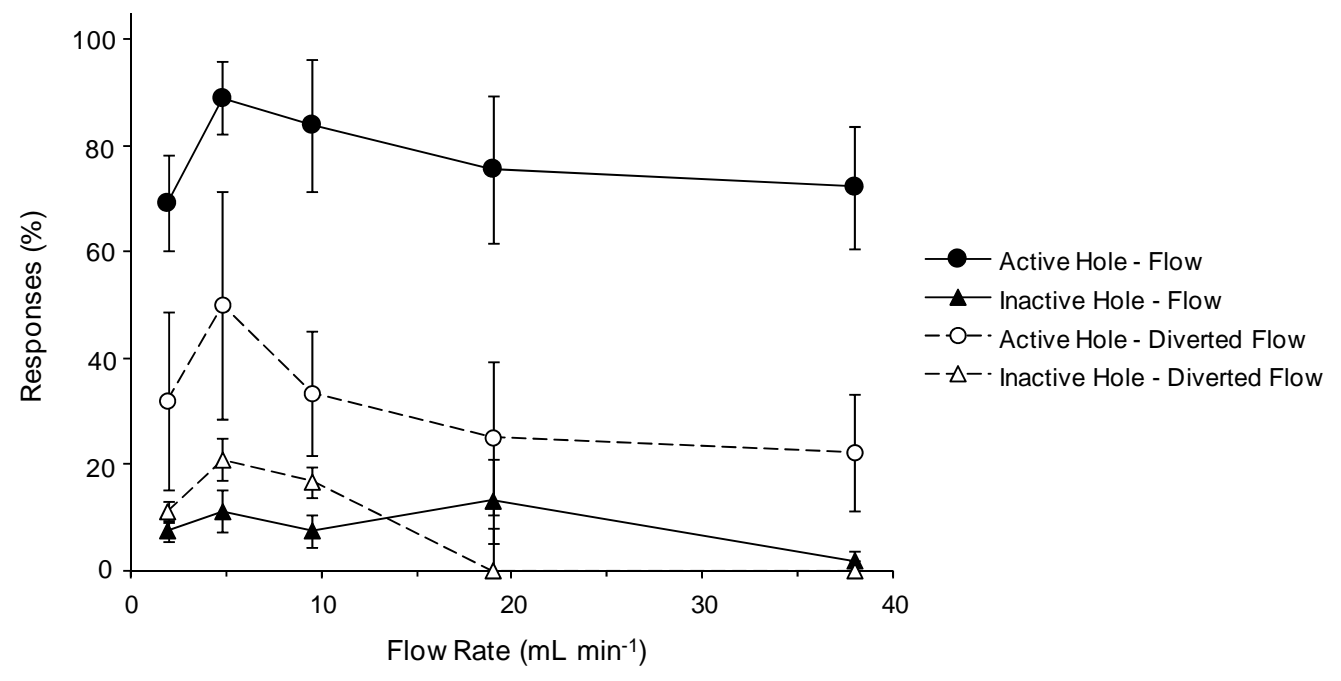

Figure 3. Number of responses (illustrated as $\%$ ) by A. stuartgranti ( $N=4$ fish) to active and inactive holes in rounds with flow and with diverted flow for (A) Type I flow and (B) Type II flow. 
A
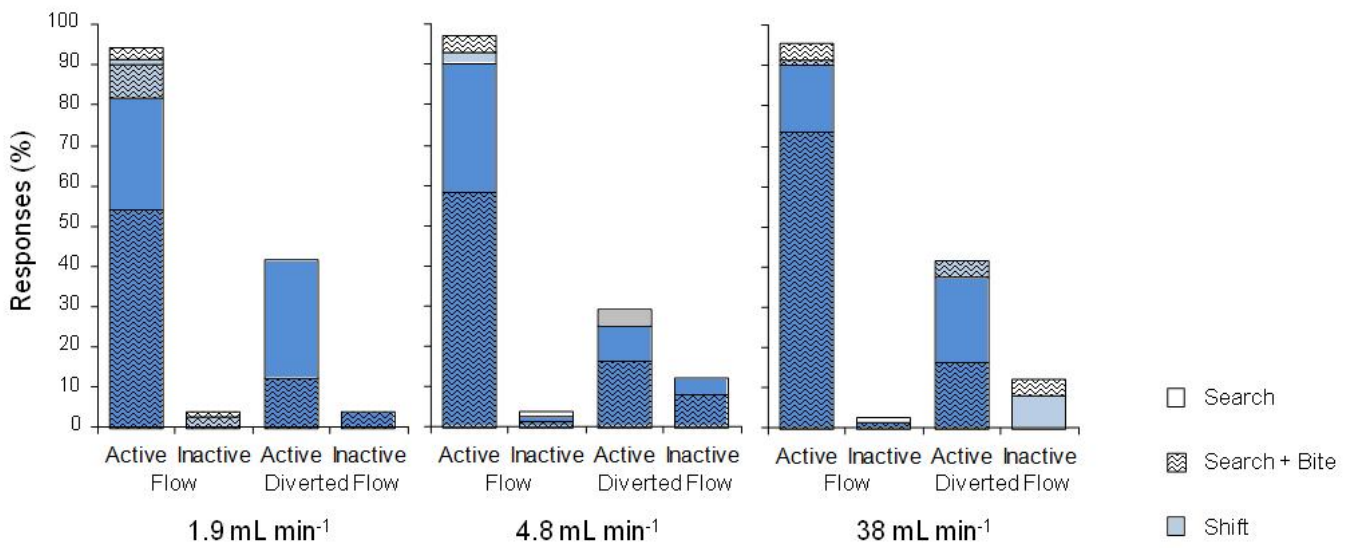

B
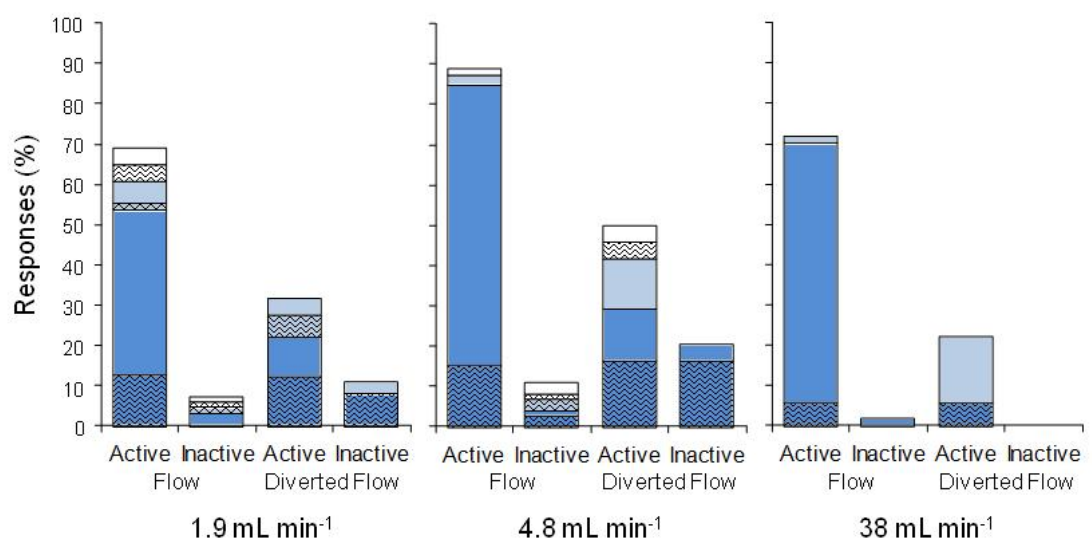

궁 Shift + Bite

$\square$ Hover

Hover+ Bite

Figure 4. Number of responses by behavioral type (illustrated as \%) by A. stuartgranti $(N=4$ fish) to active and inactive holes in rounds with flow and with diverted flow for (A) Type I and (B) Type II flows. Responses to 9.5 and $19.0 \mathrm{~mL} \mathrm{~min}^{-1}$ rates were not included because they were not statistically different from the results from the other three flow rates. 


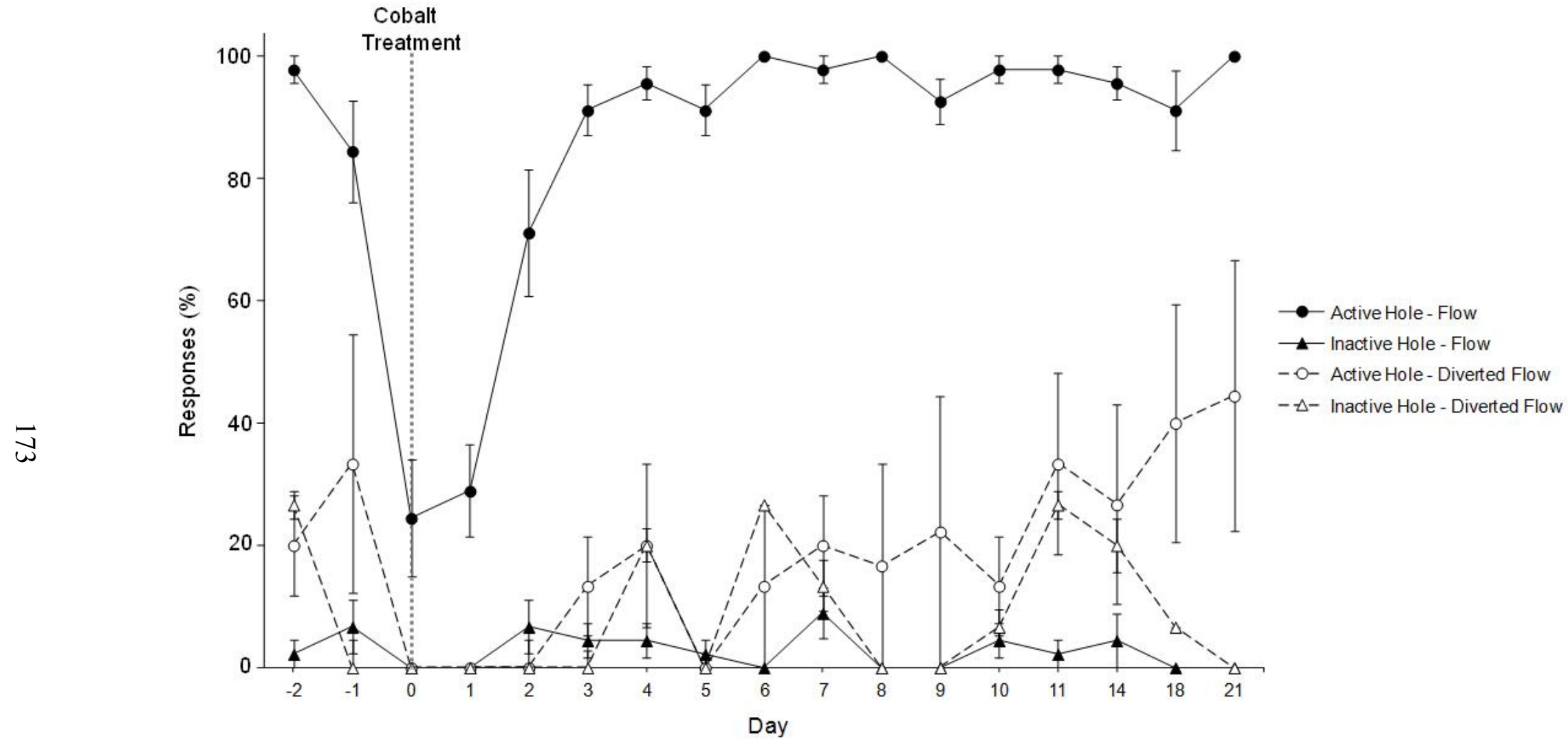

Figure 5. Number of responses (illustrated as \%) by $A$. stuartgranti ( $N=5$ fish) to active and inactive holes in rounds with flow and with diverted flow through time - before and after treatment with $\mathrm{CoCl}_{2}$ (Day -2 to Day 21). Type I flow at $4.8 \mathrm{~mL} \mathrm{~min}^{-1} \mathrm{was}$ used in all trials and the $\mathrm{CoCl}_{2}$ treatment is indicated by the vertical dotted reference line at Day 0 . Refer to text and Tables 8,9 , and 10 for statistical results. 


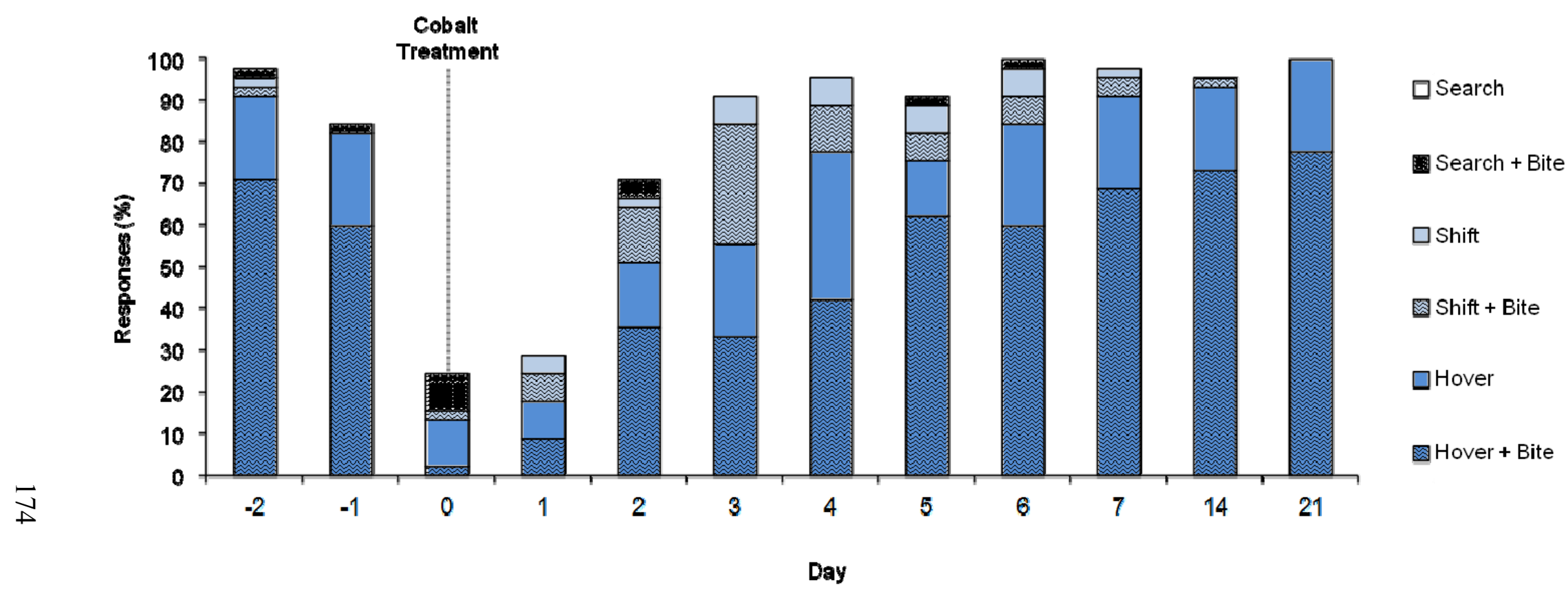

Figure 6. Proportion of different response types (illustrated as \%) by A. stuartgranti ( $N=5$ fish) to active holes only in rounds with flow, before and after treatment with $\mathrm{CoCl}_{2}$ (Day -2 - Day 7, Day 14, and Day 21). Time of $\mathrm{CoCl}_{2}$ treatment is indicated by the vertical dotted reference line at Day 0. Results were similar among Days 7-21, so only a subset of data from these days are included. Refer to text and Table 9 for statistical results. 


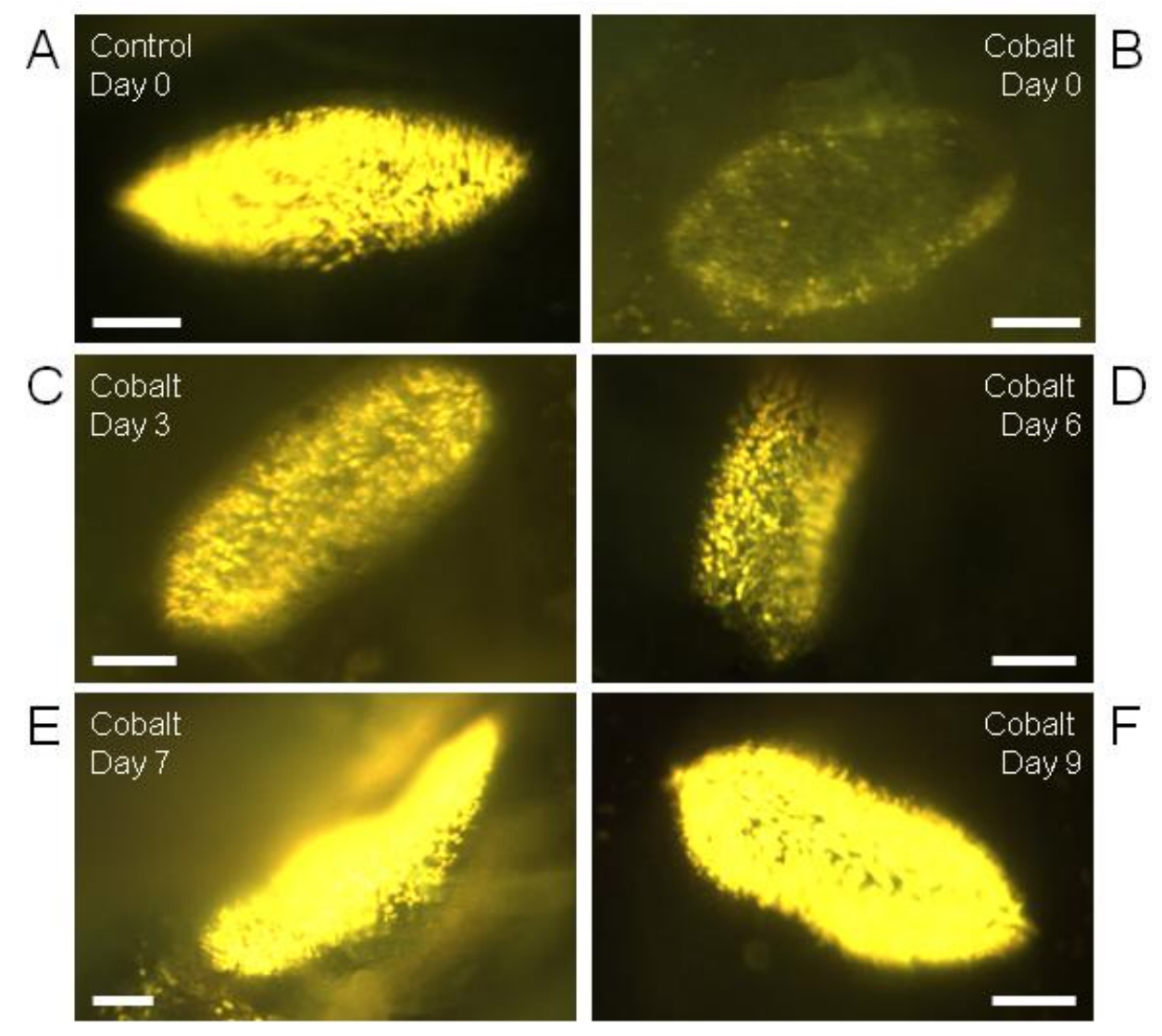

Figure 7. Canal neuromasts of adult $A$. stuartgranti stained with fluorescent dye (4DI-2-ASP). Images show negative staining and recovery of positive staining in the sensory strip of the canal neuromast over nine days following treatment of $\mathrm{CoCl}_{2}$. (A) Day 0 control treatment (conditioned tank water for three hours; mandibular neuromast, $\mathrm{TL}=114 \mathrm{~mm})$. (B) Day 0 cobalt treatment $\left(0.1 \mathrm{mM} \mathrm{CoCl}_{2}\right.$ in conditioned tank water for three hours, $\mathrm{TL}=105 \mathrm{~mm}$, mandibular neuromast). (C) Day 3 cobalt treatment ( $\mathrm{TL}=90 \mathrm{~mm}$, preopercular neuromast). (D) Day 6 cobalt treatment $(\mathrm{TL}=75$ $\mathrm{mm}$, infraorbital neuromast). (E) Day 7 cobalt treatment (TL=108 $\mathrm{mm}$, mandibular neuromast). (F) Day 9 cobalt treatment ( $\mathrm{TL}=95 \mathrm{~mm}$, preopercular neuromast). Scale bars in A-F are $\sim 100 \mu \mathrm{m}$. 


\section{REFERENCES}

Becker, E. A. (2013). The distribution and ontogeny of neuromasts receptor organs and a comparison of methods for chemical ablation of the lateral line system in two cichlid fishes. Master's Thesis, University of Rhode Island.

Bleckmann, H. (1980). Reaction time and stimulus frequency in prey localization in the surface-feeding fish Aplocheilus lineatus. J. Comp. Physiol. 140, 163-172.

Bleckmann, H., Waldner, I. and Schwartz, E. (1981). Frequency discrimination of the surface-feeding fish Aplocheilus lineatus - a prerequisite for prey localization? J. Comp. Physiol. 143, 485-490.

Catton, K. B., Webster, D. R., Brown, J. and Yen, J. (2007). Quantitative analysis of tethered and free-swimming copepodid flow fields. J. Exp. Biol. 210, 299310.

Claas, B., Münz, H. and Görner, P. (1993). Reaction to surface waves by Xenopus laevis Daudin. Are sensory systems other than the lateral line involved? J. Comp. Physiol. A 172, 759-765.

Coombs, S. and Janssen, J. (1990). Behavioral and neurophysiological assessment of lateral line sensitivity in the mottled sculpin, Cottus bairdi. J. Comp. Physiol. A 167, 557-567.

Coombs, S. and Montgomery, J. C. (1999). The enigmatic lateral line system. In Comparative Hearing: Fish and Amphibians (ed. R. R. Fay and A. N. Popper), pp. 319-362. New York: Springer-Verlag.

Coombs, S., Braun, C. B. and Donovan, B. (2001). The orienting response of Lake Michigan mottled sculpin is mediated by canal neuromasts. J. Exp. Biol. 204, 337-348.

Coombs, S., Janssen, J. and Montgomery, J. (1992). Functional and evolutionary implications of peripheral diversity in lateral line systems. In The Evolutionary Biology of Hearing (ed. D. B. Webster, R. R. Fay and A. N. Popper), pp. 267294. New York: Springer-Verlag.

Coombs, S., Janssen, J. and Webb, J. F. (1988). Diversity of lateral line systems: evolutionary and functional considerations. In Sensory Biology of Aquatic Animals (ed. J. Atema, R. R. Fay, A. N. Popper and W. N. Tavolga), pp. 553593. New York: Springer-Verlag.

Denton, E. J. and Gray, J. A. B. (1988). Mechanical factors in the excitation of the lateral lines of fish. In Sensory Biology of Aquatic Animals (ed. J. Atema, R. R. Fay, A. N. Popper and W. N. Tavolga), pp. 595-617. New York: SpringerVerlag.

Denton, E. J. and Gray, J. A. B. (1989). Some observations on the forces acting on neuromasts in fish lateral line canals. In The Mechanosensory Lateral Line: Neurobiology and Evolution (ed. S. Coombs, P. Gorner and H. Münz), pp. 229-246. New York: Springer-Verlag.

Elepfandt, A. (1982). Accuracy of taxis response to water waves in the clawed toad (Xenopus laevis Daudin) with intact or with lesioned lateral line system. $J$. Comp. Physiol. 148, 535-543. 
Fryer, G. (1959). The trophic interrelationships and ecology of some littoral communities of Lake Nyasa with especial reference to the fishes, and a discussion of the evolution of a group of rock-frequenting Cichlidae. Proc. Zool. Soc. Lond. 132, 153-281.

Herler, J., Kerschbaumer, M., Mitteroecker, P., Postl, L, and Sturmbauer, C. (2010). Sexual dimorphism and population divergence in the Lake Tanganyika cichlid fish genus Tropheus. Front. Zool. 7, 1-20.

Hoekstra, D. and Janssen, J. (1985). Non-visual feeding behavior of the mottled sculpin, Cottus bairdi, in Lake Michigan. Env. Biol. Fish. 12, 111-117.

Hoekstra, D. and Janssen, J. (1986). Lateral line receptivity in the mottled sculpin (Cottus bairdi). Copeia 1986, 91-96.

Hoyt, R.D. (1970). Food Habits of the Silverjaw Minnow, Ericymba buccata Cope, in an Intermittent Stream in Kentucky. Am. Midl. Nat. 84, 226-236

Janssen, J. (1997). Comparison of response distance to prey via the lateral line in the ruffe and yellow perch. J. Fish Biol. 51, 921-930.

Janssen, J., Coombs, S. and Pride, S. (1990). Feeding and orientation of mottled sculpin, Cottus bairdi, to water jets. Environ, Biol. Fish. 29, 43-50.

Jordan, L. K., Kajiura, S. M. and Gordon, M. S. (2009). Functional consequences of structural differences in stingray sensory systems. Part I: mechanosensory lateral line canals. J. Exp. Biol. 212, 3037-3043.

Karlsen, H. E. and Sand, O. (1987). Selective and reversible blocking of the lateral line in freshwater fish. J. Exp. Biol. 133, 249-262.

Kocher, T. D. (2004). Adaptive evolution and explosive speciation: the cichlid fish model. Nat. Rev. Genet. 5, 288-298.

Konings, A. (1990). Koning's Book of Cichlids and Other Fishes of Lake Malawi. Neptune City, NJ: TFH Publications Inc.

Konings, A. (2007). Malawi Cichlids in Their Natural Habitat, 4th edn. El Paso, TX Cichlid Press.

McHenry, M. J., Feitl, K. E., Strother, J. A. and Van Trump, W. J. (2009). Larval zebrafish rapidly sense the water flow of a predator's strike. Biol. Lett. Doi:10.1098/rsbl.2009.0048.

Liao, J. (2006). The role of the lateral line and vision on body kinematics and hydrodynamic preference of rainbow trout in turbulent flow. J. Exp. Biol. 209, 4077-4090.

Livingston, M. E. (1987). Morphological and sensory specializations of five New Zealand flatfish species, in relation to feeding behaviour. J. Fish Biol. 31, 775795.

Meyer, M. K., Riehl, R. and Zetzsche, H. (1987). A revision of the cichlid fishes of the genus Aulonocara Regan, 1922 from Lake Malawi, with descriptions of six new species (Pisces, Perciformes, Cichlidae). Cour. Forsch.-Inst. Senckenberg 94, 7-53.

Mogdans, J. and Nauroth, I. E. (2011). The oscar, Astronotus ocellatus, detects and discriminates dipole stimuli with the lateral line system. J. Comp. Physiol. A 197, 959-968. 
Morad, M. R., Khalili, A., Roskosch, A. and Lewandowski, J. (2010). Quantification of pumping rate of Chironomus plumosus larvae in natural burrows. Aquat. Ecol. 44, 143-153.

Nauroth, I. E. and Mogdans, J. (2009). Goldfish and Oscars have comparable responsiveness to dipole stimuli. Naturwissenschaften 96, 1401-1409.

Oliveira, R. F., and Almada, V. C. (1995). Sexual dimorphism and allometry of external morphology in Oreochromis mossambicus. J. Fish Biol. 46, 10551064.

Palmer, L. M., Deffenbaugh, M. and Mensinger, A. F. (2005). Sensitivity of the anterior lateral line to natural stimuli in the oyster toadfish, Opsanus tau (Linnaeus). J. Exp. Biol. 208, 3441-3450.

Pohlmann, K., Atema, J. and Breithaupt, T. (2004). The importance of the lateral line in nocturnal predation of piscivorous catfish. J. Exp. Biol. 207, 29712978.

Roberts, A., Feetham, B., Pajak, M., and Teare, T. (2009). Responses of hatchling Xenopus tadpoles to water currents: first function of lateral line receptors without cupulae. J. Exp. Biol. 212, 914-921.

Schwalbe, M. A. B, Bassett, D. K. and Webb, J. F. (2012). Feeding in the dark: lateral-line-mediated prey detection in the peacock cichlid Aulonocara stuartgranti. J. Exp. Biol. 215, 2060-2071

Schwalbe, M. A. B. and Webb, J. F. (Accepted). Sensory basis for detection of benthic prey in two Lake Malawi cichlids.

van Duran, L. A. and Videler, J. J. (2003). Escape from viscosity: the kinematics and hydrodynamics of copepod foraging and escape swimming. J. Exp. Biol. 206, 269-279.

van Netten, S. M. and van Maarseveen, J. T. P. (1994). Mechanophysiological properties of the supraorbital lateral line canal in ruffe (Acerina cernua). Proc. R. Soc. Lond. B 256, 239-246.

Webb, J. F. (1989). Gross morphology and evolution of the mechanosensory lateral line system in teleost fishes. Brain Behav. Evol. 33, 34-53.

Webb, J. F. (In Press). Morphological diversity, development, and evolution of the mechanosensory lateral line system. In The Lateral Line System (ed. S. Coombs and H. Bleckmann), New York: Springer-Verlag.

Yen, J., Brown, J. and Webster, D. R. (2003). Analysis of the flow field of the krill, Euphausia pacifica. Mar. Fresh. Behav. Physiol. 36, 307-319.

Yoshii, K. and Kurihara, K. (1983). Role of cations in olfactory reception. Brain Res. 274, 239-248. 